\title{
WestVirginiaUniversity
}

THE RESEARCH REPOSITORY @ WVU

Graduate Theses, Dissertations, and Problem Reports

1999

\section{Determination of optimal pricing and warranty policies}

Ozcan Mutlu

West Virginia University

Follow this and additional works at: https://researchrepository.wvu.edu/etd

\section{Recommended Citation}

Mutlu, Ozcan, "Determination of optimal pricing and warranty policies" (1999). Graduate Theses,

Dissertations, and Problem Reports. 3167.

https://researchrepository.wvu.edu/etd/3167

This Dissertation is protected by copyright and/or related rights. It has been brought to you by the The Research Repository @ WVU with permission from the rights-holder(s). You are free to use this Dissertation in any way that is permitted by the copyright and related rights legislation that applies to your use. For other uses you must obtain permission from the rights-holder(s) directly, unless additional rights are indicated by a Creative Commons license in the record and/ or on the work itself. This Dissertation has been accepted for inclusion in WVU Graduate Theses, Dissertations, and Problem Reports collection by an authorized administrator of The Research Repository @ WVU.

For more information, please contact researchrepository@mail.wvu.edu. 
Determination of Optimal Pricing and Warranty Policies

\title{
Özcan Mutlu
}

Dissertation submitted to the College of Engineering and Mineral Resources

at West Virginia University in partial fulfillment of the requirements

for the degree of

\author{
Doctor of Philosophy \\ in \\ Industrial Engineering
}

Wafik H. Iskander, Ph.D., Chair

Ralph W. Plummer, Ph.D.

Majid Jaraiedi, Ph.D.

Robert C. Creese, Ph.D.

John Harpell, Ph.D.

Department of Industrial and Management Systems Engineering

Morgantown, West Virginia

1999

Keywords: Warranty, Reliability, Burn-in test 


\section{ABSTRACT \\ Determination of Optimal Pricing and Warranty Policies}

\section{Özcan Mutlu}

An important problem facing manufacturers in today's competitive market is the determination of the selling price of a product and its warranty period. A longer warranty may serve as a signal of product reliability; however, it may also lead to an increase in cost and hence reduce the profit if the product reliability is low. A burn-in test may be used to improve the reliability of products prior to their shipment.

This research presented integrated models for maximizing the expected profit for products that are subjected to a burn-in test and sold with warranty. The burn-in time, warranty period, and price were chosen as three decision variables in these models. The price and warranty period were treated as marketing variables and a simple multiplicative form was used to model their effect on sales. Solution procedures were developed for several warranty policies. These procedures are applicable for any failure time distribution. Three failure time distributions were further investigated and formulas for optimal solutions were derived. Finally, two sets of data were used to illustrate the application of the models. Two computer programs were developed to solve the models both parametrically and nonparametically. 


\section{ACKNOWLEDGMENTS}

I would like to express my deep appreciation to my advisor Dr. Wafik H. Iskander for his advice, and guidance throughout the development of this dissertation. I would also like to thank Dr. Ralph W. Plummer, Dr. Majid Jaraiedi, Dr. Robert C. Creese, and Dr. John Harpell, for their help and willingness to serve as members of my committee.

I owe very special thanks to my parents, Adalet and Zülkefil Mutlu, my sisters, Remziye Inan and Hülya Mizrak, my brothers Gürcan and Sabri Mutlu for their immeasurable love, support and sacrifice throughout my study. Special thanks are extended to my friends for their help and support.

Finally, I would like to thank the Higher Educational Council of Turkey (YÖK) and Pammukkale University for their financial support during my graduate studies in the USA. 
ABSTRACT .............................................................................................................................................

ACKNOWLEDGMENTS ...........................................................................................ii

LIST OF FIGURES ........................................................................................................... ix

LIST OF TABLES .................................................................................................................................. xi

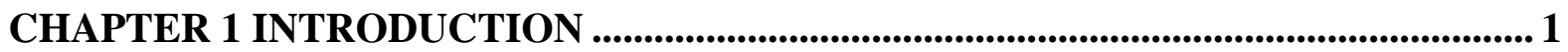

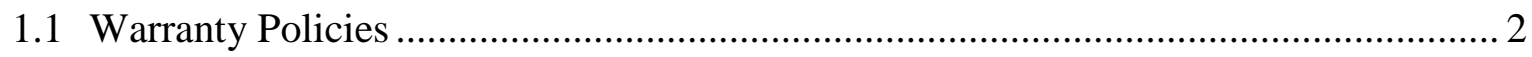

1.1.1 Types of Remedy Action............................................................................ 4

1.1.1.1 Free Replacement Warranty .................................................................... 4

1.1.1.2 Pro-rata Warranty …………………………..................................... 5

1.1.1.3 Combination Warranties ……………………….................................. 5

1.1.2 One or Two-dimensional Warranty Policies ....................................................... 6

1.1.2.1 One-dimensional Warranty Policies........................................................... 6

1.1.2.2 Two-dimensional Warranty Policies .............................................................. 6

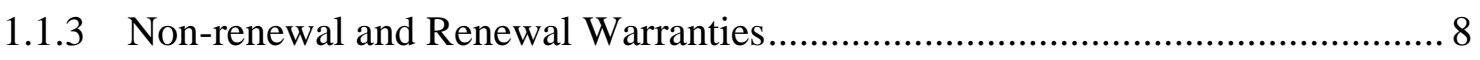

1.1.3.1 Non-renewal Warranty:................................................................... 8

1.1.3.2 Renewal Warranty ............................................................................. 9

1.1.4 Other Warranty Policies ............................................................................. 9

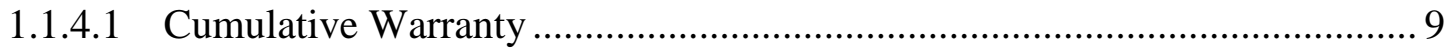

1.1.4.2 Reliability Improvement Warranty ……………..................................... 9

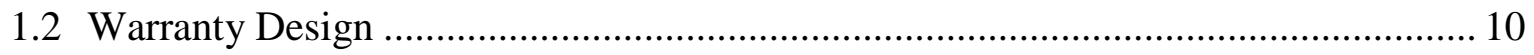




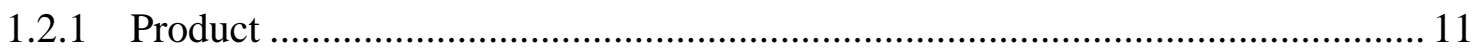

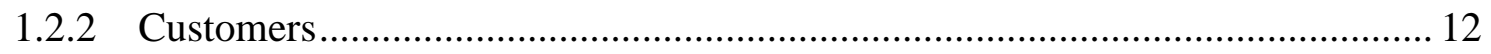

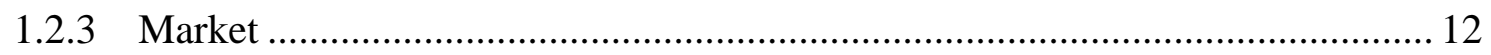

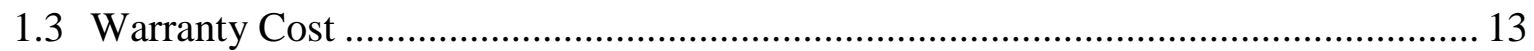

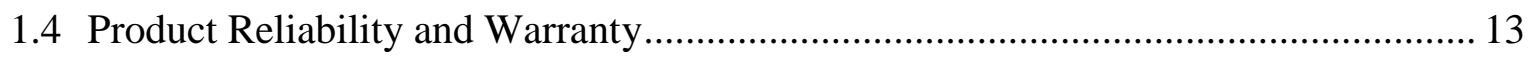

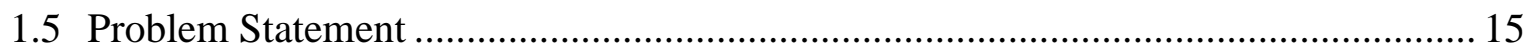

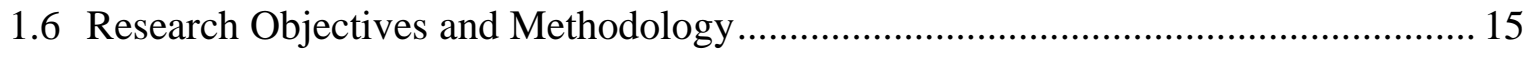

CHAPTER 2 REVIEW OF THE LITERATURE ................................................................... 18

2.1 Warranty Cost Estimation ................................................................................ 18

2.1.1 One-dimensional Warranty Cost Models ....................................................... 19

2.1.2 Two-dimensional Warranty Cost Models …………....................................... 25

2.2 Warranties as a Marketing Tool .......................................................................... 26

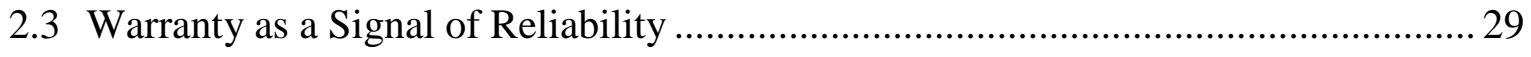

CHAPTER 3 MODEL FORMULATION AND SOLUTION METHODS ...................... 32

3.1 Modeling Product Failures ...................................................................................... 33

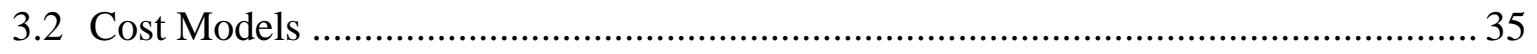

3.2.1 Burn-in Cost Model for Repairable Products..................................................... 36

3.2.2 Burn-in Cost Model for Nonrepairable Products ............................................... 38

3.2.3 Free Replacement Warranty Cost Model for Repairable Products ..................... 39

3.2.4 Free Replacement Warranty Cost Model for Nonrepairable Products ............... 40

3.2.5 Pro-rata Warranty for Nonrepairable Products ………………........................ 42 


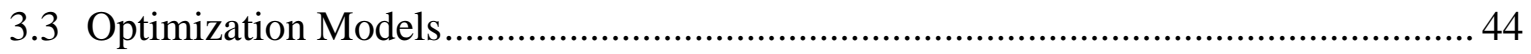

3.3.1 Free Replacement Warranty and Burn-in for Repairable Products.................... 47

3.3.2 Free Replacement Warranty and Burn-in for Nonrepairable Products .............. 48

3.3.3 Pro-Rata Warranty and Burn-in for Non-repairable Products .......................... 50

\section{CHAPTER 4 SOLUTION PROREDURES FOR SOME THEORETICAL}

DISTRIBUTIONS .............................................................................................. 52

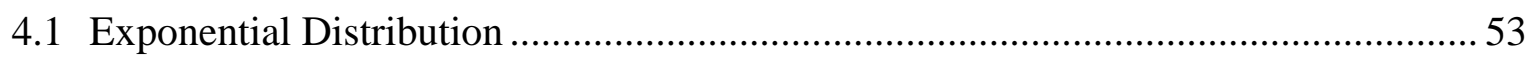

4.1.1 Free Replacement Warranty for Repairable Products .......................................55

4.1.2 Free Replacement Warranty for Nonrepairable Items ……………………...... 57

4.1.3 Pro-Rata Warranty for Nonrepairable Items …………………....................... 60

4.1.4 Numerical Example and Sensitivity Analysis .................................................. 62

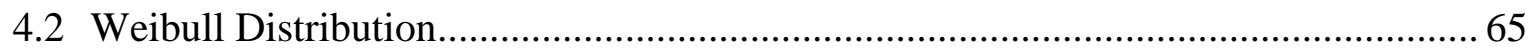

4.2.1 Free Replacement Warranty for Repairable Products..........................................67

4.2.2 Free Replacement Warranty for Non-repairable Products ................................... 71

4.2.3 Pro-rata Warranty for Nonrepairable Products .................................................. 71

4.2.4 Numerical Example and Sensitivity Analysis ................................................... 71

4.3 Mixed Weibull and Exponential Distribution ........................................................ 73

4.3.1 Free Replacement Warranty for Repairable Products........................................ 75

4.3.2 Free replacement Warranty for Nonrepairable Products.................................... 77

4.3.3 Pro-rata Warranty for Nonrepairable Products ………....................................... 78

4.3.4 Numerical Example and Sensitivity Analysis ................................................... 79 


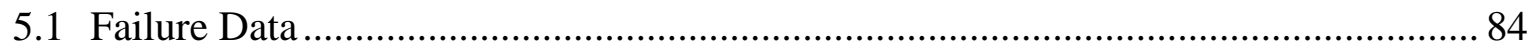

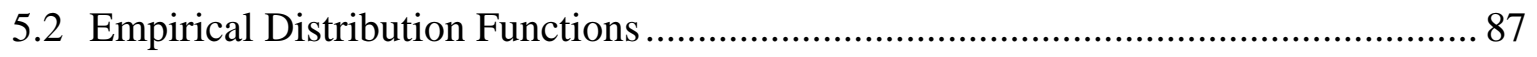

5.3 Solution Procedure for the First Set of Data ....................................................... 88

5.4 Solution Procedures for the Second Set of Data .............................................. 95

5.4.1 Free Replacement Warranty for Repairable Products ................................. 100

5.4.2 Free replacement warranty for nonrepairable products: ............................. 101

5.4.3 Pro-rata Warranty Policy for Nonrepairable Products ................................ 103

5.4.4 Numerical Solution of the Problem.......................................................... 103

CHAPTER 6 CONLUSIONS AND EXTENSIONS ...................................................... 106

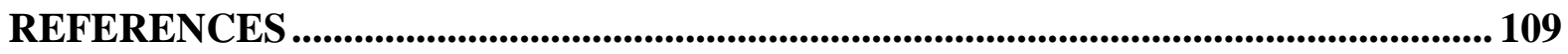

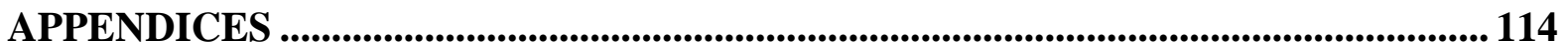

Appendix 1: The expected burn-in time for non-repairable products ........................ 115

Appendix 2: Expected time to first failure during the warranty period after the burn-in period of B (Pro-rata warranty) …................................................. 116

Appendix 3: Partial derivative of expected unit burn-in cost with respect to burn-in time (Non-repairable case).

Appendix 4: Partial Derivative of Expected total unit cost with respect to burn-in time (non-repairable products). 
Appendix 5: The optimal warranty period under pro-rata warranty (the exponential case)

Appendix 6: The computer program used when the failure time distribution is known

Appendix 7: The computer program used when the failure time distribution is unknown (nonparametric solution methods) 134 


\section{LIST OF FIGURES}

Figure 1.1 Classification of warranty policies ....................................................... 4

Figure 1.2 Two-dimensional warranty policies ........................................................ 7

Figure 3.1 The failure rate function during the lifetime of a product.[Ebeling, 1997]....... 34

Figure 3.2 The failure rate function after repair [Murthy and Blischke, 1992]................. 37

Figure 4.1 Exponential probability density, cumulative, reliability, and failure rate

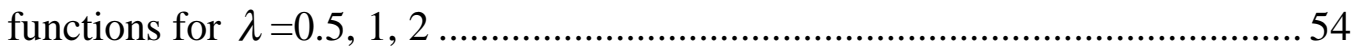

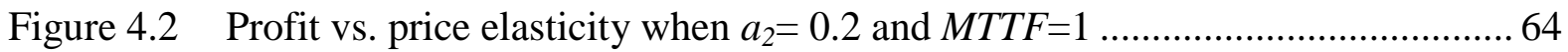

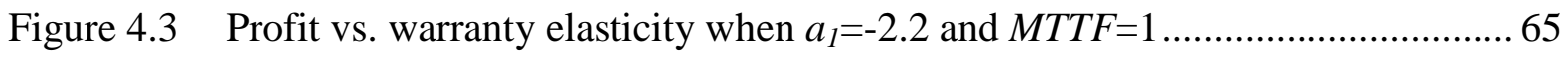

Figure 4.4 Weibull (a) density, (b) cumulative, (c) reliability and (d) failure rate functions

for $\beta=0.5,1,2$ and $\theta=2$

Figure 4.5 The total unit cost vs. burn-in time $(\beta=0.5,1,2 ; \theta=1 ; W=1) \ldots \ldots \ldots \ldots \ldots \ldots \ldots . . .69$

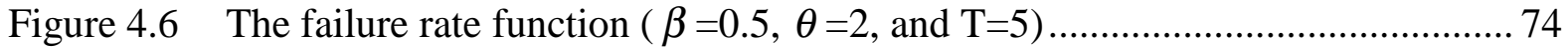

Figure 4.7 W-E cumulative and probability density functions.................................... 75

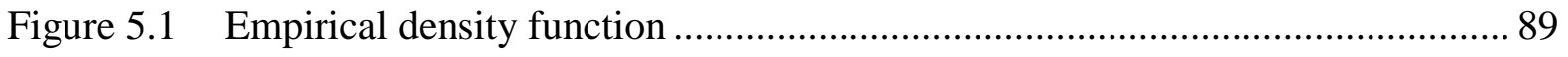

Figure 5.2 Hazard rate vs. service hours............................................................... 90

Figure $5.3 \quad$ Empirical reliability vs. service hours ................................................ 90

Figure 5.4 Probability-Probability plot for six theoretical distribution functions .............. 91

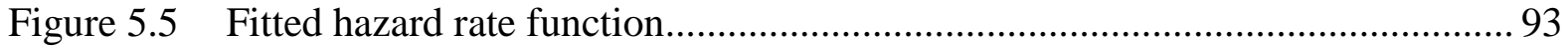

Figure 5.6 PP plot for Weibull-Exponential distribution ......................................... 94

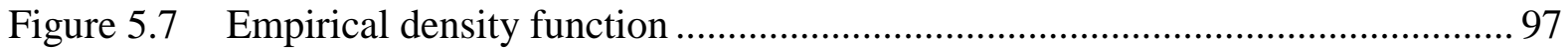

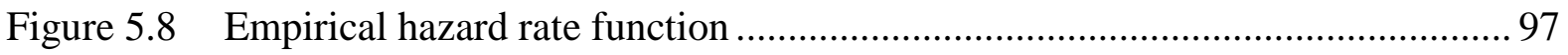




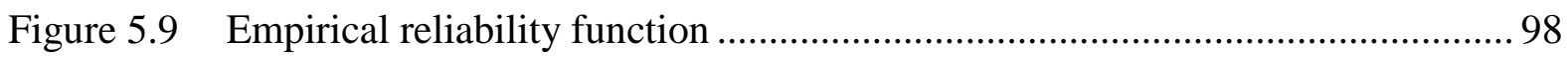

Figure 5.10 Lognormal plot for the part of an engine ................................................ 99

Figure 5.11 Lognormal probability-probability for the part of engine............................ 100

Figure 5.12 Empirical hazard rate function. .............................................................. 101

Figure 5.13 Profit as a function of warranty period and price when burn-in time is zero... 105 


\section{LIST OF TABLES}

Table 4.1 Parameter values

Table 4.2 Optimal price, warranty and burn-in policies for different MTTF values when $a_{2}=0.2$ and $a_{1}=-2.2$

Table 4.3 Optimal price, warranty and burn-in policies for different price elasticity values when $M T T F=1$ and $a_{l}=-2.2$

Table 4.4 Optimal price, warranty and burn policies for different warranty elasticity values when $M T T F=1$ and $a_{1}=-2.2$

Table 4.5 Optimal policies for different $\theta$ values when $\beta=0.7, a_{1}=-2.2$, and $a_{2}=0.2 \ldots .72$

Table 4.6 Optimal policies for different price elasticity values when $\beta=0.7, \theta=4$, and $a_{2}=0.2$

Table 4.7 Optimal policies for different warranty elasticity values when $\beta=0.7, \theta=4$, and $a_{1}=-2.2$

Table 4.8 Optimal policies for different $\theta$ values when $\beta=0.7, T=0.1, a_{1}=-2.2$, and $a_{2}=0.2$

Table 4.9 Optimal policies for different price elasticity values when $\beta=0.7, \theta=4, T=0.1$ and $a_{2}=0.2$ 80

Table 4.10 Optimal policies for different warranty elasticity values when $\beta=0.7, \theta=4$, $T=0.1$, and $a_{l}=-2.2$

Table 5.1 Failure history for a unit of electronic ground support equipment [Juran and Gryna 1970]. 85

Table 5.2 The number of repairs per 1000 vehicles 86 
Table 5.3 Life table for a unit of electronic ground support equipment.

Table 5.4 Optimal policies for different parameter values......................................... 95

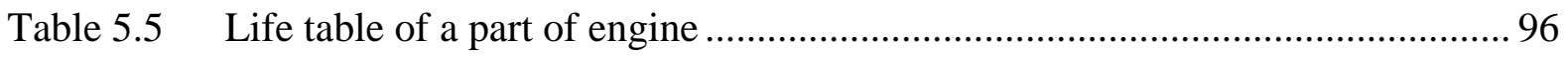

Table 5.6 Result obtained with the optimal solution................................................ 104 


\section{CHAPTER 1}

\section{INTRODUCTION}

Warranties are an important part of today's competitive markets. Most of the products, whether expensive or inexpensive, carry some kind of warranty. A warranty is an assurance given by the seller at the time of sale that the product will perform its functions satisfactorily for a specified time period. With a warranty, a seller promises to repair or replace the product if it fails during the warranty period.

Warranties are important to both sellers and customers. Sellers often use warranties as a marketing tool to increase the sales of the product. Customers usually interpret a longer warranty period as a sign of quality and reliability. This is especially true for new products in which customers have little or no information about quality and reliability. Sellers also offer warranties as a means of protection against exceptional claims by requiring certain responsibilities from customers, for instance warranties do not cover any item failures due to misuse of the product [Blischke and Murthy.1992]

From customers' point of view a warranty provides a means of redress for product failures. A product purchase decision for a rational consumer involves four stages: perception of need for product, search for information, evaluation of alternatives, and product choice. Warranty plays an important role in the last three stages [Murthy and Blischke, 1992]. Warranty coverage may vary greatly from one product to another. Thus, as customers compare the price, style and other characteristics of products before purchase, they should also compare the warranties. Sellers of consumer products, according to Magnuson-Moss Warranty Federal Trade Commission Improvement Act, must provide any 
warranty information available to customers so that they can compare different product warranties before purchase [Brennan, 1994].

Sellers incur additional costs by offering warranty coverage. However the warranty may be used as a marketing strategy to improve sales, and hence revenue. If the revenue generated by the warranty program exceeds the warranty cost, it is more sensible to sell the product with a warranty. Therefore, when designing a warranty program, the seller needs the following information

- cost of the warranty program

- expected increase in the sales,

- performance of the product

In the following sections, we will discuss some important aspects of warranty analysis that must be considered when designing an effective warranty program.

\subsection{Warranty Policies}

Effective warranty management requires proper evaluation of alternative warranty policies. There are many different warranty policies available in practice. Warranty policies can be very simple or very sophisticated depending upon the type of product, customer and seller.

From a legal point of view, all products are covered by two warranties: expressed and implied warranties. An expressed warranty is any written or oral statement provided by the seller at the time of purchase. Although there is no obligation on sellers to provide an expressed warranty, they may be held responsible for any item failures because of the implied warranty. The implied warranty is created by law, and in the absence of the expressed warranty, provides coverage equivalent to expressed warranties offered on similar 
products in the market. Basically, there are two types of implied warranty: the warranty of merchantability and the warranty of fitness for a particular purpose. The warranty of merchantability simply means that the product will perform its designed function safely and satisfactorily-i.e. a mixer will mix; a printer will print. The implied warranty of fitness for a particular purpose means that the product will perform a specific purpose (preferably in writing) as claimed. For instance, if a seller claims that the product will perform well under certain temperatures, he cannot disclaim any product failures due to the temperature according to the warranty of fitness for a particular purpose.

Warranties can also be classified as assurance or incentive based on the purpose of the warranty program. In the assurance warranty, the purpose is to give customers only an assurance that the seller will cover any failure due to defect in material or workmanship during the warranty period. In this sense, the warranty provides only protection to both customers and sellers. Consumers' product warranties fall into this category. In the incentive warranty, beside ordinary protection, sellers are encouraged to improve the product quality and reliability. The warranty may include field services and training provided by the seller or design changes when the product does not meet the requirements. Most government and military purchases fall into this category [Brennan, 1994]

This research considers only consumer warranties. Consumer warranties can be further classified into several categories based on the type of remedial action, the number of criteria used to determine the length of warranty eligibility, and whether the warranty is renewal or non-renewal. Figure 1.1 shows a simple classification of warranty policies used on consumer products. 


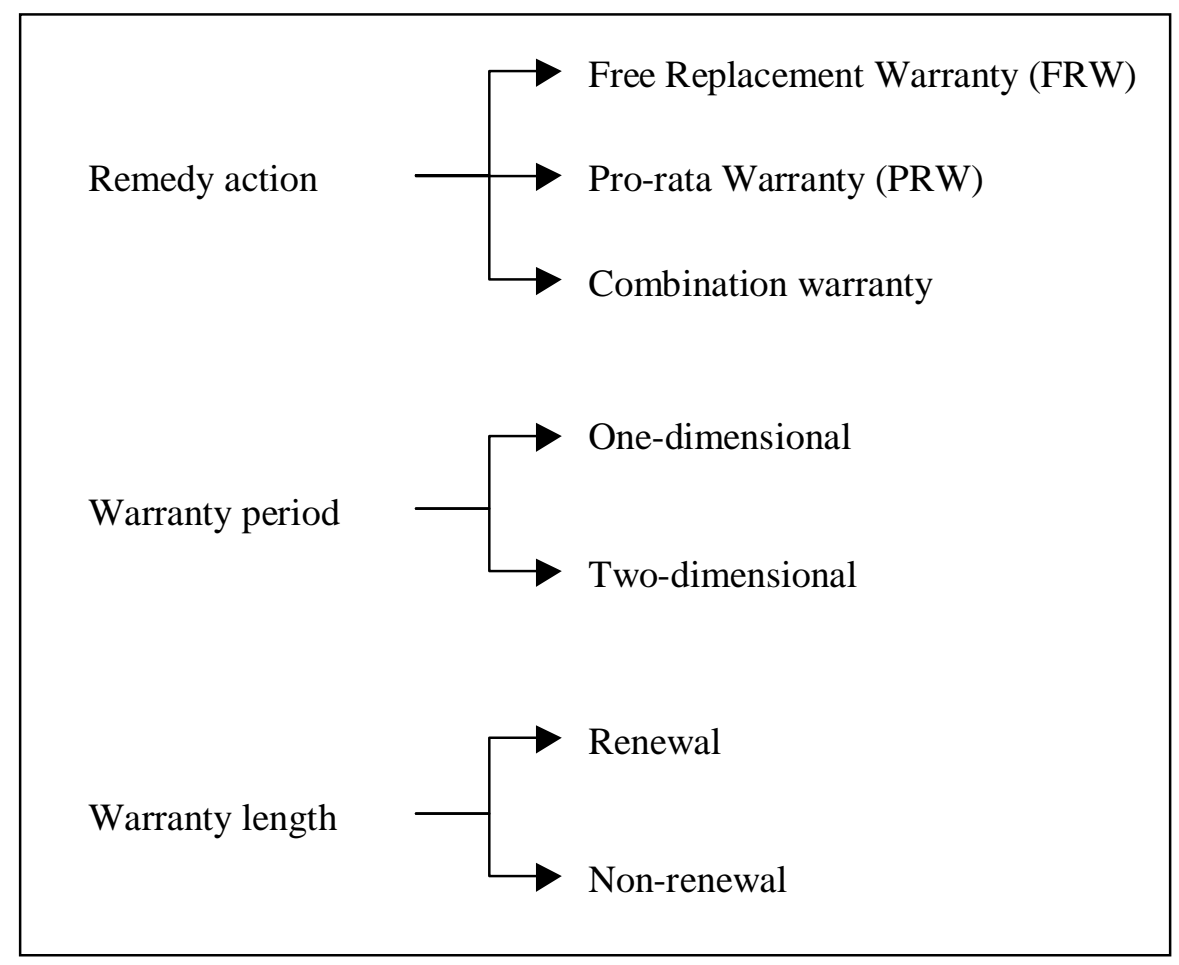

Figure 1.1 Warranty policies

\subsubsection{Types of Remedy Action}

When a product fails during the warranty period, the seller may take several remedy actions such as repair or replace, to compensate for the failure. Based on the remedy action, warranty policies are grouped as free replacement warranty (FRW), pro-rata warranty (PRW), and combination warranty.

\subsubsection{Free Replacement Warranty}

Under a free replacement warranty, the seller agrees to replace or repair the product if a failure occurs during the warranty period, free of charge to the customers. There is usually no limit on the number of replacements and repairs as long as the failures are due to poor product quality. Sometimes, sellers may offer a full (money back guarantee) or partial 
refund (lump-sum warranty) for failures instead of repair or replacement. FRW is the most common warranty policy used on consumer durables such as television sets, personal computers, etc.

\subsubsection{Pro-rata Warranty}

Under a pro-rata warranty, the seller and customer share the cost of failure on a prorated basis. The seller may replace the product or give a rebate. The cost of replacement or the amount of rebate depends on the age of the item. For example, a linear rebate function can be defined as

$$
r(t)= \begin{cases}\left(1-\frac{t}{W}\right) P & \text { if } t \leq W \\ 0 & \text { otherwise }\end{cases}
$$

where $t$ is the time of failure, $W$ is the warranty period, and $P$ is the purchase price. According to this policy, the amount of rebate decreases as a linear function of time and becomes zero after the warranty period. There are several rebate functions available in practice. The rebate does not have to be continuous linear function of time. PRW is usually offered for non-repairable products such as automobile tires and batteries where failures occur due to wear or deterioration.

\subsubsection{Combination Warranties}

A combination warrant usually includes two or more FRW and/or PRW. The most common application of the combination warranty is the one in which coverage begins with a FRW period followed by a PRW period. A combination warranty may be used to attract more customers without a substantial increase in the warranty cost. 


\subsubsection{One or Two-dimensional Warranty Policies}

Based on the number of criteria used to determine the length of the coverage, warranty policies can be one or two-dimensional.

\subsubsection{One-dimensional Warranty Policies}

In one-dimensional policies, the length of the warranty coverage is characterized by one criterion. Time (or age) is the most common variable used in practice because of its simplicity. The warranty coverage starts at the time of purchase and ends after a certain period of time, called the warranty period. This is a reasonable criterion because most product failures are related to their age. In some cases, however, failures occur purely due to the usage frequency of the product. The amount of usage, such as miles, the number of operation or flying hours, etc., can be used for such products to terminate the warranty eligibility.

\subsubsection{Two-dimensional Warranty Policies}

In this case, the length of the coverage is determined by two characteristics of the product, such as age and usage. For most products, failures are not only due to aging phenomenon or usage frequency but combination of the two. Therefore, one needs to consider these two factors in order to determine the warranty eligibility. Some twodimensional warranty policies defined by Blischke and Murthy [1992] are depicted in Figure

$$
1.2 \text {. }
$$

Policy A: The warranty duration is determined by the rectangle $[0, W] \times[0, U]$ as shown in Figure 1.2 (a). According to this policy, a customer may have maximum coverage of $W$ units of time and/or $U$ units of usage. The warranty expires at $U$ or $W$, whichever comes first. This 
policy is in favor of sellers because it protects sellers from excessive warranty claims of customers due to usage limit. Automobile warranties are the most famous example of this policy.

Policy B: Under policy B, the customer is guaranteed at least $W$ units of time or $U$ units of usage. The warranty expires when both the time and usage exceeds their limits. This policy is in favor of customers because if the usage is very light, the customer will be provided warranty coverage beyond the minimum time period $W$ as long as the total usage is less than $U$, and if the usage is heavy, the warranty will expire at time $W$.

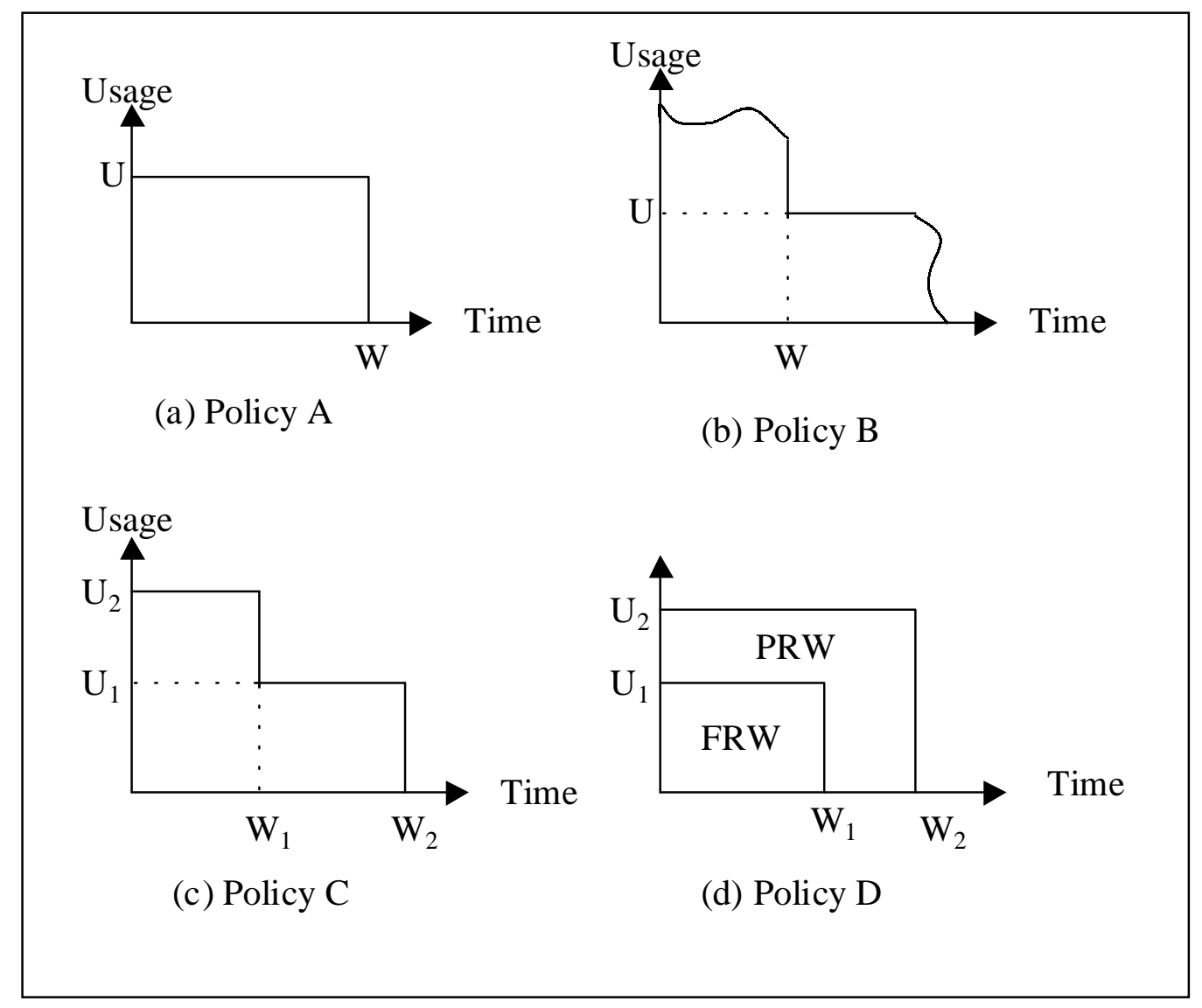

Figure 1.2 Two-dimensional warranty policies. 
Policies A and B represent two extreme cases. Policy A is preferred mostly by sellers, however there is no application of Policy B. Blischke and Murthy suggest the following policies in order to bring a compromise between customers and sellers.

Policy C: Under this policy, a customer may be covered up to $W_{1}$ or $W_{2}$ units of time depending on his usage level. If usage is less than $U_{1}$, the warranty expires at time $W_{2}$, otherwise it expires at time $W_{l}$. This policy rewards customers who have low usage level by providing extra protection period and protects seller from heavy users by limiting the usage level.

Policy D: Under this warranty, a product is covered first by a FRW and then followed by a PRW. This policy provides an extra coverage to customers by sharing with the seller the cost of the failure occurring outside of the free replacement area.

\subsubsection{Non-renewal and Renewal Warranties}

Warranty policies may also be classified into two groups based on how long a seller should provide the warranty service.

\subsubsection{Non-renewal Warranty}

The length of coverage is specified at the time of purchase and remains fixed. Replacement or repair of the product does not change the original warranty period. The coverage expires at the end of original warranty period. This is the most common warranty policy used on relatively inexpensive consumer products. 


\subsubsection{Renewal Warranty:}

In renewal warranty, every time a failure occurs, the product is repaired or replaced with a new warranty. This type of policy is usually offered for non-repairable products with a PRW. For example, if a car battery fails before the warranty period, a new battery may be replaced on a prorated basis with a new warranty.

\subsubsection{Other Warranty Policies}

In addition to the policies given in the previous sections, there are several other kinds of warranty policies available to meet some special needs. Two of the most important ones are cumulative and reliability improvement warranties (RIW).

\subsubsection{Cumulative Warranty}

The cumulative warranty may be offered when a single customer purchases a large quantity of products. Instead of covering each product individually, the lot size of $\mathrm{N}$ products is warranted for a total time period of $\mathrm{N}^{*} \mathrm{~W}$. The warranty expires when the total service time exceeds the total warranty period. The advantage of this policy to the seller is that fewer warranty claims may be expected because the longer lived products can offset early failures of low quality products. This type of warranty would be suitable for commercial and governmental purchases since consumers seldom buy a large quantity of products.

\subsubsection{Reliability Improvement Warranty}

The reliability improvement warranty (RIW) is an example of assurance warranty. The basic idea is to give an incentive to the seller to provide high quality product. Under 
RIW, the seller promises not only to cover failures but also to increase the reliability of the product through engineering design changes. The warranty contract may include field services, guaranteed mean time between failures (MTBF), a guaranteed turn-around time (TAT) for replacement or a guaranteed mean time to repair (MTTR) for repairable products. The types of products covered by RIW are usually more sophisticated and intended to be used for long periods of time. RIW was first used in aircraft purchasing, and later adopted in military purchasing [Blischke, 1992].

\subsection{Warranty Design}

When a new product is introduced into the market, it is often viewed with some degree of uncertainty by customers [Blischke and Murthy 1992]. It is usually a good practice to sell the new product with a better warranty than the competitors' in order to gain the customers' trust and hence increase the sales. Thus, the important question the warranty management must answer before introducing a new product into the market is how long and what type of warranty should be offered in order to reduce the uncertainty regarding product quality and reliability.

Basically, designing a warranty program involves

- $\quad$ selection of the type of warranty policy

- determination of the length of warranty period

- specification of the breadth of warranty coverage

The type and length of warranty are the most important features that affect the customer's decision to buy. The seller may repair or replace any failed product or give a refund or offer different combinations of repair-replace during the warranty period. The selection of the type of warranty policy should be based on the product and market. The 
length of the warranty should reflect the performance of the product. It should be long enough to meet the market objectives and short enough to achieve certain cost objectives. Finally, the breadth of coverage specifies in details what is covered and what is not by the warranty. The seller usually takes responsibility for defects in material and workmanship, any exception must be clearly stated in the warranty. For instance, the warranty may cover only certain parts of the product and labor.

Before offering a warranty program, the seller must have sufficient knowledge in the following

- product

- market

- customers

\subsubsection{Product}

Depending on the ultimate users, products can be classified as consumer products and commercial products. Consumer products are any tangible personal goods, which are used normally for personal, family, or household purposes. Consumer products are under regulation of the Magnuson-Moss Federal Trade Commission Improvement Act. Commercial products are any goods sold between commercial organizations. Technical complexity of such products may vary considerably. Commercial products are regulated by the Uniform Commercial Code. If more than ten percent of a commercial product is purchased by consumers, it becomes a consumer product and is subject to Magnuson-Moss regulations [Brennan, 1994].

Because the warranty regulation changes based on type of the product, the seller must design the warranty program according to this regulation. Under Magnuson-Moss 
regulations, sellers are imposed more obligations than that of the Uniform Commercial Code.

\subsubsection{Customers}

In general, customers can be grouped as expert and non-expert, based on their knowledge of the product. Expert customers usually depend less on the warranty to estimate the product quality. Examples of the expert customers include industrial or commercial organizations such as airline companies buying airplanes, and governments buying defenserelated products. On the other hand, non-expert customers may use warranties as a signal of quality when they cannot determine the quality from other characteristics of the product. Average citizens buying consumer durables are typical examples of non-expert customers.

\subsubsection{Market}

Competition plays an important role when designing a warranty program. If the seller is one of a few firms in the market (i.e. monopolistic situation) and controls most of the market, improving the warranty program may not have a significant effect on the sales. On the other hand, if there are too many sellers in the market, which is often the case for consumer products, then the warranty could become an important selling point. Of course, in this case, we assume that a rational customer would prefer a product that has a better warranty when the other characteristics are similar. 


\section{Warranty Cost}

When a product is returned under warranty, the seller incurs a variety of costs. The warranty cost may drastically reduce the seller's profit when the warranty program is not entirely evaluated. Typically, the warranty costs may include

- administrative cost,

- transportation cost,

- repair/replacement cost,

- transportation cost to return product,

- handling costs of retailer,

- inventory cost of spare parts,

- court costs in case of dispute.

In addition to these, there are some intangible costs associated with loosing the goodwill of customers when the product fails under the warranty. The warranty cost is unpredictable since the product failures occur randomly, and the usage and operating conditions vary significantly over time and from customer to customer. McGuire has analyzed various product sectors and has found that warranty cost as a percentage of sales price varies between $1 \%$ and $10 \%$ and the majority of firms having these costs as less than 5\%. [Blischke \& Murthy, 1992]

\subsection{Product Reliability and Warranty}

The product reliability is the key to maintaining a good customer base while maximizing the profits of the manufacturer. Reliability is defined as the probability that the product will perform its required function for a specified period of time when used under 
given operating conditions. Product reliability plays an important role in warranty analysis since higher reliability means less warranty cost to the sellers. However, higher reliability is usually achieved at the expense of increased manufacturing cost per unit. The trade-off between the two costs needs to be considered when offering a warranty.

The reliability can be improved through better design, improved manufacturing process, and good quality control. Burn-in test is one of the methods used to increase the reliability of products. The purpose of the burn-in test is to detect and eliminate weak or defective components in the product before it is distributed to the market. Each product is put into the burn-in test following its production. During the test, the product is monitored for failures under environmental conditions close to its field operating conditions, assuming that weak components will fail in a shorter period of time than good ones. "Since the failure cost during the production process is usually cheaper than the failure cost during the warranty period, burn-in is considered as a means to reduce the warranty cost" [Nguyen and Murthy, 1982]. However, the burn-in test adds extra cost to the manufacturing process. The problem is how long the burn-in test should continue so that there will be less or no defective components in the product, and hence less warranty problems in the future. Thus, the choice of burn-in time should be determined in order to optimize certain objectives. There are different objectives of burn-in program. First, a burn-in test may be used in order to improve the mean time to failure of products that survive the test. Second objective of burn-in test may be to obtain pre-determined reliability goal. Finally, the minimum total cost often considered as an objective when performing burn-in program. 


\subsection{Problem Statement}

In this research, the warranty period and price are treated as marketing variables. That is, the other marketing variables such as advertising expenditure, environmental factors are assumed to be determined, and the seller wishes to find the best price and warranty policy in order to increase the total profit. In this sense, we assume that customers view the warranty as one of the important purchasing criteria. Further, the seller uses burn-in test in order to eliminate or reduce weak components that might be present in the product before distributing it to the market. The objective of the seller is to maximize profit. Thus, the problem is to find the optimal burn-in time, warranty period and price in order to maximize profit.

\subsection{Research Objectives and Methodology}

The objectives of this research are to identify the failure characteristic of the product, determine the expected cost of selling the product with a certain type of warranty, and finally build and solve some optimization models in order to determine the best price, warranty and burn-in policies that maximize the profit.

First, some cost models associated with burn-in and warranty policies will be built. The total cost to a seller can be simply separated into two parts: costs occurring before sale and costs occurring after sale. Before sale cost, which will be referred to as the burn-in cost in this dissertation, includes manufacturing cost plus cost of testing the product during the burn-in period. Two burn-in models will be investigated for repairable and nonrepairable products.

After sale cost, which will be referred to as the warranty cost, includes repair or replacement costs during the warranty period. Three types of warranty policies widely used 
in the real world will be considered: (1) a free replacement warranty for repairable products, (2) a free replacement warranty for nonrepairable products, and (3) a pro-rata warranty for nonrepairable products.

The literature on warranty has mainly focused on the estimation of the warranty cost for different warranty policies when the warranty period is known. However, the marketing role of warranty has received little attention from researchers. On the other hand, the literature on burn-in tests has mainly focused on determining the burn-in time in order to optimize certain objectives such as the expected total cost. In this research, the marketing role of warranty along with burn-in as a means of reducing the warranty cost will be incorporated into the models. To model the expected sales, a simple multiplicative model will be used.

The models developed in this research can be applied to any lifetime distributions, however analytical solutions are possible only when the product failures follow simple lifetime distribution functions, for instance the exponential distribution. The solution of the models requires numerical methods when the lifetime of the product follows rather complex distributions such as Weibull. A computer program will be developed in order to solve these optimization models.

We will also describe solution procedures when the lifetime of the product cannot be modeled by any known theoretical distribution function. In this case, nonparametric or distribution free methods must be used to obtain solutions. A computer program using nonparametric solution procedures to estimate certain quantities such as the expected number of failures during both burn-in and warranty periods will be developed for this case. Two sets of data will be used in testing and applying the procedures developed. 
This dissertation is planned as follows. Chapter 2 presents literature related to the problem. Chapter 3 gives detailed formulation of the mathematical models for a general failure distribution function. Chapter 4 shows the application of the models when the failure times follow certain distribution functions. Chapter 5 describes solution procedures for two types of product. Chapter 6 presents conclusions and some areas for future research as an extension to this research. 


\section{CHAPTER 2}

\section{REVIEW OF THE LITERATURE}

The literature on warranty analysis is very broad since it involves so many disciplines such as economics, law, management, marketing, statistics, etc. Each discipline has investigated different aspects of the warranty. The marketing literature has considered warranties as a marketing tool and analyzed their effects on product sales and the impact of warranties on customers' perceptions of risk. The industrial and management literatures have examined warranties in terms of their relationship to reliability, costs, reserves and cash flows. The economics literature on product warranties focuses on social welfare and regulatory issues [Menezes and Currim, 1992].

This chapter reviews only literature related to the research under three main topics

- Warranty cost estimation,

- Warranties as a marketing tool,

- Warranties as a signal of reliability.

\subsection{Warranty Cost Estimation}

Warranty cost is important to sellers for several reasons. First, the warranty cost is included into the price of the product. Therefore, an accurate estimation is necessary for the pricing policy. Second, the knowledge of warranty cost helps sellers compare different policies and select the best policy in some sense. Finally, it increases seller's ability to manage future cash flows.

From customers' point of view, the knowledge of warranty cost may help customers to decide between products with different warranties, and whether to buy an extended 
warranty when such an option exists. However, customers, in most cases, cannot get access to this information.

The warranty cost estimation is a very challenging task since product failures occur randomly, and operating conditions and customers' usage vary greatly. The literature in this area can be grouped as one and two-dimensional warranty cost modeling.

\subsubsection{One-dimensional Warranty Cost Models}

The literature on one-dimensional cost modeling has mainly focused on estimation of the expected cost per product during the warranty period and the expected total cost during the product life cycle from both customers' and sellers' perspective. For life cycle cost models, $L C C$, it is often assumed that customers will immediately replace the product during its life cycle if it fails after the warranty period.

Blischke and Scheuer [1975] analyzed FRW and PRW from both customers' and sellers' points of view. Customers have the choice of buying the product with or without a warranty. They calculated the cost (profit) to the customer (seller) at which the customer (seller) would be indifferent between buying (selling) the product with or without a warranty.

Balachandran et. al. [1981] developed a Markov model. They assumed that the product consists of three independent components whose failure times are distributed as exponential. The seller repairs a component on the first two breakdowns and replaces the component on its third breakdown during the warranty period. According to this policy, they estimated the expected warranty cost.

Thomas [1983] considered a combination warranty policy for nonrepairable products. The warranty period was divided into two intervals. Products failing in the interval 
$\left[0, W_{1}\right]$ are replaced with a new one, and failures in the interval $\left[W_{1}, W_{2}\right]$ result in prorated rebates. He derived a unit warranty cost formula for different failure distributions. He also developed a procedure to find the optimum warranty period in order to minimize the expected warranty cost.

Blischke and Scheuer [1981] studied the expected number of replacements during the life cycle of the product since the warranty cost is directly related to the number of failures. First, they investigated several different failure distributions, including exponential, uniform, gamma, and Weibull analytically, and later, adopted a numerical approach because of the complexity encountered in the analytical examination. Finally, a simulation program was developed to evaluate different failure distributions.

Nguyen and Murthy [1984a] developed a general model for repairable products sold with FRW. It was assumed that the failure time distribution is arbitrary, and the repair cost depends on the number of repairs carried out. They estimated (i) the expected total warranty cost and its confidence interval for a fixed lot size, and (ii) the expected number of units returned for repair and expected warranty cost incurred in any time interval during the product life cycle when sales occur continuously.

Mamer [1982, 1987] examined the expected warranty cost for a product sold with a FRW and a PRW. In the first paper, he derived an expression for the expected total warranty cost assuming that the product would be replaced by an identical one until the end of the life cycle. He also found the average costs for three cases: no warranty, PRW and FRW. In the second paper, he assumed that some customers might switch to another seller because of their bad experience with the first purchase. That is, there is a certain probability that the customer will not replace the product from the same seller if it fails after the warranty 
period. He also introduced a random damage process into the model so that a product will fail either because it wears out or because it has been damaged accidentally. He assumed that damage occurs according to Poisson processes, and calculated the expected discounted profit to the seller and the expected discounted cost to customers for FRW and PRW policies.

Balcer and Sahin [1986] found the mean and variance of the total replacement cost for a PRW and FRW during the product life cycle. They also investigated the case where the failure time distribution depends continuously on time.

Nguyen and Murthy [1984b] examined a combination warranty in which coverage starts with a FRW period and is followed by a PRW period. The customer instantaneously purchases an identical replacement if the failure is not covered by a FRW. They assumed that the product has an increasing failure rate. They calculated the expected warranty price to customers and expected profit to the seller during the life cycle of the product. They also obtained the expected number of purchases and its minimum and maximum limits during the life cycle of the product.

Nguyen and Murthy [1986] considered a special case where the product is replaced with a new one if it fails in the interval $[0, \mathrm{~W}-\mathrm{t}]$ and with a repaired one if it fails in the interval $[\mathrm{W}-\mathrm{t}, \mathrm{W}]$. Further, they assumed that a failed unit is repaired and added to the collection of repaired products only if it was not subjected to repair earlier and its age at failure is less than or equal to $\alpha$. They determined the optimal replacement interval in order to minimize the expected warranty cost.

Ritchken and Fuh [1986] investigated the optimal age replacement policies for nonrepairable product sold with PRW from the customers' point of view. In the age replacement 
policy, a product is replaced upon its failure or at a fixed time interval whichever comes first. This type policy is often used when the product has increasing failure rate with age. They calculated the optimal replacement period after the expiration of warranty in order to minimize the expected average cost.

In the warranty cost estimation models, it is often assumed that the product is used continuously. This is true for some industrial products, but most consumer products are used intermittently during their lifetimes. The product failure rate, in general, is less when it is idle. Additionally, the product failure depends not only on its age but also on its usage frequency. Murthy [1992] proposed two different models to model the failure times for both repairable and nonrepairable products. In the first model, the product failure depended on its age and usage without considering whether it is in use or not at the time of failure. In the second model, he assumed a constant failure rate when the product is idle. He used a Markov process to model the failure distribution function.

Generally, the failure time distribution of a product is unknown in reliability analysis, and one must estimate it from available data. However, in warranty analysis, the seller usually knows about failures during the warranty period, and is not aware of failures after the warranty. Thus, available data are often incomplete and not enough to drive any statistical conclusion -i.e. they are censored. Another problem is that a typical warranty cost estimation analysis usually involves complex mathematical expressions such as intricate numerical integrals and convolution or Laplace transformation of distribution functions. Analytical solutions are available only for some simple distribution functions. Many researchers studied some approximation techniques to overcome this problem. Frees [1986] investigated three approximation techniques to estimate the expected warranty cost. 
Frees and Nam [1988] studied a combination warranty where the seller replaces the product free of charge to customers in the period $(0, \mathrm{~W}]$, and customers buy a new product at a fraction of the sale's price in the period $(\mathrm{W}, \mathrm{W}+\mathrm{T}]$. They assumed that a customer would own the product for a lifetime of $\mathrm{L}(\mathrm{L}>\mathrm{W}+\mathrm{T})$ and calculated the total expected cost during the lifetime of the product by using a "straight-line approximation (SLA)".

Kao and Smith [1993] used a "phase-type" distribution to approximate the failure distribution. For a phase type distribution, it is assumed that there is a continuous-time Markov chain with $m+1$ states. States. $1,2 \ldots m$ are transient and state $m+1$ is absorbing. When the failure distribution is a phase-type, the computation is reduced substantially because of its structure. It requires only simple matrix operations and simple numerical integration. They also calculated the life cycle cost of a product under the phase type assumption.

Warranty claims occur in the future. Therefore, the seller must reserve a part of his revenue in order to meet these claims. Overestimating warranty reserves will result in a lost opportunity due to committed fund that could be invested for greater returns. On the other hand, underestimating will result in hidden losses that must be covered from future profit [Thomas, 1983].

Tapiero and Posner [1988] assumed that the seller would reserve a fraction of the income generated through sales and that the seller would discontinue the product when the warranty reserve drops under its lower limit. They considered two cases. In the first case, the warranty reserve is unbounded from above and in the second case, it was bounded from above and the excess reserves are invested in some of the seller's activities. They calculated the probability that the warranty reserve does not reach its lower limit. 
Amato and Anderson [1976] considered the discount rate and the effect of the time value of money in estimating the total warranty reserve for PRW policy. The seller may invest the reserved money assigned to cover future warranty claims in some of his activities to generate extra revenue. Additionally, if there are increases in the general price level, the amount of rebate at the time of failure will be discounted. Therefore, the actual warranty price charged at the time of sales will be less than the face value. The seller may reflect this on the price of the product to increase his competing power in the market.

Patankar and Worm [1981] estimated cash flows for a given time interval during the warranty period and the expected total warrant reserve for a fixed lot size of $\mathrm{N}$ products sold with PRW policy. They assumed an exponential failure time distribution and discounted warranty cost. Since the product failures occur randomly, the amount of rebate given for each failure is also a random variable. Therefore, the total rebate given for a lot size of $\mathrm{N}$ products, from central limit theorem, would be normally distributed. Based on this, they calculated a prediction interval for expected total warranty reserve and cash flows.

Thomas [1989] predicted total warranty reserves for a product sold under a nonrenewal PRW. He calculated total warranty costs for several failure distributions. He also considered discounting value of the money since warranty claims are realized in the future.

Amato et. al. [1976] obtained formulas to distribute future warranty costs into given accounting periods for products sold with PRW. In PRW, the major cost element is the rebates given to customers. However, having a warranty program involves additional costs. For example, a seller may maintain a service to evaluate whether the claims are valid or not. Amato et. al. calculated the evaluation costs assuming that some proportions of the claims 
are invalid. Finally, they proposed several approaches to distribute the fixed cost associated with warranty administration into the unit cost of the product.

\subsubsection{Two-dimensional Warranty Cost Models}

Two-dimensional cost modeling has received little attention by researchers compared to one-dimensional cost modeling.

Murthy et. al. [1995] studied two-dimensional, FRW policies for nonrepairable products. They proposed three alternative two-dimensional warranty policies that sellers should consider beside fixed $x$-year-y-usage warranty coverage. They calculated the expected unit warranty cost and life cycle cost of products for each two-dimensional warranty policy.

Eliashberg et. al. [1997] developed a two dimensional model for a FRW in order to find the optimal warranty reserve. They assumed that the usage is a monotonically increasing function of time. A "stochastic logistic function" was used for this purpose. They also assumed that the seller repairs the product and the type of repair is imperfect. They defined a loss function associated with having established a warranty reserve and calculated the warranty reserve that minimizes the loss function.

As mentioned earlier, two-dimensional warranties in practice are in favor of the sellers and create inequity among customers. In order to be equal to all customers, the seller may provide different warranty plans to fit different customers needs. As in the automobile example, he may offer a 7-year 50,000-mile warranty for customers who travel less and a 5year 70,000-mile warranty for customers who travel frequently. Moskowitz and Chun [1994] developed two types of two-dimensional warranty models based on a Poisson regression model and expected utility theory. First, they determined the optimal warranty 
price per product that is sold with a fixed two-dimensional warranty. Later, they generated different two-dimensional warranty plans for a given warranty price so that all customers will have the same expected repair or replacement cost.

\subsection{Warranties as a Marketing Tool}

As mentioned earlier, there is an increasing trend among sellers to use warranties as a marketing tool. The literature on this area has mainly focused on determination of the optimum price and/or warranty period. Since the performance of a product during the warranty period is uncertain to customers and sellers, the cost that a seller should charge and the price that a customer is willing to pay for the warranty service depend on their attitudes toward uncertainty.

If there exists a relationship between the warranty period and sales, one can model sales as a function of the warranty period as well as some other marketing variables such as price, advertising, quality, appearance, etc. The problem is to find the best marketing strategy that optimizes certain objective such as profit or market share of the seller.

Blair and Inis [1996] investigated the effects of warranty and brand name on consumers. They grouped consumers as experts and nonexperts based on their knowledge about the product. Their study showed that both experts and nonexperts evaluated warranty more important than brand name, and concluded that the length of the warranty serves as a cue for product quality when the brand name is not well known and consumer is not highly knowledgeable.

Glickman and Berger [1976] studied optimal selling price and warranty period for repairable products. The sales were modeled as a log-linear function of price and warranty period. They found the optimal price and warranty period for FRW assuming that the 
product failure time is distributed with gamma probability density function, and performed a sensitivity analysis to show the changes in the optimal solution corresponding to some parameters of the model.

Menezes and Curim [1992] viewed warranties as a marketing tool and found the optimal price and warranty period for a product sold with FRW and PRW. The sales were also assumed to be dependent mainly on the price and warranty period. They first considered a single-period planning horizon and derived formulas to calculate the optimal warranty period and price when failure times are random variables with exponential and Weibull distributions. They later extended the analysis to a multi-period planning horizon by incorporating the "diffusion effect" -i.e. the present number of sales will effect the number of sales in the future. They described a methodology to estimate the warranty elasticity and, based on this estimation, calculated the optimal warranty period for Chrysler automobiles.

Mesak [1996] studied diffusion models which incorporate price and warranty period. The decision-maker is interested not only in determining pricing policy over time but also in designing the associated warranty policy. Mesak considered the effect of experience on production cost and found the optimal warranty period and pricing policy over a planning horizon for a monopolistic market situation. He concluded that the warranty period depends on the pricing policy and is influenced by the shape of the pricing response function.

Chun and Tang [1995] proposed a warranty model to determine the optimal warranty price for a repairable product sold with non-renewal and FRW. They assumed constant failure rate, constant repair cost and a concave utility function. Customers have a choice to buy the product either with or without warranty. If customers expect a higher product failure rate, they will most likely buy the warranty and will be willing to pay a higher warranty 
price. Chun and Tang showed that customers would be willing to pay a higher warranty price if the producer is the only repair supplier for the failed products (monopolistic situation) or if it is more costly to repair the failed products at an external place. They also analyzed the sensitivity of the optimal warranty price to some parameters of the model.

Anderson [1977] attempted to formulate a cost model for nonrepairable products sold with PRW. The decision variables were the warranty period and price. He concluded that the optimal solution depends primarily on the failure time distribution of the product, size of the rebates promised to the customer over the warranty period, and combinations of price and warranty duration.

Ritchken and Tapiero [1986] evaluated PRW for nonrepairable products according to risk preferences of both buyers and sellers. Some customers are willing to pay high prices to get a long term coverage while others may prefer low price and short term warranty coverage. Adjusting the price and warranty length to specific customers' needs may increase sales. They provided all prices and warranty lengths such that the seller would have the same expected utility from the product. They also investigated the relationship between quality and warranty coverage. As quality increases, the warranty cost to the seller decreases. However, increasing the quality may require a new technology, more quality inspections, etc. They established different quality levels and warranty prices such that all warranty-quality levels in the set yield the same expected utility for the product.

Patankar and Mitra [1989] and Mitra and Patankar [1993] developed an integrated model for estimating the warranty period and price when there are several goals at different priority levels. They assumed a PRW policy and an exponential failure distribution. In the first paper, the warranty period and price of the product were entered into the model as 
decision variables. Later they included the lot size and production quantity into the model as additional decision variables. A goal programming approach was used to solve the problem. A sensitivity analysis was performed on some parameters to determine the effect of changing their values on the attainment of the goals.

\subsection{Warranty as a Signal of Reliability}

Planning a warranty program without considering the reliability of product as well as other aspects may drastically reduce the seller's expected future profit. Therefore, when designing a new product, a seller should consider the reliability and warranty simultaneously. In general, the warranty period is determined according to competitors' warranties in the same market. Sellers usually tend to offer an equivalent or more warranty coverage than competitors. After setting the length of coverage, the minimum reliability requirement must be determined in order for the warranty program to be successful. If the designed product reliability is less than the required reliability, different design alternatives or manufacturing processes should be compared to attain the desired product reliability. Increasing reliability reduces the warranty cost, however it may add extra cost on manufacturing. Thus the comparison of different alternatives must be made based the tradeoff between the warranty cost and manufacturing cost.

Research in the literature has shown that a significant number of customers infer that a product with a superior warranty will have a better reliability. Weiner [1985] analyzed some consumers' durables and motor vehicles to investigate the accuracy of whether a warranty is an accurate signal of a product's reliability. By using a one-tail two-sample Kolmogorov-Smirnov test, he concluded that products with superior warranties are indeed more reliable among selected products. 
Gal-Or [1989] considered an oligopolistic market and investigated, through an example, whether warranties can serve as signal of quality. He concluded that warranties are a perfect signal only in cases in which the intrinsic attributes of the product are neither too clustered nor widely spaced.

Nguyen and Murthy [1982] determined the optimal burn-in time in order to minimize the expected total manufacturing and warranty cost for both FRW and PRW policies. They concluded that burn-in is beneficial when the initial failure rate is large and failures during the warranty period are costly. They supported their findings with some numerical examples.

Chou and Tang [1992] formulated two cost models to find the optimal burn-in time when the product has an initial decreasing failure rate followed by a constant failure rate. The seller is responsible for repairing or replacing all the failed products during the warranty period. A mixture of Weibull and exponential distributions (W-E) was used to describe the failure rate function. They showed that the optimal burn-in time does not exceed "the infant mortality phase" (the first phase in product lifetime in which the failure rate decreases monotonically). They also suggested a Maximum-likelihood estimation to find the so-called "change point", (a point in time at which the product enters the second phase of its lifetimerefer to Figure 3.1) when it is unknown.

Mi [1997] considered a general model in which the failure rate function of the product has a bathtub shape. Similarly, he showed that the optimal burn-in time that minimizes the cost function never exceeds the infant mortality phase for both FRW and PRW policies. He also studied the sensitivity of the model to some cost parameters. 
Murthy and Nguyen [1987] studied two reliability growth models, in which products are subject to test-fix-test process upon completion of the production. In the first model, it was assumed that the failure rate of the product depends continuously on the testing time or the number of modifications carried on during the testing time. In the second model, the reduction in the failure rate after each modification was treated as a random variable. They also assumed that the failure rate would be constant after the end of the testing period. They found optimal testing plans to minimize the expected costs for products sold with FRW.

Nguyen and Murthy [1988] investigated the optimal reliability allocation problem for a fixed warranty period for both repairable and nonrepairable products. The product consists of several independent and serially connected components that have constant failure rates. The lower and upper limits of failure rates for each component are known. The seller's objective is to minimize the total expected cost that includes both manufacturing and warranty costs, subject to some minimum reliability constraint.

Lie and Chun [1987] provided a proposition to determine an optimum sampling plan in order to minimize the sum of the expected warranty cost and quality control cost for both FRW and PRW policies within the assigned seller and customer risk. A single-sample attribute plan with non-destructive testing was considered. 


\section{CHAPTER 3}

\section{MODEL FORMULATION AND SOLUTION METHODS}

Before introducing a new product, the seller must design a marketing strategy in order to improve his chances for success. Designing the marketing strategy involves the choice of marketing variables (such as price, advertising expenditure, etc.) and performance measures (such as maximization of profit or market share), the determination of functional relations between variables, and the estimation of parameters. The marketing variables are determined based on the behavior of consumers in the market, the performance measures are set by the decision maker, the relations among variables may be determined based on past experiences or judgment of the decision maker, and parameter estimations are done based on data.

Suppose that a seller wants to introduce a new product in a highly competitive market. Marketing research has shown that price and warranty period play an important role on the purchase decision of customers. Thus, in order to model the sales of the product, price and warranty period have been selected as primary marketing variables. In addition, it is assumed that the functional relationship between sales, price, and warranty period is known, and that all parameters have been estimated. The goal of the seller is to find the best warranty and pricing policies in order to maximize profit. Determination of the best policy depends on product reliability as well as customers' behavior. Therefore, it is also assumed that the reliability can be improved through a burn-in test following production.

This research mainly investigates the following questions:

- How long should the product be tested in the burn-in period? 
- What should be the length of the warranty coverage?

- What should be the price of the product?

- How much is the expected profit?

This chapter starts with modeling of the failure rate function. Next, some cost models will be developed for different burn-in and warranty policies in order to estimate the total expected cost of the product. Later, these cost models will be used in the optimization models to find the optimum price, warranty and burn-in policies.

\subsection{Modeling Product Failures}

No product is produced to last forever; it would eventually experience one or more failures in its lifetime. A failure occurs when a product stops performing its required function. The cause of failure can be intrinsic, i.e. due to weakness or wearout within the product or extrinsic, i.e. due to designed stress level being less than the applied stress [Birolini, 1994].

Let $\tau$ be continuous non-negative random variable that represents the failure time and $f(t)$ be the failure density function and $F(t)$ be corresponding distribution function. The reliability function is given by

$$
R(t)=1-F(t)
$$

Let $h(t)$ be the failure (or hazard) rate function. The hazard rate is defined as the conditional probability of failure per unit time given that it has not failed earlier. Formally

$$
h(t)=\lim _{\delta t \rightarrow 0} \frac{1}{\delta t} P\{t<\tau \leq t+\delta t \mid \tau>t\}=\frac{f(t)}{R(t)}
$$

In general, three phases can be observed during the lifetime of most products. The first phase is known as infant mortality or burn-in phase where the failure rate decreases 
with time. Failures during this phase are mainly due to defective material and/or poor manufacturing processes. The next phase is called the useful or operational phase where the failure rate is usually constant. Failures during this phase occur mainly due to random overload of the product or accidents. The third phase represents the wear out phase where failures occur due to fatigue, gradual deterioration of the material, and accumulation of shocks. Figure 3.1 shows the failure rate function during the lifetime of the product. $t_{1}$ and $t_{2}$ are the change points when the product enters and leaves its useful lifetime. Because of its shape, it is often called the "bathtub failure rate function".

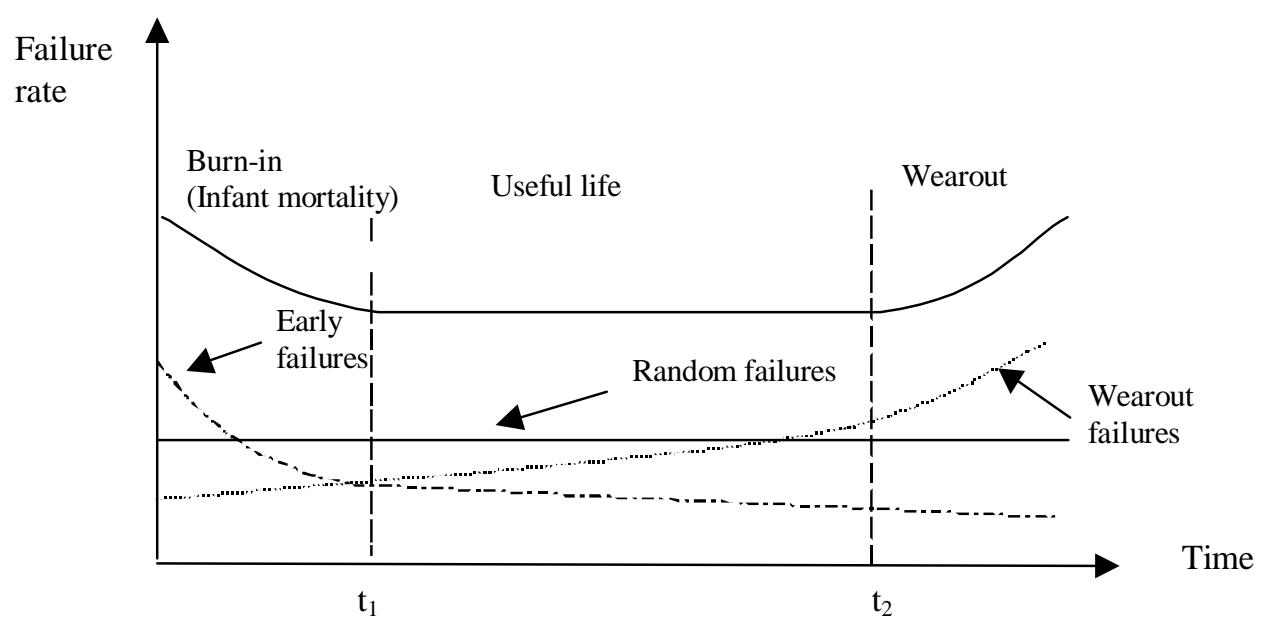

Figure 3.1 The failure rate function during the lifetime of a product [Ebeling, 1997]

Not all products have a bathtub failure rate function. Some products may have a strictly increasing failure rate (IFR), while others may initially have a decreasing failure rate (DFR) due to defective parts followed by an increasing failure rate due to aging. For example, most mechanical products exhibit increasing failure rate functions in their lifetime.

Burn-in test is a method proven to be useful when the product has a decreasing failure rate function. During the burn-in, early failures, due to weak components or assembly errors, are eliminated so that the product is left out with good components. As a result of the 
burn-in test, the reliability of the product increases, therefore fewer claims are expected during the warranty period.

\subsection{Cost Models}

A burn-in program incurs additional cost to the seller. However, when a product fails under the warranty, the seller may face some extra costs such as shipping and handling, the cost of loosing the goodwill of the customer, or in extreme cases, court costs. Therefore, fixing a possible failure during the burn-in period is less costly than during the warranty period.

The total cost consists of the manufacturing, burn-in, and warranty costs. The burn-in cost includes three cost items as defined below. The following notations will be used to represent these costs:

$c_{m}$ : the manufacturing cost per product without burn-in (\$/unit),

$c_{1}$ : Fixed burn-in cost per product (\$/unit). It is independent of the number of failures occurring during the burn-in period, and independent of burn-in time. It includes costs of installing the equipments for the burn-in test and removing them again, or costs of unpacking and repackaging, etc.

$c_{2}$ : Time-dependent burn-in cost associated with product testing and failure monitoring during the burn-in period such as inspector cost, as well as costs due to the fact that the total production time is delayed. (\$/time),

$c_{3}$ : Failure-dependent burn-in cost, which includes repair costs and/or handling cost such as removing and reinstalling the product (\$/unit), 
$c_{4}$ : The extra cost per failure during the warranty period. It includes shipping and handling cost, repair or replacement cost as well as some intangible costs (\$/unit) [Jensen and Petersen, 1982].

The same cost parameters were considered by Nguyen and Murthy [1982], Chou and Tang [1992], and Mi [1996] when building the cost models. It is assumed that all cost parameters have been estimated, and that they are fixed. When developing the cost models, the burn-in and warranty costs will be considered separately. Two burn-in cost models will be developed based on whether the product is repairable or not. For warranty cost models, three warranty policies will be investigated: a free replacement warranty for repairable products, a free replacement warranty for nonrepairable products, and a pro-rata warranty for nonrepairable products. These are the most common warranty policies offered by sellers in practice.

\subsubsection{Burn-in Cost Model for Repairable Products}

In this case, products are placed on a burn-in test after the completion of the manufacturing process for a certain period of time, during which they are monitored for failure. When a failure occurs, the failed product is repaired and put back into the test. The burn-in test clock continuos from the point where it was stopped when the product failed. This test-repair-test-repair process continues until the end of the burn-in test. In this model, the following assumptions are made:

- Repair time is zero

- The type of repair is "minimal repair" 
For most products, repair time is very small compared to time between failures. While repair time can be measured in hours, time between failure is measured in months or years. In the model, it is assumed that repair time is negligibly small so it can be ignored.

The performance of the product after repair is important. Depending on this performance, the repair action can be classified as perfect repair, imperfect repair, or minimal repair. Figure 3.2 shows the failure rate function after the different repair actions.

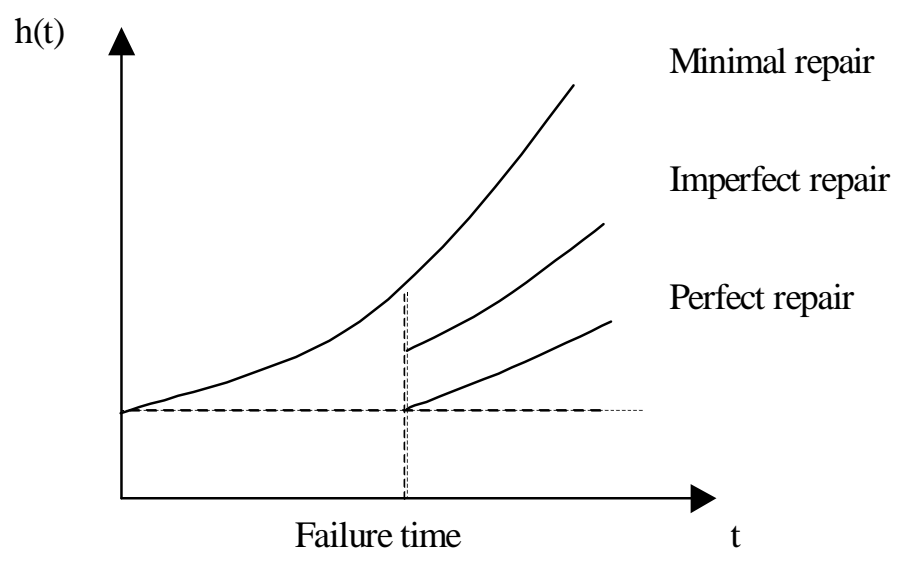

Figure 3.2 The failure rate function after repair [Murthy and Blischke, 1992].

Perfect repair: After perfect repair, the product is considered as new. In other words, the repaired product will have the same failure rate as a new one.

Imperfect repair: After imperfect repair, the condition of the product is assumed to be uncertain- i.e. the failure rate after the imperfect repair is a random variable. The repaired product may have higher or lower failure rate than the one before failure.

Minimal repair: After minimal repair, the performance of the product does not change i.e. the repaired product will have the same failure rate as before it failed. This is usually the case for multicomponent products where the product failure occurs due to component failures. When the failed component is replaced with a new one, the product becomes 
operational. Since the rest of the components are not affected by this replacement, the product as a whole would have the same failure rate.

Let $B$ be burn-in period. The burn-in cost including manufacturing cost is given by

$$
c_{m}+c_{1}+c_{2} B+c_{3} N(B)
$$

where $N(B)$ is the expected number of failures during the burn-in period. Under the minimal repair, $N(B)$ is given by

$$
\int_{0}^{B} h(t) d t
$$

Hence, the expected burn-in cost per product becomes

$$
C_{B}=c_{m}+c_{1}+c_{2} B+c_{3} \int_{0}^{B} h(t) d t
$$

\subsubsection{Burn-in Cost Model for Nonrepairable Products}

In this case, if the product fails during the burn-in test, it is replaced with a new one.

The new product is also put into burn-in test and the test is restarted by setting the burn-in clock to zero. This test-replace-test-replace process continues until one completes the burnin without a failure.

The burn-in cost per product consists of the manufacturing cost, burn-in fixed cost, and the cost of testing the product. It is determined based on whether the product fails before the burn-in time and is given by,

$$
\left\{\begin{array}{l}
c_{m}+c_{1}+c_{2} t \quad \text { if } t \leq B \\
c_{m}+c_{1}+c_{2} B \quad \text { if } t>B
\end{array}\right.
$$


Since failures occur randomly, the burn-in cost per product is also a random variable and depends on the time spent in the burn-in test. The expected burn-in time per product is given by (see Appendix 1)

$$
\int_{0}^{B} R(t) d t
$$

Hence, the expected burn-in cost per product is

$$
c_{m}+c_{1}+c_{2} \int_{0}^{B} R(t) d t
$$

The burn-in test continues until the first survivor, therefore the number of products tested until the first surviving product is a random variable. If it is assumed that each product comes from the same manufacturing process with the same failure distribution, then the number of products tested until the first survivor is a geometrically distributed random variable with a success probability $p=R(B)$ and mean, $\mu=R(B)^{-1}$ where $R(B)$ is the probability that the product will not fail during the burn-in. Therefore the expected burn-in cost per surviving product is simply the sum of the costs of all the tested units. This cost is given by;

$$
C_{B}=\left[c_{m}+c_{1}+c_{2} \int_{0}^{B} R(t) d t\right] \frac{1}{R(B)}
$$

\subsubsection{Free Replacement Warranty Cost Model for Repairable Products}

In this model, the seller repairs failures during the warranty period. It is also assumed that the type of repair during the warranty period is minimal. When a product fails under the warranty, the seller incurs an extra cost $c_{4}$ in addition to the repairing cost of $c_{3}$. 
Let $W$ be the warranty period. The expected warranty cost per product under minimal repair is given by

$$
C_{W}=\left(c_{3}+c_{4}\right) \int_{B}^{B+W} h(t) d t
$$

The warranty cost in Equation 3.5 is dependent on the burn-time and the warranty period. If $h(t)$ is a decreasing function of $t$, then the warranty cost decreases as the burn-in time increases.

\subsubsection{Free Replacement Warranty Cost Model for Nonrepairable Products}

When a failure occurs during the warranty period, the failed product is replaced with an identical one with no charge to customers.

In this case, the failure distribution of the products after the burn-in is important. At the end of the burn-in period, the product would be at the age of $B$. Suppose that the failure distribution remains the same. Let $F_{B}(t)$ and $f_{B}(t)$ be the conditional distribution and probability density function of the failure time $t$ given that the product has survived the burn-in period of $B$. Formally,

$$
\begin{array}{ll}
F_{B}(t)=\frac{F(t+B)-F(B)}{R(B)} & t \geq 0 \\
f_{B}(t)=\frac{d F_{B}(t)}{d t}=\frac{f(t+B)}{R(B)} & t \geq 0
\end{array}
$$

In order to find the expected warranty cost, one must to calculate the expected number of replacements during the warranty period. Let $\left\{t_{\mathrm{n}}, n=1,2,3 \ldots\right\}$ be a sequence of failure times of the product. Each failed product is replaced with a new one that has come from the same production process and burn-in. Therefore, it can be assume that failure times 
are independent and identically distributed (i.i.d.) with a common distribution function $F_{B}(t)$. Let $N(t)$ be the number of replacements in $[0, \mathrm{t}]$ and $S_{n}$ be the time of $n^{\text {th }}$ replacement defined as:

$$
S_{0}=0, \quad S_{n}=\sum_{i=1}^{n} t_{i} \quad n \geq 1
$$

The following relation exists between $N(t)$ and $S_{n}$

$$
S_{n} \leq t \Leftrightarrow N(t) \geq n
$$

In words, the number of replacements in the interval $[0, t]$ is greater or equal to $n$ if and only if the $n^{\text {th }}$ replacement occurs by time $t$ [Ross, 1970]. Let

$$
F_{B}^{(n)}(t)=P\left(S_{n} \leq t\right)
$$

Since $t_{1}, t_{2}, \ldots$ are i.i.d., $F_{B}^{(n)}(t)$ is the n-fold convolution of $F_{B}(t)$. Let $M_{B}(t)$ be the expected number of replacements in the interval $[0, t]$. It can be shown that $M_{B}(t)$ is given by(see Ross, 1970)

$$
M_{B}(t)=E[N(t)]=\sum_{n=1}^{\infty} F_{B}^{(n)}(t)
$$

$M_{B}(t)$ is called the renewal function. There is a one to one relationship between the failure time distribution, $F_{B}(t)$ and the renewal function $M_{B}(t)$.

Let $m_{B}(t)=\frac{d M_{B}(t)}{d t}$ be the renewal density function.

$$
\tilde{m}_{B}(s)=\frac{\tilde{f}_{B}(s)}{1-\tilde{f}_{B}(s)}
$$

where $\tilde{f}_{B}(s)$ and $\tilde{m}_{B}(s)$ are the Laplace transforms of $f_{B}(t)$ and $m_{B}(\mathrm{t})$, respectively. Thus, if the Laplace transforms exist, $F_{B}(t)$ is determined by $M_{B}(t)$ and vice versa. $M_{B}(t)$ is also obtained using the following integral equation [Birolini, 1994]. 


$$
M_{B}(t)=F_{B}(t)+\int_{0}^{t} f_{B}(x) M_{B}(t-x) d x
$$

The above equation is known as the renewal equation. $M_{B}(t)$ can be obtained analytically when $F_{B}(t)$ is the linear combination of exponential distributions. For a general failure distribution, $M_{B}(t)$ can be obtained only by some numerical procedures [Nguyen and Murthy, 1982].

The expected warranty cost per product is given by

$$
C_{W}=\left[C_{B}+c_{4}\right] M_{B}(W)
$$

where $C_{B}$ is the burn-in cost given in Equation $3.4, M_{B}(W)$ is the expected number of replacements during the warranty period.

\subsubsection{Pro-rata Warranty for Nonrepairable Products}

In this case, when a product fails during the warranty period, a rebate is given to the customer. The rebate depends on the age of product at the time of failure and is determined based on the purchase price $P$. Suppose that the seller offers a linear rebate function defined as follows

$$
r(t)= \begin{cases}\left(1-\frac{t}{W}\right) P & \text { if } t \leq W \\ 0 & \text { otherwise }\end{cases}
$$

Notice that the amount of rebate decreases linearly as the product ages and becomes zero at $W$. Hence, the expected warranty cost per product is equal to the expected rebate given to the customer. Formally

$$
C_{W}=\int_{0}^{W} r(t) f_{B}(t) d t
$$




$$
\begin{aligned}
& =\int_{0}^{W}\left(1-\frac{t}{W}\right) P f_{B}(t) d t \\
& =P\left[F_{B}(W)-\frac{1}{W} \mu_{B}(W)\right]
\end{aligned}
$$

where $\mu_{B}(W)$ is the partial expectation and is given by (see Appendix 2)

$$
\begin{aligned}
\mu_{B}(W) & =\int_{0}^{W} t f_{B}(t) d t \\
& =\frac{1}{R(B)}\left[W \cdot F(B+W)-\int_{0}^{W} F(t+B) d t\right]
\end{aligned}
$$

Substituting $F_{B}(W)$ and $\mu_{B}(W)$ into Equation 3.7 yields

$$
\begin{aligned}
C_{W} & =P\left[\frac{F(B+W)-F(B)}{R(B)}-\frac{1}{W \cdot R(B)}\left(W \cdot F(B+W)-\int_{0}^{W} F(t+B) d t\right)\right] \\
& =\frac{P}{R(B)}\left[F(B+W)-F(B)-F(B+W)+\frac{1}{W} \int_{0}^{W} F(t+B) d t\right] \\
& =\frac{P}{R(B)}\left[\frac{1}{W} \int_{0}^{W} F(t+B) d t-F(B)\right]
\end{aligned}
$$

or

$$
\begin{aligned}
& =\frac{P}{R(B)}\left[R(B)-\frac{1}{W} \int_{0}^{W} R(t+B) d t\right] \\
& =P\left[1-\frac{1}{W R(B)} \int_{0}^{W} R(t+B) d t\right]
\end{aligned}
$$




\subsection{Optimization Models}

There are two important issues that arise from warranty considerations when introducing a new product into the market. The first is the specification of optimum price and warranty period in order to be competitive, and the second is the determination of the reliability level in order to support the first one. In the models developed, price, warranty period and burn-in time are incorporated in order to derive the optimal price, warranty and burn-in policies over the planning horizon. Suppose that the primary goal of the manufacturer is to maximize profit. Let $\Pi$ be the total expected profit. Then, the manufacturer total expected profit is approximately the product of its expected sales and its expected unit profit minus fixed cost:

$$
\Pi=(P-C) Q \text {-Fixed cost }
$$

where $P$ is unit price, $C$ is unit expected cost including both burn-in and warranty costs, $Q$ is expected sales volume in the planning horizon.

In general, $Q$ can be modeled as a function of several marketing variables as well as the warranty period

$$
Q=f\left(P, W, A, D, R, F, P^{\prime}, W^{\prime}, A^{\prime}, D^{\prime}, R^{\prime}, F^{\prime}\right)
$$

where $W$ is warranty period, $A$ is advertising, $D$ is distribution, $R$ is quality, $F$ is product features, $\left(P^{\prime}, W^{\prime}, A^{\prime}, D^{\prime}, R^{\prime}, F^{\prime}\right)$ are the corresponding competitor's variables. This research considers only the warranty period and price as decision variables. All other variables will be assumed to be known and fixed (i.e. the decision-maker either has already determined their values or does not have control over them). Further, it is assumed that the sales volume is inversely related to the price and increasingly related to the warranty period. That is

$$
\frac{\partial Q}{\partial P}<0, \quad \frac{\partial Q}{\partial W}>0
$$


Suppose that the sales volume is defined as a function of $P$ and $W$ as follows:

$$
Q=k P^{a_{1}} W^{a_{2}}
$$

where $k>0$ is a constant multiplier, $a_{1}<-1$ is the price elasticity, $0<a_{2}<1$ is the warranty elasticity, and $a_{1}<-\left(a_{2}+1\right)$. The above model is known as the multiplicative model. The sales function decreases exponentially with price and increases exponentially with warranty period. The relationship between sales and price in Equation 3.10 is supported by empirical research findings. Although there is no similar studies available to support the functional relationship between sales and warranty period, the selection of exponential form is not unreasonable [Glickman and Berger]. It is assumed that parameters $k, a_{1}$, and $a_{2}$ are known parameters, and have been estimated by considering the other marketing variables.

Let $P^{*}, W^{*}$, and $B^{*}$ be the optimal price, warranty period, and burn-in time that maximize the profit. The necessary condition for optimality is that the first derivatives must be equal to zero. Formally,

$$
\frac{\partial \Pi}{\partial P}=0, \quad \frac{\partial \Pi}{\partial W}=0, \quad \frac{\partial \Pi}{\partial B}=0,
$$

The sufficient condition is that the Hessian matrix evaluated at $P^{*}, W^{*}$, and $B^{*}$ is negative definite. Differentiating the expected total profit function with respect to $P$ yields

$$
\frac{\partial \Pi}{\partial P}=(P-C) \frac{\partial Q}{\partial P}+Q\left[1-\frac{\partial C}{\partial P}\right]=0
$$

where

$$
\frac{\partial Q}{\partial P}=k a_{1} P^{a_{1}-1} W^{a_{2}}=Q \frac{a_{1}}{P}
$$

Substituting the above quantity into Equation 3.11yields

$$
(P-C) a_{1}+P\left[1-\frac{\partial C}{\partial P}\right]=0
$$


Thus

$$
P^{*}=C\left(\frac{a_{1}}{a_{1}+1-\frac{\partial C}{\partial P}}\right)
$$

Differentiating the profit function with respect to $W$ yields

$$
\frac{\partial \Pi}{\partial W}=(P-C) \frac{\partial Q}{\partial W}-Q \frac{\partial C}{\partial W}=0
$$

where

$$
\frac{\partial Q}{\partial W}=k a_{2} P^{a_{1}} W^{a_{2}-1}=Q \frac{a_{2}}{W}
$$

Substituting the above quantity and the optimal price $P^{*}$ into Equation 3.13 yields

$$
C\left(\frac{a_{1}}{a_{1}+1-\frac{\partial C}{\partial P}}-1\right) \frac{a_{2}}{W}-\frac{\partial C}{\partial W}=0
$$

Thus, the optimal warranty period is given by

$$
W^{*}=\frac{C}{\frac{\partial C}{\partial W}}\left(\frac{a_{1}}{a_{1}+1-\frac{\partial C}{\partial P}}-1\right) a_{2}
$$

Differentiating the profit function with respect to $B$ yields

$$
\frac{\partial \Pi}{\partial B}=-Q \frac{\partial C}{\partial B}=0
$$

Hence

$$
\frac{\partial C}{\partial B}=0
$$

Three different models will be considered: free replacement warranty for repairable products, free replacement warranty for non-repairable products, and pro-rata warranty for non-repairable products. 


\subsubsection{Free Replacement Warranty and Burn-in for Repairable Products}

Failures during both burn-in period and warranty period are repaired by the manufacturer. The expected unit cost from Equation 3.3 and Equation 3.5 is given by

$$
C=C_{B}+C_{W}=c_{m}+c_{1}+c_{2} B+c_{3} \int_{0}^{B} h(t) d t+\left(c_{3}+c_{4}\right) \int_{B}^{B+W} h(t) d t
$$

The optimal burn-in period from Equation 3.15 is obtained by minimizing the expected unit cost.

$$
\begin{gathered}
\frac{\partial C}{\partial B}=c_{2}+c_{3} h(B)+\left(c_{3}+c_{4}\right)[h(B+W)-h(B)]=0 \\
c_{2}-c_{4} h(B)+\left(c_{3}+c_{4}\right) h(B+W)=0
\end{gathered}
$$

and

$$
h\left(B^{*}\right)=\frac{c_{2}+\left[c_{3}+c_{4}\right] h\left(B^{*}+W^{*}\right)}{c_{4}}
$$

The optimal warranty period from Equation 3.14

$$
W^{*}=\frac{C}{\frac{\partial C}{\partial W}}\left(\frac{a_{1}}{a_{1}+1-\frac{\partial C}{\partial P}}-1\right) a_{2}
$$

where

$$
\begin{aligned}
& \frac{\partial C}{\partial W}=\left[c_{3}+c_{4}\right] h(B+W) \\
& \frac{\partial C}{\partial P}=0
\end{aligned}
$$

thus

$$
W^{*}=\frac{C}{\left[c_{3}+c_{4}\right] h(B+W)}\left(\frac{a_{2}}{-a_{1}-1}\right)
$$


The optimal price from Equation 3.12 is

$$
P^{*}=C\left(\frac{a_{1}}{a_{1}+1-\frac{\partial C}{\partial P}}\right)
$$

Because the unit cost does not depend on the price, derivation of the unit cost with respect to price yields zero, thus

$$
P^{*}=C\left(\frac{a_{1}}{a_{1}+1}\right)
$$

\subsubsection{Free Replacement Warranty and Burn-in for Nonrepairable Products}

Failures during the burn-in period and warranty period are replaced with new ones. The expected unit cost from Equation 3.4 and Equation 3.6 is given by

$$
\begin{aligned}
C & =C_{B}+C_{W} \\
& =C_{B}+\left[C_{B}+c_{4}\right] M_{B}(W) \\
& =C_{B}\left[1+M_{B}(W)\right]+c_{4} M_{B}(W) \\
& =\frac{1}{R(B)}\left[c_{m}+c_{1}+c_{2} \int_{0}^{B} R(t) d t\right]\left[1+M_{B}(W)\right]+c_{4} M_{B}(W)
\end{aligned}
$$

The optimal burn-in time from Equation 3.15

$$
\frac{\partial C}{\partial B}=\frac{\partial C_{B}}{\partial B}\left[1+M_{B}(W)\right]+C_{B} \frac{\partial M_{B}(W)}{\partial B}+c_{4} \frac{\partial M_{B}(W)}{\partial B}=0
$$

where $\frac{\partial C_{B}}{\partial B}=c_{2}+C_{B} h(B)$ (see Appendix 3). Substitution yields

$$
\frac{\partial C}{\partial B}=\left[c_{2}+C_{B} h(B)\right]\left[1+M_{B}(W)\right]+\left[C_{B}+c_{4}\right] \frac{\partial M_{B}(W)}{\partial B}=0
$$

and 


$$
h\left(B^{*}\right)=-\frac{c_{2}\left[1+M_{B}(W)\right]+\left[C_{B}+c_{4}\right] \frac{\partial M_{B}(W)}{\partial B}}{C_{B}\left[1+M_{B}(W)\right]}
$$

The optimal warranty period from Equation 3.14

$$
W^{*}=\frac{C}{\frac{\partial C}{\partial W}}\left(\frac{a_{1}}{a_{1}+1-\frac{\partial C}{\partial P}}-1\right) a_{2}
$$

where

$$
\begin{aligned}
& \frac{\partial C}{\partial W}=\left[C_{B}+c_{4}\right] m_{B}(W) \\
& \frac{\partial C}{\partial P}=0
\end{aligned}
$$

hence

$$
W^{*}=\frac{C}{\left[C_{B}+c_{4}\right] m_{B}(W)}\left(\frac{a_{2}}{-a_{1}-1}\right)
$$

The optimal price from Equation 3.12 is

$$
P^{*}=C\left(\frac{a_{1}}{a_{1}+1-\frac{\partial C}{\partial P}}\right)
$$

thus

$$
P^{*}=C\left(\frac{a_{1}}{a_{1}+1}\right)
$$




\subsubsection{Pro-Rata Warranty and Burn-in for Nonrepairable Products}

In this case, the seller replaces the failed product with a new one during the burn-in period and offers a rebate during the warranty period. The expected unit cost from Equation 3.4 and Equation 3.8 is

$$
\begin{aligned}
& C=C_{B}+C_{W}=\frac{1}{R(B)}\left[c_{m}+c_{1}+c_{2} \int_{0}^{B} R(t) d t\right]+\frac{P}{R(B)}\left[R(B)-\frac{1}{W} \int_{0}^{W} R(B+t) d t\right] \\
& C=\frac{1}{R(B)}\left[c_{m}+c_{1}+c_{2} \int_{0}^{B} R(t) d t+P\left(R(B)-\frac{1}{W} \int_{0}^{W} R(B+t) d t\right)\right]
\end{aligned}
$$

The optimal burn-in period from Equation 3.15 is obtained from, (see Appendix 4)

$$
\begin{gathered}
\frac{\partial C}{\partial B}=c_{2}+C_{B} h(B)+\frac{P}{R(B) W}\left[F(B+W)-F(B)-h(B) \int_{0}^{W} R(B+t) d t\right]=0 \\
h\left(B^{*}\right)=\frac{c_{2}+\frac{P}{R\left(B^{*}\right) W}\left[F\left(B^{*}+W\right)-F\left(B^{*}\right)\right]}{\frac{P}{R\left(B^{*}\right) W} \int_{0}^{W} R\left(B^{*}+t\right) d t-C_{B}}
\end{gathered}
$$

The optimal warranty period from Equation 3.14 is

$$
W^{*}=\frac{C}{\frac{\partial C}{\partial W}}\left(\frac{a_{1}}{a_{1}+1-\frac{\partial C}{\partial P}}-1\right) a_{2}
$$

where

$$
\begin{aligned}
& \frac{\partial C}{\partial W}=\frac{P}{W^{2}}\left[\int_{0}^{W} R(B+t) d t-W R(B+W)\right] \\
& \frac{\partial C}{\partial P}=R(B)-\frac{1}{W} \int_{0}^{W} R(B+t) d t
\end{aligned}
$$


hence

$$
W^{*}=\frac{C}{\frac{P}{W^{* 2}}\left[\int_{0}^{W^{*}} R\left(B^{*}+t\right) d t-W^{*} R\left(B^{*}+W^{*}\right)\right]}\left(\frac{a_{1}}{a_{1}+1+\frac{1}{W^{*}} \int_{0}^{W^{*}} R(B+t) d t-R\left(B^{*}\right)}-1\right) a_{2}
$$

The optimal price from Equation 3.12 is

$$
\begin{aligned}
& P^{*}=C\left(\frac{a_{1}}{a_{1}+1-\frac{\partial C}{\partial P}}\right) \\
& P^{*}=C\left(\frac{a_{1}}{a_{1}+1+\frac{1}{W^{*}} \int_{0}^{W^{*}} R\left(B^{*}+t\right) d t-R\left(B^{*}\right)}\right)
\end{aligned}
$$




\section{CHAPTER 4}

\section{SOLUTION PROREDURES FOR SOME THEORETICAL DISTRIBUTIONS}

In Chapter 3, three optimization models were developed for two warranty policies: a free replacement warranty for repairable products and a free replacement warranty for nonrepairable products, and a pro-rata warranty for nonrepairable products. The models do not assume any specific theoretical lifetime distributions such as exponential, Weibull etc. Therefore they can be used with all types of failure distributions.

In general, lifetime distributions of products are unknown and need to be estimated from failure data. In some cases, product failures can be modeled by a known theoretical distribution function. For instance, some mechanical products that tend to have increasing failure rate may be modeled by a Weibull distribution with a shape parameter greater than one or by a lognormal distribution.

In this research, three distribution functions that are widely used in reliability analysis will be considered in order to model the failure time of a product: exponential, Weibull and Weibull-exponential mixed distribution functions. Implementation with other lifetime distributions such as lognormal or gamma distributions would follow the same procedure. However, analytical solutions are available only when the lifetime of the product follows an exponential distribution. For other lifetime distributions, numerical methods will be used to obtain optimal solutions. 


\subsection{Exponential Distribution}

The exponential distribution is the most common distribution used in reliability analysis. The exponential distribution is suitable for items when failures occur due to completely random or chance events [Ebeling, 1996]. Most of the electronic items' failures follow the exponential distribution. The probability density function, with parameter $\lambda>0$, is given by

$$
f(t)=\lambda e^{-\lambda t} \quad t \geq 0
$$

Its cumulative distribution, reliability, and failure rate functions are given as

$$
\begin{aligned}
& F(t)=1-e^{-\lambda t} \quad t \geq 0 \\
& R(t)=\bar{F}(t)=1-F(t)=e^{-\lambda t} \quad t \geq 0 \\
& h(t)=\frac{f(t)}{R(t)}=\lambda
\end{aligned}
$$

The exponential distribution has a constant failure rate, therefore it does not exhibit the classical bathtub failure characteristic. However, if the early failures caused by weak or defective parts are eliminated as a result of quality control, the exponential distribution can be justified. The exponential distribution also possesses the memoryless property, which simply means that the behavior of the item in the future does not depend on how long it has already been used. Because of the memoryless property, the exponential distribution is also the easiest distribution to analyze statistically. Figure 4.1 shows the probability density function, cumulative distribution, reliability function, and failure rate function for the exponential distribution for different values of $\lambda$. 

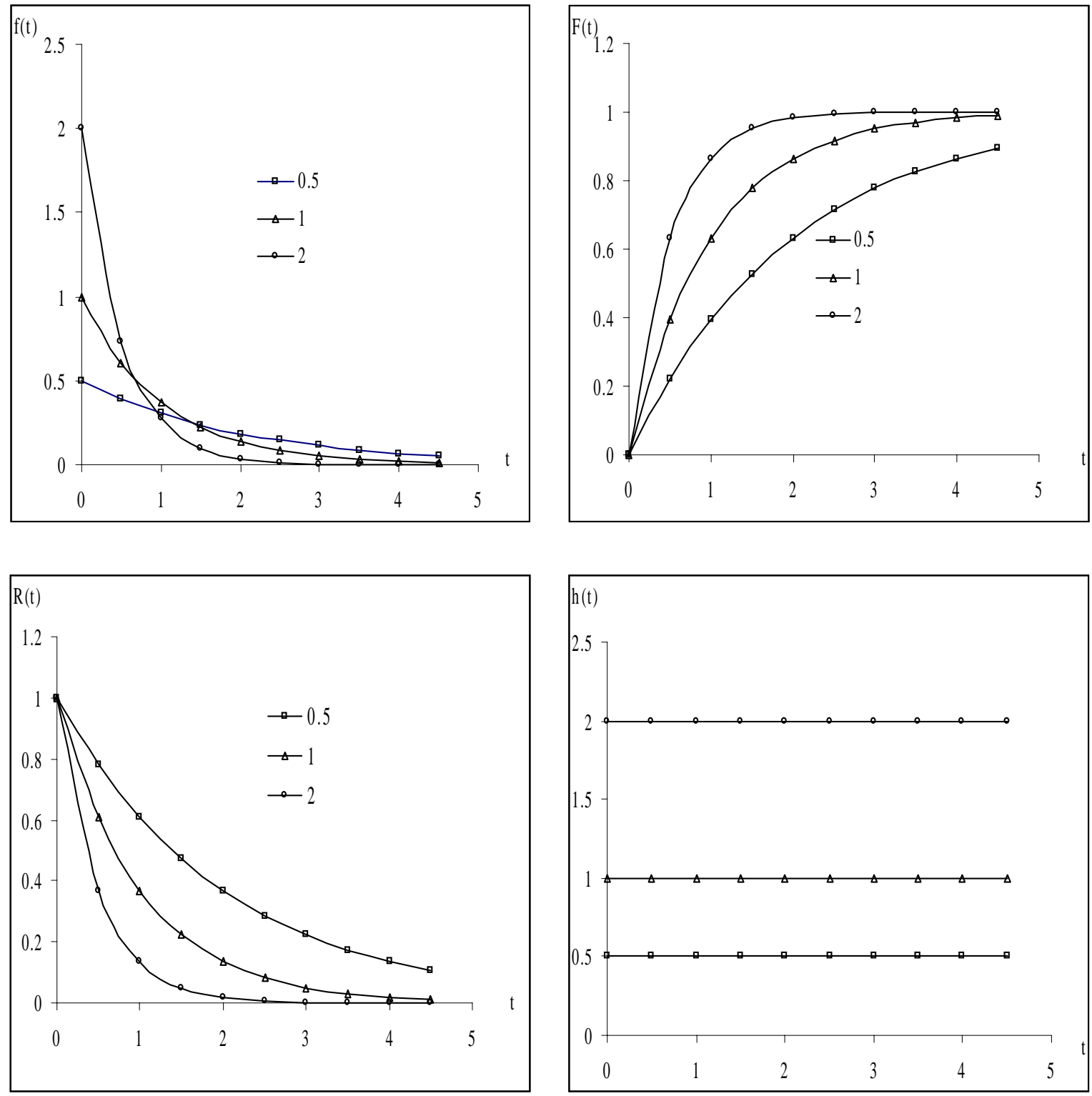

Figure 4.1 Exponential probability density, cumulative, reliability, and failure rate functions for $\lambda=0.5,1,2$

The mean (or the mean time to failure, MTTF) and variance of the exponential distribution are given by

$$
\mu=\frac{1}{\lambda} \quad \sigma^{2}=\frac{1}{\lambda^{2}}
$$


The Laplace transform of $f(t)$ is

$$
\tilde{f}(s)=\frac{\lambda}{\lambda+s}
$$

\subsubsection{Free Replacement Warranty for Repairable Products}

The expected total unit cost to seller for a repairable product under free replacement warranty is

$$
C=c_{m}+c_{1}+c_{2} B+c_{3} \int_{0}^{B} h(t) d t+\left(c_{3}+c_{4}\right) \int_{B}^{B+W} h(t) d t
$$

After substituting the failure rate function into above equation and integrating, the expected total unit cost becomes

$$
C=c_{m}+c_{1}+c_{2} B+c_{3} \lambda B+\left(c_{3}+c_{4}\right) \lambda W
$$

Result 1: Under the free replacement warranty and minimal repair policy, the optimal burn-in period that maximizes profit is equal to zero (i.e. $B^{*}=0$ ) when the product has a constant failure rate function.

Proof : The burn-in period affects only the total unit cost. Since the expected total unit cost in Equation 4.1 is an increasing linear function of burn-in time the minimum cost (or maximum profit) occurs when $B$ is equal to zero. This result is expected because of the constant failure rate. During the burn-in test the failure rate remains the same because of the minimal repair assumption. Therefore, having a burn-in test would add an extra cost to the manufacturer, without improving the performance of the product.

Since, in the optimal solution, burn-in time is zero, the expected total unit cost includes only the manufacturing cost and the warranty cost, formally

$$
C=c_{m}+\left(c_{3}+c_{4}\right) \lambda W
$$


The optimal warranty period from Equation 3.18 is

$$
W^{*}=\frac{C}{\left[c_{3}+c_{4}\right] h(B+W)}\left(\frac{a_{2}}{-a_{1}-1}\right)
$$

Substituting the total unit cost and the constant failure rate function into above equation yields

$$
W^{*}=\frac{c_{m}+\left(c_{3}+c_{4}\right) \lambda W^{*}}{\left(c_{3}+c_{4}\right) \lambda}\left(\frac{a_{2}}{-a_{1}-1}\right)
$$

which can be further simplified to

$$
W^{*}=\frac{c_{m}}{\left(c_{3}+c_{4}\right) \lambda}\left(\frac{a_{2}}{-a_{1}-a_{2}-1}\right) \quad \text { with } \quad a_{1}<-1 \text { and } 0<a_{2}<1
$$

In the above formula, the warranty period increases as the failure rate decreases, which is expected. The other parameters also show meaningful relationships. For example, as the warranty elasticity $a_{2}$ increases, -i.e. the warranty period becomes more important for product sales, the warranty period also increases.

The optimal price is calculated from Equation 3.19 as

$$
P^{*}=C\left(\frac{a_{1}}{a_{1}+1}\right)
$$

Substituting the expected total unit cost into the above equation, the optimal price is found as

$$
P^{*}=\left[c_{m}+\left(c_{3}+c_{4}\right) \lambda W^{*}\right]\left(\frac{a_{1}}{a_{1}+1}\right)
$$

Substituting $W^{*}$ into above equation yields

$$
P^{*}=c_{m}\left(\frac{a_{1}}{a_{1}+a_{2}+1}\right) \quad \text { with } a_{1}<-1 \text { and } 0<a_{2}<1
$$


In the above formula, the optimal price is a function of manufacturing cost, price and warranty elasticity.

\subsubsection{Free Replacement Warranty for Nonrepairable Items}

The expected total unit cost to the seller for a non-repairable product under the free replacement warranty is

$$
C=\frac{1}{R(B)}\left[c_{m}+c_{1}+c_{2} \int_{0}^{B} R(t) d t\right]\left[1+M_{B}(W)\right]+c_{4} M_{B}(W)
$$

where

$$
\int_{0}^{B} R(t) d t=\frac{1}{\lambda}\left(1-e^{-\lambda B}\right)
$$

is the expected time spend in the burn-in test. In order to calculate the number of failures, $M_{B}(W)$ during the warranty period, the failure distribution function for products that have survived the burn-in test must be determined. Since all products spend $B$ units of time in the burn-in test, the failure density function of a surviving product (assuming that it has the same failure distribution after the burn-in period) can be expressed as

$$
f_{B}(t)=\frac{f(B+t)}{R(B)}=\frac{\lambda e^{-\lambda(B+t)}}{e^{-\lambda B}}=\lambda e^{-\lambda t}=f(t)
$$

This result shows that the product after the burn-in period will have the same failure distribution function (i.e. the memoryless property). From the renewal theory, it is known that

$$
m_{B}(s)=\frac{f_{B}(s)}{1-f_{B}(s)}
$$

where 


$$
f_{B}(s)=\frac{\lambda}{s+\lambda}
$$

is the Laplace transform of $f_{B}(t)$. Substitution yields

$$
m_{B}(s)=\frac{\lambda}{s}
$$

The exponential renewal density function, $m_{B}(t)$ is obtained by taking the inverse Laplace transform of $m_{B}(s)$, as

$$
m_{B}(t)=\lambda
$$

Therefore, the expected number of replacements during the warranty period is

$$
M_{B}(W)=\int_{0}^{W} m_{B}(t) d t=\int_{0}^{W} \lambda d t=\lambda W
$$

Hence, the expected total unit cost per item becomes

$$
C=\frac{1}{e^{-\lambda B}}\left[c_{m}+c_{1}+\frac{c_{2}}{\lambda}\left(1-e^{-\lambda B}\right)\right](1+\lambda W)+c_{4} \lambda W
$$

which can be further simplified to

$$
C=(1+\lambda W)\left[\left(c_{m}+c_{1}+\frac{c_{2}}{\lambda}\right) e^{\lambda B}-\frac{c_{2}}{\lambda}\right]+c_{4} \lambda W
$$

Result 2: Under the free replacement warranty, the optimal burn-in period that maximize profit function is equal to zero $\left(B^{*}=0\right)$.

Proof: The proof follows the same reasoning specified in Result 1 . The expected total unit cost is an increasing function of $B$, and the minimum cost is obtained when $B$ is equal to zero. Since all the products come from the same manufacturing process with a constant failure rate of $\lambda$, the product surviving the burn-in test will have the same failure rate. Thus, the burn-in test would not improve the reliability of the product. 
The optimal warranty period from Equation 3.22 is

$$
W^{*}=\frac{C}{\left[C_{B}+c_{4}\right] m_{B}(W)}\left(\frac{a_{2}}{-a_{1}-1}\right)
$$

where $C_{B}$ is the expected burn-in cost per item, and $m_{B}(W)$ is the renewal density function. Since, in the optimal solution, no burn-in test is needed, the burn-in cost includes only the manufacturing cost, that is

$$
C_{B}=c_{m}
$$

and the expected total unit cost without the burn-in test is

$$
C=c_{m}+\left(c_{m}+c_{4}\right) \lambda W
$$

hence

$$
W^{*}=\frac{c_{m}+\left(c_{m}+c_{4}\right) \lambda W^{*}}{\lambda\left(c_{m}+c_{4}\right)}\left(\frac{a_{2}}{-a_{1}-1}\right)
$$

which can be further simplified to

$$
W^{*}=\frac{c_{m}}{\lambda\left(c_{m}+c_{4}\right)}\left(\frac{a_{2}}{-a_{1}-a_{2}-1}\right) \quad \text { with } \quad a_{1}<-1 \text { and } 0<a_{2}<1
$$

The optimal price from Equation 3.23 is

$$
P^{*}=C\left(\frac{a_{1}}{a_{1}+1}\right)
$$

thus

$$
P^{*}=\left[c_{m}+\left(c_{m}+c_{4}\right) \lambda W^{*}\right]\left(\frac{a_{1}}{a_{1}+1}\right)
$$

Substituting $W^{*}$ in the above equation yields

$$
P^{*}=c_{m}\left(\frac{a_{1}}{a_{1}+a_{2}+1}\right) \quad \text { with } \quad a_{1}<-1 \text { and } 0<a_{2}<1
$$


For both the repair and replace cases, the models have yielded the same pricing policy. However, in the free replacement case, the length of the warranty period is shorter than for the repairable case since, in general, repair cost is less than manufacturing cost. Thus, the seller should choose a repair warranty over a replacement warranty.

\subsubsection{Pro-Rata Warranty for Nonrepairable Items}

The expected total unit cost to the seller for a non-repairable product under pro-rata warranty is

$$
C=\frac{1}{R(B)}\left[c_{m}+c_{1}+c_{2} \int_{0}^{B} R(t) d t+P\left(R(B)-\frac{1}{W} \int_{0}^{W} R(B+t) d t\right)\right]
$$

where

$$
\begin{aligned}
& \int_{0}^{B} R(t) d t=\frac{1}{\lambda}\left(1-e^{-\lambda B}\right) \\
& \int_{0}^{W} R(B+t) d t=\frac{1}{\lambda}\left[e^{-\lambda B}-e^{-\lambda(B+W)}\right]
\end{aligned}
$$

are the partial expected failure times during the burn-in and warranty periods, respectively. Substituting above integrals yields

$$
C=\left(c_{m}+c_{1}+\frac{c_{2}}{\lambda}\right) e^{\lambda B}-\frac{c_{2}}{\lambda}+P\left[1-\frac{1}{\lambda W}\left(1-e^{-\lambda W}\right)\right]
$$

Result 3: Under a pro-rata warranty, the optimal burn-in period that maximizes the profit function is equal to zero (i.e. $B^{*}=0$ ) when the failure rate function is constant.

Proof: The proof follows the same reasoning as in Result 1 and Result 2.The total cost is an increasing function of $B$. 
Therefore, the total unit cost includes the manufacturing cost plus the expected refund given to the customer during the warranty period, that is

$$
C=c_{m}+P\left[1-\frac{1}{\lambda W}\left(1-e^{-\lambda W}\right)\right]
$$

The optimal price from Equation 3.28 is

$$
P^{*}=C\left(\frac{a_{1}}{a_{1}+1+\frac{1}{W^{*}} \int_{0}^{W^{*}} R\left(B^{*}+t\right) d t-R\left(B^{*}\right)}\right)
$$

since $B^{*}=0$, it reduces to

$$
P^{*}=C\left(\frac{a_{1}}{a_{1}+1+\frac{1}{W^{*}} \int_{0}^{W^{*}} R(t) d t-1}\right)
$$

Substituting $C$ into above equation, it becomes

$$
P^{*}=\left[c_{m}+P^{*}\left(1-\frac{1}{\lambda W^{*}}\left(1-e^{-\lambda W^{*}}\right)\right]\left(\frac{a_{1}}{a_{1}+\frac{1}{\lambda W^{*}}\left(1-e^{-\lambda W^{*}}\right)}\right)\right.
$$

which can be further simplified to

$$
P^{*}=c_{m} \frac{a_{1} \lambda W^{*}}{\left(a_{1}+1\right)\left(1-e^{-\lambda W^{*}}\right)} \quad \text { with } a_{1}<-1
$$

Here, the optimal price depends on the warranty period, price elasticity, $a_{1}$ and failure rate $\lambda$. It is an increasing function of the warranty period due to the increase in expected amount of rebate given to the customer.

The optimal warranty period from Equation 3.27 for $B^{*}=0$ is 


$$
W^{*}=\frac{C}{\frac{P}{W^{* 2}\left[\int_{0}^{W^{*}} R(t) d t-W^{*} R\left(W^{*}\right)\right]}}\left(\frac{a_{1}}{a_{1}+\frac{1}{W^{*}} \int_{0}^{W^{*}} R(t) d t}-1\right) a_{2}
$$

Substituting $C$ and $P$ into above equation, it reduces to (see Appendix 5 for details)

$$
e^{-\lambda W^{*}}\left(a_{1}+a_{1} \lambda W^{*}+a_{2}\right)=a_{1}+a_{2}
$$

which has a trivial solution at $W^{*}=0$. The other solutions of Equation 4.7 can be obtained numerically. Once $W^{*}$ is obtained, $P^{*}$ is calculated from Equation 4.6.

\subsubsection{Numerical Example and Sensitivity Analysis}

The optimal burn-in time, warranty period, and price depend on the model parameters. However, in practice, these parameters cannot be determined exactly. Therefore, the sensitivity analysis should be performed to study the effect of making changes in the model parameters on the optimal burn-in time, warranty period and price. Suppose that a product has an exponential failure function. The parameter values chosen for the example are given in Table 4.1 .

Table 4.1 Parameter values

\begin{tabular}{|l|l|}
\hline \hline Price elasticity, $a_{1}$ & -2.2 \\
\hline Warranty elasticity, $a_{2}$ & 0.2 \\
\hline Constant multiplier, $k$ & $10^{6}$ \\
\hline Manufacturing cost (\$/unit), $c_{m}$ & 20.0 \\
\hline Burn-in fixed cost (\$/unit), $c_{1}$ & 0.5 \\
\hline Testing cost (\$/unit/hour), $c_{2}$ & 0.5 \\
\hline Repair cost (\$/unit), $c_{3}$ & 3.0 \\
\hline Extra cost during warranty (\$/unit), $c_{4}$ & 1.0 \\
\hline \hline
\end{tabular}


Solutions for several different parameters for the three warranty policies are presented in Tables 4.2, 4.3, and 4.4. The optimal burn-in time is always zero for all warranty policies as proved.

From Table 4.2, it can be seen that as the MTTF increases from 1 to 3, the optimal warranty period and profit increase while the price remains fixed. This is expected as the number of failures during the warranty period decreases as MTTF increases, which allows the seller to offer a longer warranty period and hence increase the expected sales volume.

Table 4.2 Optimal price, warranty and burn-in policies for different MTTF values when $a_{2}=0.2$ and $a_{1}=-2.2$

\begin{tabular}{|c|c|c|c|c|c|c|}
\hline Warranty policies & $\begin{array}{c}\text { MTTF } \\
\text { (year) }\end{array}$ & Price $(\$)$ & $\begin{array}{l}\text { Warranty } \\
\text { Period } \\
\text { (year) } \\
\end{array}$ & $\begin{array}{l}\text { Burn-in } \\
\text { Time } \\
\text { (year) } \\
\end{array}$ & $\begin{array}{l}\text { Expected } \\
\text { sales }\end{array}$ & $\begin{array}{l}\text { Expected } \\
\text { Profit (\$) }\end{array}$ \\
\hline \multirow{3}{*}{$\begin{array}{l}\text { Free replacement } \\
\text { warranty for a } \\
\text { repairable product }\end{array}$} & 1.0 & 44.00 & 1.00 & 0 & 242 & 4846.57 \\
\hline & 2.0 & 44.00 & 2.00 & 0 & 278 & 5567.24 \\
\hline & 3.0 & 44.00 & 3.00 & 0 & 302 & 6037.52 \\
\hline \multirow{3}{*}{$\begin{array}{l}\text { Free replacement } \\
\text { warranty for a } \\
\text { nonrepairable product }\end{array}$} & 1.0 & 444.00 & 0.19 & 0 & 174 & 3478.58 \\
\hline & 2.0 & 44.00 & 0.38 & 0 & 200 & 3995.84 \\
\hline & 3.0 & 44.00 & 0.57 & 0 & 217 & 4333.38 \\
\hline \multirow{3}{*}{$\begin{array}{l}\text { Pro-rata warranty for } \\
\text { a nonrepairable } \\
\text { product }\end{array}$} & 1.0 & 40.22 & 0.19 & 0 & 212 & 3521.70 \\
\hline & 2.0 & 40.22 & 0.37 & 0 & 242 & 4045.87 \\
\hline & 3.0 & 40.22 & 0.56 & 0 & 263 & 4388.21 \\
\hline
\end{tabular}

In Table 4.3 the price elasticity varies from -2 to -2.5 . The price, warranty period and expected profit decrease for all warranty policies as the price elasticity decreases (increases in absolute value), which is expected. The decrease in price elasticity means that customers in the market are more sensitive to changes in price. As a result, the seller must lower his price to maintain his position in the market. The amount of decrease in profit is very drastic due to the multiplicative form of the sales response function. Figure 4.2 shows the changes in the expected profit for a wider range of price elasticity values.

In Table 4.4, the warranty elasticity ranges from 0.15 to 0.25 . As expected, the increase in warranty elasticity results in an increase in the warranty period. The increase in 
warranty elasticity means that the warranty period becomes more important for customers when buying a product. The price also increases as the warranty elasticity increases, in order to cover the additional warranty cost. The expected profit, in general, increases with the warranty elasticity for the repairable case, does not change much for nonrepairable case, and slightly decreases for pro-rata warranty.

Table 4.3 Optimal price, warranty and burn-in policies for different price elasticity values when $M T T F=1$ and $a_{1}=-2.2$

\begin{tabular}{|c|c|c|c|c|c|c|}
\hline Warranty policies & $\begin{array}{c}\text { Price } \\
\text { Elasticity }\end{array}$ & $\begin{array}{l}\text { Price } \\
(\$)\end{array}$ & $\begin{array}{l}\text { Warranty } \\
\text { Period } \\
\text { (year) }\end{array}$ & $\begin{array}{l}\text { Burn-in } \\
\text { Time } \\
\text { (year) }\end{array}$ & $\begin{array}{l}\text { Expected } \\
\text { sales }\end{array}$ & $\begin{array}{l}\text { Expected } \\
\text { Profit (\$) }\end{array}$ \\
\hline \multirow{3}{*}{$\begin{array}{l}\text { Free replacement } \\
\text { warranty for a } \\
\text { repairable product }\end{array}$} & -2.0 & 50.00 & 1.25 & 0 & 418 & 10546.40 \\
\hline & -2.2 & 44.00 & 1.00 & 0 & 242 & 4846.57 \\
\hline & -2.5 & 38.46 & 0.77 & 0 & 103 & 1591.22 \\
\hline \multirow{3}{*}{$\begin{array}{l}\text { Free replacement } \\
\text { warranty for a } \\
\text { nonrepairable product }\end{array}$} & -2.0 & 50.00 & 0.24 & 0 & 301 & 7505.00 \\
\hline & -2.2 & 44.00 & 0.19 & 0 & 174 & 3478.58 \\
\hline & -2.5 & 38.46 & 0.15 & 0 & 75 & 1142.09 \\
\hline \multirow{3}{*}{$\begin{array}{l}\text { Pro-rata warranty for } \\
\text { a nonrepairable } \\
\text { product }\end{array}$} & -2.0 & 444.29 & 0.21 & 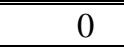 & 373 & 7440.90 \\
\hline & -2.2 & 40.22 & 0.19 & 0 & 212 & 3521.70 \\
\hline & -2.5 & 36.10 & 0.16 & 0 & 89 & 1182.32 \\
\hline
\end{tabular}

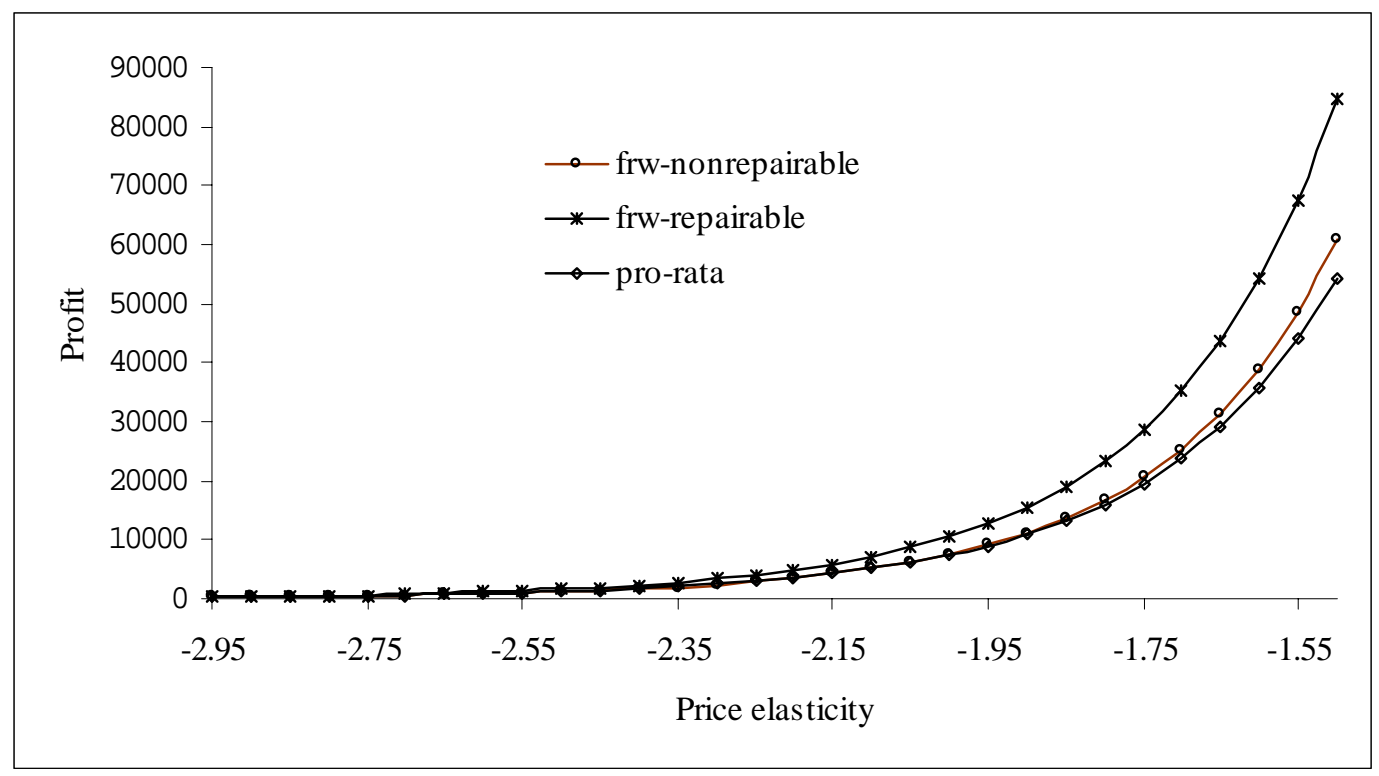

Figure 4.2 Profit vs. price elasticity when $a_{2}=0.2$ and $M T T F=1$ 
Table 4.4 Optimal price, warranty and burn policies for different warranty elasticity values when $M T T F=1$ and $a_{1}=-2.2$

\begin{tabular}{|l|c|c|c|c|c|c|}
\hline \hline Warranty policies & $\begin{array}{l}\text { Warranty } \\
\text { Elasticity }\end{array}$ & $\begin{array}{l}\text { Price } \\
(\$)\end{array}$ & $\begin{array}{l}\text { Warranty } \\
\text { Period } \\
\text { (year) }\end{array}$ & $\begin{array}{l}\text { Burn-in } \\
\text { Time } \\
(\text { year) }\end{array}$ & $\begin{array}{l}\text { Expected } \\
\text { sales }\end{array}$ & $\begin{array}{l}\text { Expected } \\
\text { Profit }(\$)\end{array}$ \\
\hline \hline \multirow{2}{*}{\begin{tabular}{l} 
Free replacement $\begin{array}{l}\text { warranty for a repairable } \\
\text { product }\end{array}$ \\
\cline { 2 - 7 }
\end{tabular}} & 0.15 & 41.90 & 0.71 & 0 & 256 & 4885.87 \\
\cline { 2 - 7 } & 0.20 & 44.00 & 1.00 & 0 & 242 & 4846.57 \\
\hline \hline \multirow{2}{*}{$\begin{array}{l}\text { Free replacement } \\
\text { warranty for a } \\
\text { nonrepairable product }\end{array}$} & 0.15 & 41.90 & 0.14 & 0 & 201 & 3809.94 \\
\cline { 2 - 7 } & 0.20 & 44.00 & 0.19 & 0 & 174 & 3478.58 \\
\hline \hline \multirow{2}{*}{$\begin{array}{l}\text { Pro-rata warranty for a } \\
\text { nonrepairable product }\end{array}$} & 0.25 & 46.32 & 0.25 & 0 & 153 & 3224.48 \\
\cline { 2 - 7 } & 0.15 & 39.39 & 0.14 & 0 & 230 & 3855.91 \\
\cline { 2 - 7 } & 0.20 & 40.22 & 0.19 & 0 & 212 & 3521.70 \\
\hline \hline
\end{tabular}

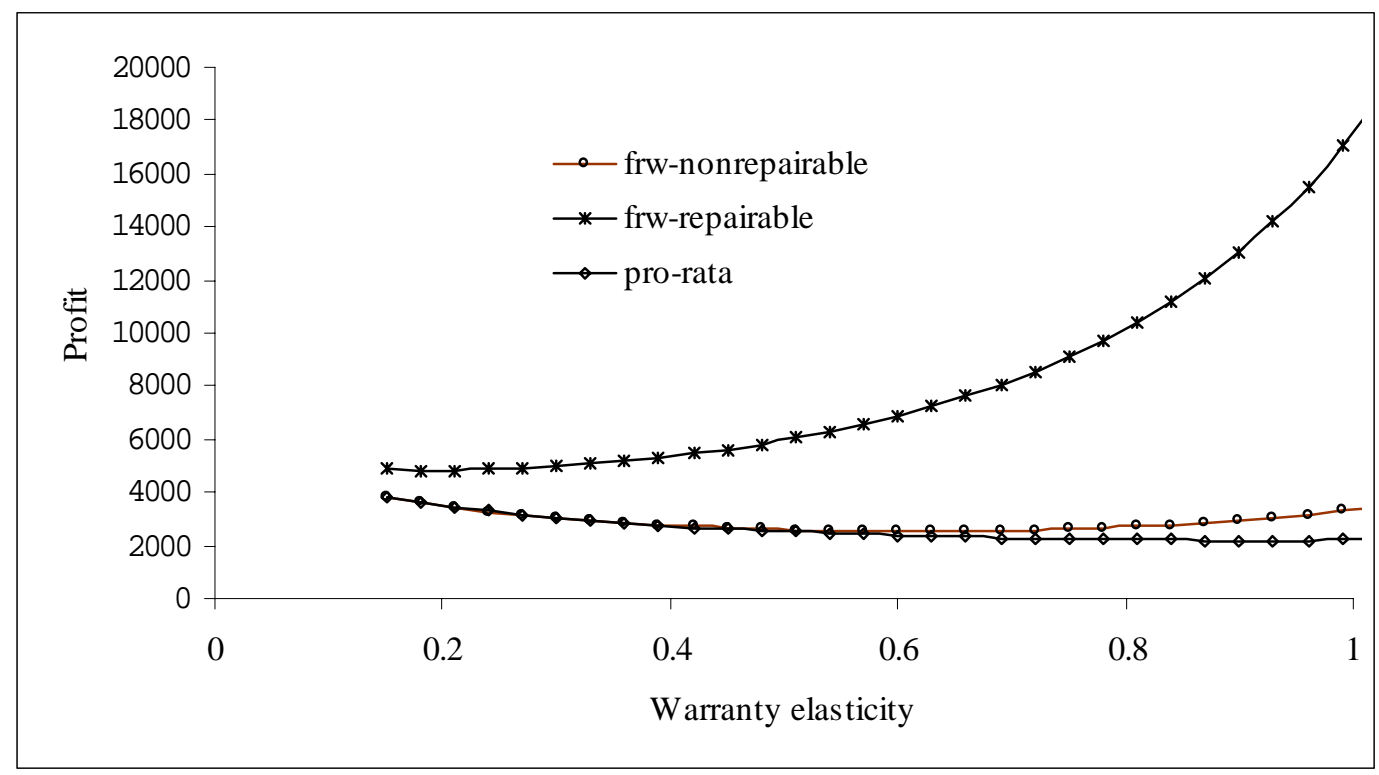

Figure 4.3 Profit vs. warranty elasticity when $a_{l}=-2.2$ and $M T T F=1$

\subsection{Weibull Distribution}

The Weibull distribution is the another widely used lifetime distribution in reliability analysis because of its versatility in modeling item failures. The two-parameter Weibull density function is given by

$$
f(t)=\beta \theta^{-\beta} t^{\beta-1} e^{-(t / \theta)^{\beta}} \quad \text { with } \beta>0 \text { and } \theta>0
$$


where $\beta$ is the shape parameter and $\theta$ is the scale parameter. The scale parameter is also known as the characteristic life. The cumulative distribution function and reliability function are given as [Ebeling, 1997]:

$$
\begin{aligned}
& F(t)=1-e^{-(t / \theta)^{\beta}} \\
& R(t)=e^{-(t / \theta)^{\beta}}
\end{aligned}
$$

The failure rate function is given by

$$
h(t)=\beta \theta^{-\beta} t^{\beta-1}
$$

Figure 4.4 shows the probability, cumulative, reliability, and failure rate functions for the Weibull distribution for different values of $\beta$ when $\theta=2$. As shown in Figure 4.4-d, the failure rate is decreasing when $\beta<1$, constant when $\beta=1$, and increasing when $\beta>1$.

The mean and variance for the Weibull distribution are given by

$$
\begin{aligned}
& \mu=\theta \Gamma\left(1+\frac{1}{\beta}\right) \\
& \sigma^{2}=\theta^{2}\left\{\Gamma\left(1+\frac{2}{\beta}\right)-\left[\Gamma\left(1+\frac{1}{\beta}\right)\right]^{2}\right\}
\end{aligned}
$$

where $\Gamma(\cdot)$ is the gamma function and is given by

$$
\Gamma(x)=\int_{0}^{\infty} u^{x-1} e^{-u} d u
$$




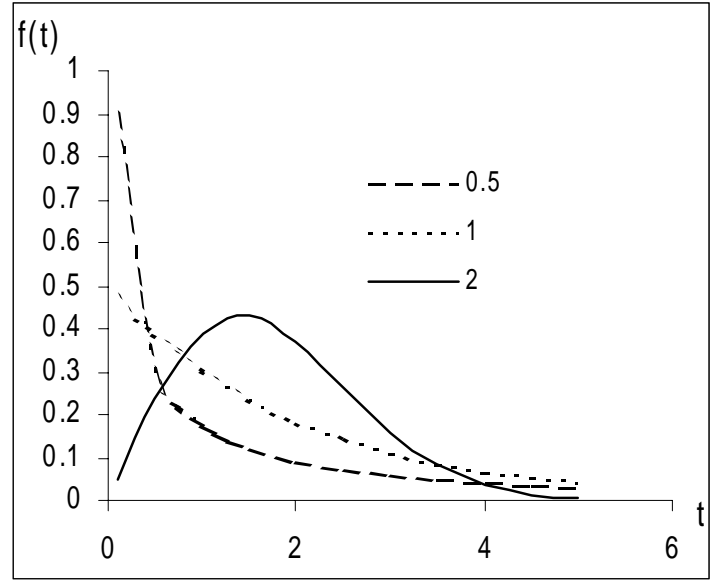

(a)

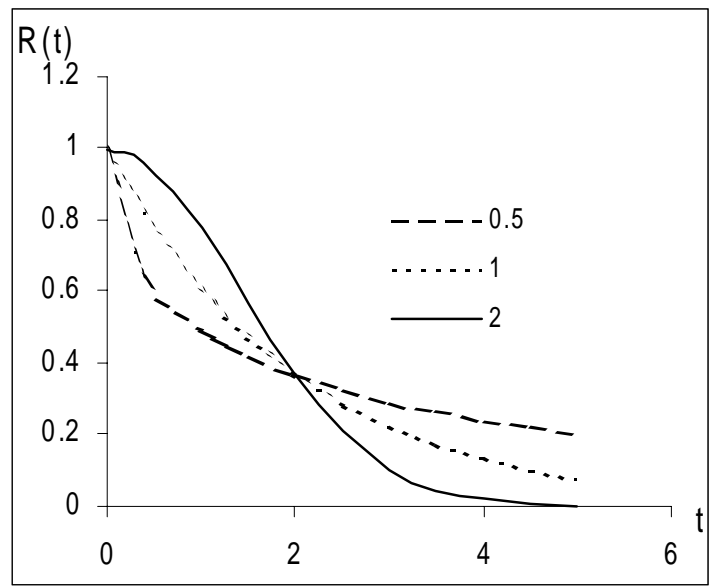

(c)

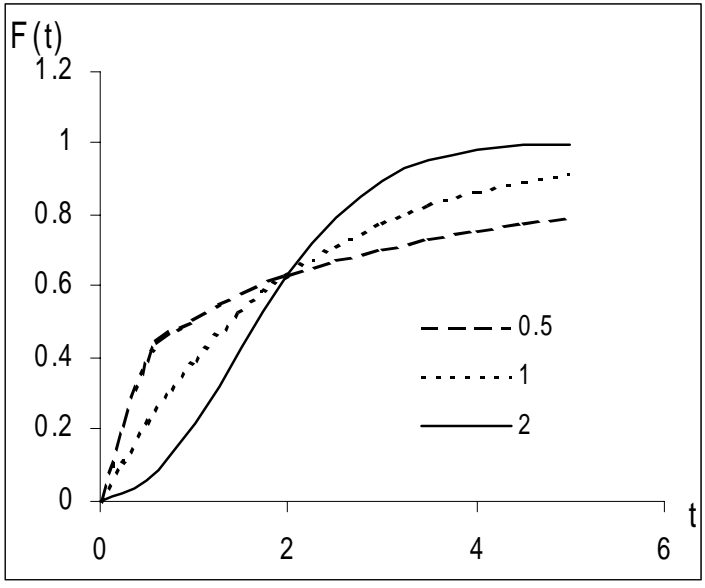

(b)

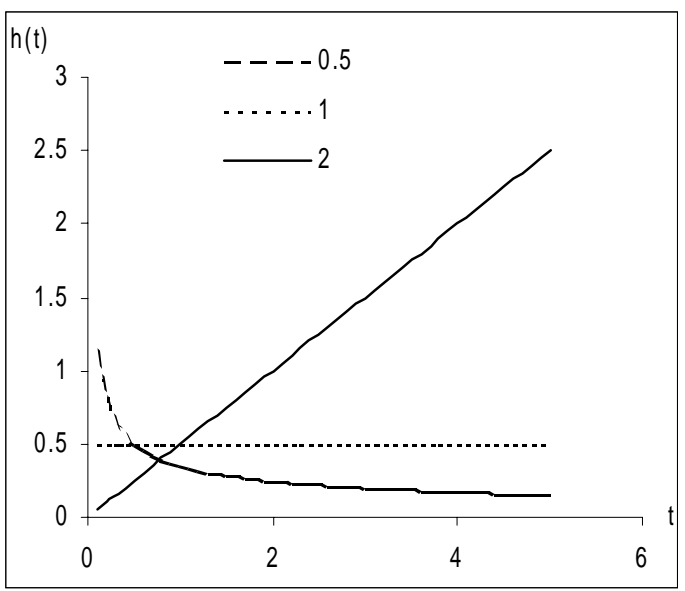

(d)

Figure 4.4 Weibull (a) density, (b) cumulative, (c) reliability and (d) failure rate functions for $\beta=0.5,1,2$ and $\theta=2$.

\subsubsection{Free Replacement Warranty for Repairable Products}

The expected total unit cost for a repairable product under free replacement warranty

is

$$
C=c_{m}+c_{1}+c_{2} B+c_{3} \int_{0}^{B} h(t) d t+\left(c_{3}+c_{4}\right) \int_{B}^{B+W} h(t) d t
$$

Substituting the failure rate function into the above function and integrating yields 


$$
C=c_{m}+c_{1}+c_{2} B-c_{4} \theta^{-\beta} B^{\beta}+\left(c_{3}+c_{4}\right) \theta^{-\beta}(B+W)^{\beta}
$$

Result 4: In the optimal solution, $B^{*}=0$ when $\beta \geq 1$. In other words, if the failure rate function is constant or increasing function of time, no burn-in test is necessary.

Proof: Differentiating $C$ with respect to $B$ yields

$$
\begin{aligned}
\frac{\partial C}{\partial B} & =c_{2}-\beta c_{4} \theta^{-\beta} B^{\beta-1}+\beta\left(c_{3}+c_{4}\right) \theta^{-\beta}(B+W)^{\beta-1} \\
& =c_{2}+\beta c_{4} \theta^{-\beta}\left[(B+W)^{\beta-1}-B^{\beta-1}\right]+\beta c_{3} \theta^{-\beta}(B+W)^{\beta-1}
\end{aligned}
$$

From above equation, it can be seen that

$$
\frac{\partial C}{\partial B}>0 \text { for } \forall B>0 \text { when } \beta \geq 1
$$

Since the total unit cost is increasing function of $B$ when $\beta \geq 1$, in the optimal solution, the burn-in time must be equal to zero. This result also confirms the finding in Section 4.1.1, since the Weibull distribution reduces to the exponential distribution function for $\beta=1$. For $\beta>1$, the Weibull distribution has an increasing failure rate function, i.e. the product ages with time.

In order for the burn-in test to be profitable, $\beta$ must be less than one, i.e. the failure rate has to be a decreasing function of time. Figure 4.5 shows the total unit cost functions when the failure rate is a decreasing, constant and increasing function of time. 


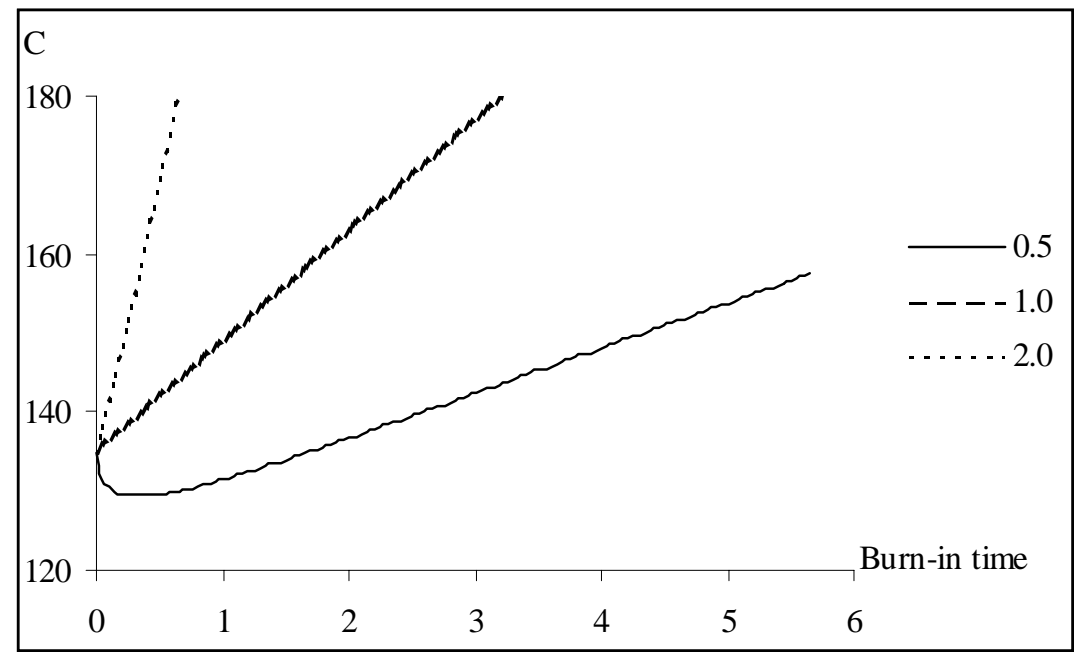

Figure 4.5 The total unit cost vs. burn-in time $(\beta=0.5,1,2 ; \theta=1 ; W=1)$

For $\beta<1$, the optimal burn-in time can be obtained from Equation 3.17 as

$$
h\left(B^{*}\right)=\frac{c_{2}+\left(c_{3}+c_{4}\right) h\left(B^{*}+W^{*}\right)}{c_{4}}
$$

Substituting the values of $h(B)$ and $h(B+W)$ into above equation, it reduces to

$$
B^{*}=\left\{\frac{\theta^{\beta}}{\beta c_{4}}\left[c_{2}+\left(c_{3}+c_{4}\right) \beta \theta^{-\beta}\left(B^{*}+W\right)^{\beta-1}\right]\right\}^{\frac{1}{\beta-1}}
$$

The optimal warranty period from Equation 3.18 is:

$$
W^{*}=\frac{C}{\left[c_{3}+c_{4}\right] h(B+W)}\left(\frac{a_{2}}{-a_{1}-1}\right)
$$

Substituting for the values of $C$ and $h(B+W)$ into above equation yields

$$
W^{*}=\frac{c_{m}+c_{1}+c_{2} B^{*}-c_{4} \theta^{-\beta} B^{* \beta}+\left(c_{3}+c_{4}\right) \theta^{-\beta}\left(B^{*}+W^{*}\right)^{\beta}}{\left(c_{3}+c_{4}\right) \beta \theta^{-\beta}\left(B^{*}+W^{*}\right)^{\beta-1}}\left(\frac{a_{2}}{-a_{1}-1}\right)
$$

The optimal price from Equation 3.19 is

$$
P^{*}=\left[c_{m}+c_{1}+c_{2} B^{*}-c_{4} \theta^{-\beta} B^{* \beta}+\left(c_{3}+c_{4}\right) \theta^{-\beta}\left(B^{*}+W^{*}\right)^{\beta}\right] \cdot\left(\frac{a_{1}}{a_{1}+1}\right)
$$


The optimal values can be obtained by solving these three equations simultaneously using some numerical analysis methods. However, this may be more difficult than solving the original optimization problem. Hence, instead of solving this three equation system, the optimal values of $B, W$ and $P$ that maximize profit will be obtained numerically. A computer program using a simple search procedure was developed for this purpose. The program was written in $\mathrm{C}++$ and is given in Appendix 6.

For $\beta \geq 1, W^{*}$ and $P^{*}$ can be easily obtained from Equation 4.9 and Equation 4.10. By substituting $B^{*}=0$, Equation 4.9 reduces to

$$
\begin{aligned}
& W^{*}=\frac{c_{m}+\left(c_{3}+c_{4}\right) \theta^{-\beta} W^{* \beta}}{\left(c_{3}+c_{4}\right) \beta \theta^{-\beta}\left(W^{*}\right)^{\beta-1}}\left(\frac{a_{2}}{-a_{1}-1}\right) \\
& \left(c_{3}+c_{4}\right) \beta \theta^{-\beta} W^{\beta}=\left[c_{m}+\left(c_{3}+c_{4}\right) \theta^{-\beta} W^{\beta}\right]\left(\frac{a_{2}}{-a_{1}-1}\right) \\
& \left(c_{3}+c_{4}\right) \theta^{-\beta} W^{\beta}\left(\beta-\frac{a_{2}}{-a_{1}-1}\right)=c_{m}\left(\frac{a_{2}}{-a_{1}-1}\right)
\end{aligned}
$$

which can be further simplified to

$$
W^{*}=\theta\left(\frac{c_{m}}{c_{3}+c_{4}}\right)^{1 / \beta}\left(\frac{a_{2}}{-a_{1} \beta-\beta-a_{2}}\right)^{1 / \beta}
$$

and

$$
P^{*}=\left[c_{m}+\left(c_{3}+c_{4}\right) \theta^{-\beta} W^{* \beta}\right]\left(\frac{a_{1}}{a_{1}+1}\right)
$$

Substituting $W^{*}$ into above equation yields

$$
P^{*}=c_{m}\left(\frac{a_{1} \beta}{a_{1} \beta+a_{2}+\beta}\right)
$$




\subsubsection{Free Replacement Warranty for Nonrepairable Products}

The expected total unit cost for a non-repairable product with a burn-in period of $B$ and free replacement warranty period of $W$ is given by

$$
C=e^{(B / \theta)^{\beta}}\left[c_{m}+c_{1}+c_{2} \int_{0}^{B} e^{-(t / \theta)^{\beta}} d t\right]\left[1+M_{B}(W)\right]+c_{4} M_{B}(W)
$$

where $M_{B}(W)$ is the expected number of replacements during the warranty period. Unfortunately, for the Weibull distribution, there is no close form solution for $M_{B}(W)$, therefore it must be obtained numerically. As a result, the optimal burn-in time, warranty period, and price can also be obtained only numerically.

\subsubsection{Pro-rata Warranty for Nonrepairable Products}

The expected total unit cost for non-repairable product under pro-rata warranty is given by

$$
C=e^{(B / \theta)^{\beta}}\left[c_{m}+c_{1}+c_{2} \int_{0}^{B} e^{-(t / \theta)^{\beta}} d t+P\left(e^{-(B / \theta)^{\beta}}-\frac{1}{W} \int_{0}^{W} e^{-((B+t) / \theta)^{\beta}} d t\right)\right]
$$

The integrals in the above equation are not available. Therefore the optimal burn-in time, warranty period and price can be obtained only numerically.

\subsubsection{Numerical Example and Sensitivity Analysis}

A similar sensitivity analysis will be performed for the Weibull case. The same parameters in Table 4.1 will be used in the example with a few additional parameters.

From Table 4.5 it can be seen that, for all warranty policies, as the MTTF increases the warranty period and expected profit increase while the price remains fixed. The 
interesting result is that, for the parameters chosen, with the increase of the MTTF, the optimal burn-in time decreases for the FRW-repairable products as expected, does not change for the FRW-nonrepairable products, and increases for the pro-rata warranty for nonrepairable products. One might expect that, in all cases, the burn-in period should decrease as the $M T T F$ increases.

Table 4.5 Optimal policies for different $\theta$ values when $\beta=0.7, a_{1}=-2.2$, and $a_{2}=0.2$

\begin{tabular}{|l|c|c|c|c|c|r|r|}
\hline \hline Warranty policies & $\theta$ & $\begin{array}{l}\text { MTTF } \\
\text { (year) }\end{array}$ & Price & $\begin{array}{l}\text { Warranty } \\
\text { Period } \\
\text { (year) }\end{array}$ & $\begin{array}{l}\text { Burn-in } \\
\text { Time } \\
\text { (year) }\end{array}$ & $\begin{array}{l}\text { Expected } \\
\text { sales }\end{array}$ & $\begin{array}{l}\text { Expected } \\
\text { Profit }(\$)\end{array}$ \\
\hline \hline \multirow{2}{*}{$\begin{array}{l}\text { Free replacement } \\
\text { warranty for a } \\
\text { repairable product }\end{array}$} & 3 & 3.797 & 49.32 & 5.88 & 0.0110 & 267 & 6023.41 \\
\cline { 2 - 8 } & 4 & 5.063 & 49.32 & 7.84 & 0.0095 & 285 & 6379.72 \\
\hline \hline \multirow{2}{*}{$\begin{array}{l}\text { Free replacement } \\
\text { warranty for a } \\
\text { nonrepairable product }\end{array}$} & 5 & 6.329 & 49.32 & 9.80 & 0.0082 & 298 & 6670.59 \\
\cline { 2 - 8 } & 4 & 5.063 & 47.00 & 0.31 & 0 & 161 & 3434.58 \\
\hline \hline \multirow{2}{*}{$\begin{array}{l}\text { Pro-rata warranty for } \\
\text { a nonrepairable } \\
\text { product }\end{array}$} & 3 & 3.797 & 43.20 & 0.37 & 0.0087 & 207 & 3541.36 \\
\cline { 2 - 8 } & 4 & 5.063 & 43.20 & 0.49 & 0.0113 & 219 & 3802.50 \\
\cline { 2 - 8 } & 5 & 6.329 & 43.20 & 0.62 & 0.0140 & 229 & 3975.72 \\
\hline \hline
\end{tabular}

Table 4.6, displays similar trends to those obtained with the exponential case. As the price elasticity increases, the price, warranty period and expected profit increase when the warranty elasticity remains fixed. The optimal burn-in time in general, decreases with the decrease in price elasticity.

From Table 4.7, the optimal values of price and warranty period increase with the increase in warranty elasticity. As in the exponential case, the expected profit increases monotonically for the repairable case and decreases monotonically for the pro-rata warranty. The optimal burn-in time increases, in general, with the warranty elasticity. 
Table 4.6 Optimal policies for different price elasticity values when $\beta=0.7, \theta=4$, and $a_{2}=0.2$

\begin{tabular}{|c|c|c|c|c|c|c|c|}
\hline Warranty policies & $a_{1}$ & $\begin{array}{l}\text { MTTF } \\
\text { (year) }\end{array}$ & $\begin{array}{l}\text { Price } \\
(\$)\end{array}$ & $\begin{array}{l}\text { Warranty } \\
\text { Period } \\
\text { (year) }\end{array}$ & $\begin{array}{l}\text { Burn-in } \\
\text { Time } \\
\text { (year) }\end{array}$ & $\begin{array}{l}\text { Expected } \\
\text { sales }\end{array}$ & $\begin{array}{l}\text { Expected } \\
\text { Profit (\$) }\end{array}$ \\
\hline \multirow{3}{*}{$\begin{array}{l}\text { Free replacement } \\
\text { warranty for a } \\
\text { repairable product }\end{array}$} & $\begin{array}{c}-2.0 \\
\end{array}$ & 5.063 & 57.59 & 11.16 & 0.114 & 4488 & $=14113.00$ \\
\hline & -2.2 & 5.063 & 49.32 & 7.84 & 0.0095 & 285 & 6379.72 \\
\hline & -2.5 & 5.063 & 42.20 & 5.23 & 0.0076 & 120 & 2031.13 \\
\hline \multirow{3}{*}{$\begin{array}{l}\text { Free replacement } \\
\text { warranty for a } \\
\text { nonrepairable product } \\
\end{array}$} & -2.0 & 5.063 & 54.00 & 0.41 & 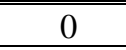 & 287 & 7751.41 \\
\hline & -2.2 & 5.063 & 47.00 & 0.31 & 0 & 166 & 3541.36 \\
\hline & -2.5 & 5.063 & 41.00 & 0.22 & 0 & 69 & 1141.96 \\
\hline \multirow{3}{*}{$\begin{array}{l}\text { Pro-rata warranty for } \\
\text { a nonrepairable } \\
\text { product }\end{array}$} & -2.0 & 5.063 & 47.97 & 0.57 & 0.0190 & 388 & 8156.39 \\
\hline & -2.2 & 5.063 & 43.20 & 0.49 & 0.0113 & 219 & 3802.50 \\
\hline & -2.5 & 5.063 & 38.51 & 0.40 & 0.0060 & 97 & 1251.64 \\
\hline
\end{tabular}

Table 4.7 Optimal policies for different warranty elasticity values when $\beta=0.7$, $\theta=4$, and $a_{1}=-2.2$

\begin{tabular}{|c|c|c|c|c|c|c|c|}
\hline Warranty policies & $a_{2}$ & $\begin{array}{l}\text { MTTF } \\
\text { (year) }\end{array}$ & $\begin{array}{l}\text { Price } \\
(\$)\end{array}$ & $\begin{array}{l}\text { Warranty } \\
\text { Period } \\
\text { (year) }\end{array}$ & $\begin{array}{l}\text { Burn-in } \\
\text { Time } \\
\text { (year) }\end{array}$ & $\begin{array}{l}\text { Expected } \\
\text { sales }\end{array}$ & $\begin{array}{l}\text { Expected } \\
\text { Profit (\$) }\end{array}$ \\
\hline \multirow{3}{*}{$\begin{array}{l}\text { Free replacement } \\
\text { warranty for a } \\
\text { repairable product }\end{array}$} & 0.15 & 5.063 & 45.75 & 4.67 & 0.0071 & 280 & 5827.85 \\
\hline & 0.20 & 5.063 & 49.32 & 7.84 & 0.0095 & 285 & 6379.72 \\
\hline & 0.25 & 5.063 & 53.50 & 12.11 & 0.0119 & 294 & 7150.82 \\
\hline \multirow{3}{*}{$\begin{array}{l}\text { Free replacement } \\
\text { warranty for a } \\
\text { nonrepairable product }\end{array}$} & 0.15 & 5.063 & 45.21 & 0.20 & 0.005 & 180 & 3683.39 \\
\hline & 0.20 & 5.063 & 47.00 & 0.31 & 0 & 166 & 3541.36 \\
\hline & 0.25 & 5.063 & 50.23 & 0.44 & 0 & 147 & 3370.63 \\
\hline \multirow{3}{*}{$\begin{array}{l}\text { Pro-rata warranty for } \\
\text { a nonrepairable } \\
\text { product }\end{array}$} & 0.15 & 5.063 & 41.70 & 0.32 & 0.0076 & 230 & 3979.85 \\
\hline & 0.20 & 5.063 & 43.20 & 0.49 & 0.0113 & 219 & 3802.50 \\
\hline & 0.25 & 5.063 & 44.98 & 0.71 & 0.0160 & 212 & 3700.51 \\
\hline
\end{tabular}

\subsection{Mixed Weibull and Exponential Distribution}

As mentioned earlier, most products exhibit a bathtub failure pattern in their lifetime.

However, none of the existing single failure distributions used in reliability analysis has a failure rate function that follows a bathtub pattern. For example, the failure rate of the exponential distribution is constant and the failure rate of the Weibull distribution can be strictly decreasing, constant, or increasing depending on its parameters. Thus, in order to 
model the failure rate following a bathtub pattern, two or more distribution functions need to be used simultaneously.

In this research, a mixed Weibull-exponential distribution $(W-E)$ suggested by Chou and Tang [1992], is considered to model the product failures. Here, it is assumed that the product has two phases: the infant mortality phase and the operational phase. This is a reasonable assumption if the product has long normal operational phase and the warranty period expires before the wear-out phase starts. The infant mortality phase is described by a Weibull distribution with shape parameter less than one, and the normal operational phase is described by an exponential distribution. The failure rate function is defined as follows

$$
h(t)= \begin{cases}\beta \theta^{-\beta} t^{\beta-1} & 0 \leq t \leq T \\ \lambda & t>T\end{cases}
$$

where $\lambda=\beta \theta^{-\beta} T^{\beta-1}, 0<\beta<1, \theta>0$ and $T$ is the change point. The change point is a point in time where the product life changes from infant mortality phase to normal operational phase. The failure rate function is shown in Figure 4.6.

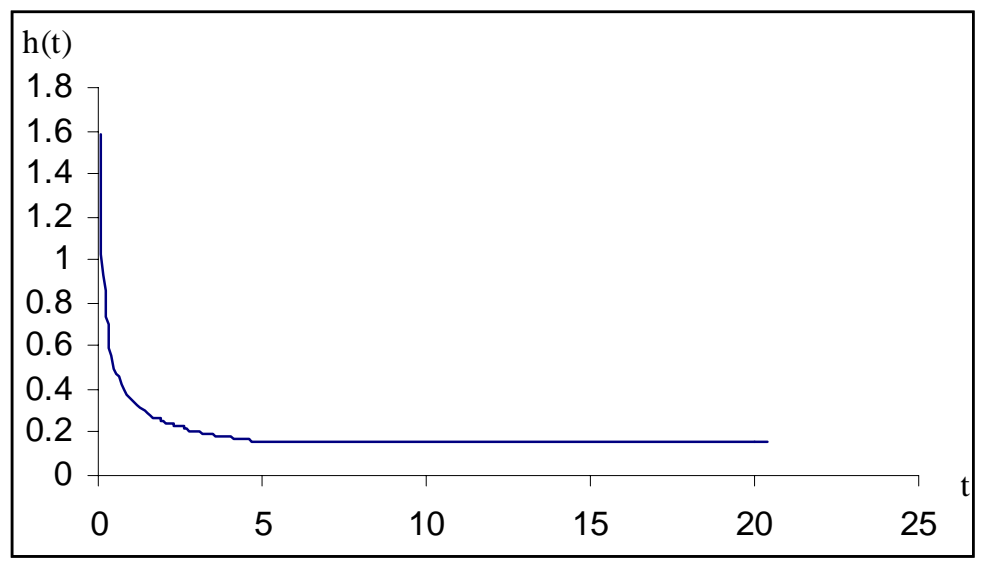

Figure 4.6 The failure rate function $(\beta=0.5, \theta=2$, and $T=5)$ 
The cumulative distribution function and the probability density function are given

by

$$
\begin{gathered}
F(t)= \begin{cases}1-e^{-(t / \theta)^{\beta}} & 0 \leq t \leq T \\
1-e^{-(T / \theta)^{\beta}-\lambda(t-T)} & t>T\end{cases} \\
f(t)= \begin{cases}\beta \theta^{-\beta} t^{\beta-1} e^{-(t / \theta)^{\beta}} & 0 \leq t \leq T \\
\lambda e^{-(T / \theta)^{\beta}-\lambda(t-T)} & t>T\end{cases}
\end{gathered}
$$

Figure 4.7 shows the cumulative distribution function and density function of the $W$ $E$ distribution.
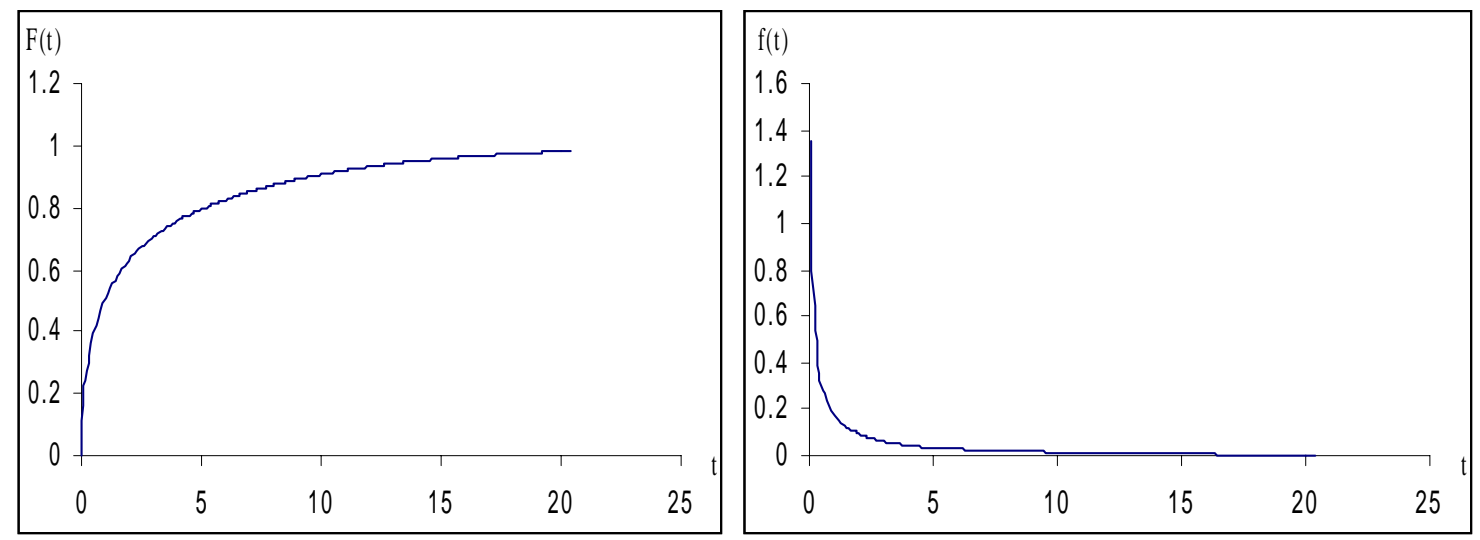

Figure 4.7 $W$ - $E$ cumulative and probability density functions.

\subsubsection{Free Replacement Warranty for Repairable Products}

The expected total unit cost for repairable products under free replacement is given by

$$
C=c_{m}+c_{1}+c_{2} B+c_{3} \int_{0}^{B} h(t) d t+\left(c_{3}+c_{4}\right) \int_{B}^{B+W} h(t) d t
$$

Result 5: Under minimal repair, the optimal burn-in time for a product that has the mixed Weibull-exponential failure time distribution does not exceed the change point (i.e. 
$\left.B^{*}<T\right)$. In other words, the burn-in test must be stopped before the end of the infant mortality phase.

Proof: The proof is straightforward. Consider these two cases. Suppose that for the first case, $B=T$, and for the second case $B>T$. The second integral in the cost function yields the same result for both cases for any positive fixed value of $W$ because the failure rate after the change point of $T$ is constant (see Figure 4.6). Because the first integral and the time dependent burn-in cost $\left(c_{2} * B\right)$ are increasing functions of $B$ in both cases, the minimum cost occurs when $B \leq T$.

Since $B^{*}$ is less than and equal to $T$, the expected total unit cost can be separated at $t=T$ as

$$
C=c_{m}+c_{1}+c_{2} B+c_{3} \int_{0}^{B} \beta \theta^{-\beta} t^{\beta-1} d t+\left(c_{3}+c_{4}\right)\left[\int_{B}^{T} \beta \theta^{-\beta} t^{\beta-1} d t+\int_{T}^{B+W} \lambda d t\right]
$$

Integrating yields

$$
\begin{aligned}
C & =c_{m}+c_{1}+c_{2} B+c_{3} \theta^{-\beta} B^{\beta}+\left(c_{3}+c_{4}\right)\left[\theta^{-\beta}\left(T^{\beta}-B^{\beta}\right)+\lambda(B+W-T)\right] \\
& =c_{m}+c_{1}+\left[c_{2}+\left(c_{3}+c_{4}\right) \lambda\right] B-c_{4} \theta^{-\beta} B^{\beta}+\left(c_{3}+c_{4}\right) \lambda\left[\frac{T(1-\beta)}{\beta}+W\right]
\end{aligned}
$$

The optimal burn-in time occurs when the total unit cost is minimum. Differentiating $C$ with respect to $B$ yields

$$
\frac{\partial C}{\partial B}=c_{2}+\left(c_{3}+c_{4}\right) \lambda-c_{4} \beta \theta^{-\beta} B^{\beta-1}=0
$$

hence

$$
B^{*}=\left[\frac{c_{2}+\left(c_{3}+c_{4}\right) \lambda}{c_{4} \beta \theta^{-\beta}}\right]^{\frac{1}{\beta-1}}
$$

Substituting $\lambda$ into above equation, the optimal burn-in time is found as 


$$
B=\left[\frac{1}{c_{4}}\left(\frac{c_{2} \theta^{\beta}}{\beta}+\left(c_{3}+c_{4}\right) T^{\beta-1}\right)\right]^{\frac{1}{\beta-1}}
$$

The optimal warranty period from Equation 3.18 is,

$$
\left.\left.W^{*}=\frac{c_{m}+c_{1}+\left[c_{2}+\left(c_{3}+c_{4}\right) \lambda\right] B^{*}-c_{4} \theta^{-\beta} B^{* \beta}+\left(c_{3}+c_{4}\right) \lambda\left[\frac{T(1-\beta)}{\beta}+W\right.}{\left(c_{3}+c_{4}\right) \lambda}\right] \frac{a_{2}}{-a_{1}-1}\right]
$$

which simplifies to

$$
W^{*}=\frac{c_{m}+c_{1}+\left[c_{2}+\left(c_{3}+c_{4}\right) \lambda\right] B^{*}-c_{4} \theta^{-\beta} B^{* \beta}+\left(c_{3}+c_{4}\right) \lambda T\left(\frac{1-\beta}{\beta}\right)}{\left(c_{3}+c_{4}\right) \lambda}\left[\frac{a_{2}}{-a_{1}-a_{2}-1}\right]
$$

The optimal price is found from Equation 3.19 as

$$
P^{*}=\left\{c_{m}+c_{1}+\left[c_{2}+\left(c_{3}+c_{4}\right) \lambda\right] B^{*}-c_{4} \theta^{-\beta} B^{* \beta}+\left(c_{3}+c_{4}\right) \lambda\left[\frac{T(1-\beta)}{\beta}+W^{*}\right]\right\}\left[\frac{a_{1}}{a_{1}+1}\right]
$$

\subsubsection{Free Replacement Warranty for Nonrepairable Products}

The expected total unit cost to seller under FRW is given by

$$
C=C_{B}+C_{W}
$$

where

$$
C_{B}=\left[c_{m}+c_{1}+c_{2} \int_{0}^{B} R(t) d t\right] \frac{1}{R(B)}
$$

and

$$
C_{W}=\left[C_{B}+c_{4}\right] M_{B}(W)
$$


Result 6: Under free replacement warranty, the optimal burn-in time for a product that has the Weibull-exponential failure time distribution does not exceed the change point (i.e. $\left.B^{*}<T\right)$

Proof: The proof follows the same reasoning as in Result 5. The number of replacement remains the same when $B=T$ and $B>T$ during the warranty period of $W$ because of the constant failure rate. However $C_{B}$ is an increasing function of $B$. Therefore, the total unit cost is minimum when $B \leq T$.

Based on this result, $C_{B}$ from Equation 3.4 can be written as

$$
C_{B}=\left[c_{m}+c_{1}+c_{2} \int_{0}^{B} e^{-(t / \theta)^{\beta}} d t\right] e^{(B / \theta)^{\beta}}
$$

However, the warranty cost can not be evaluated analytically because there is no simple form expression for $M_{B}(W)$. Therefore, the optimal values for $B, W$, and $P$ that maximize the profit can be obtained only by using numerical search procedures.

\subsubsection{Pro-rata Warranty for Nonrepairable Products}

The expected total unit cost to seller under PRW is given by

$$
C=\frac{1}{R(B)}\left[c_{m}+c_{1}+c_{2} \int_{0}^{B} R(t) d t+P\left(R(B)-\frac{1}{W} \int_{0}^{W} R(B+t) d t\right)\right]
$$

Result 7: Under pro-rata warranty, the optimal burn-in time for a product that has the Weibull-exponential failure time distribution does not exceed the change point (i.e. $B^{*}<T$ )

Proof: First derivative of $C$ with respect to $B$, from Appendix 4 is

$$
\frac{\partial C}{\partial B}=c_{2}+C_{B} h(B)+\frac{P}{R(B) W}\left[F(B+W)-F(B)-h(B) \int_{0}^{W} R(B+t) d t\right]
$$

For $B>T$ 


$$
\begin{aligned}
& F(B+W)=1-e^{-(T / \theta)^{\beta}-\lambda(B+W-T)} \\
& F(B)=1-e^{-(T / \theta)^{\beta}-\lambda(B-T)} \\
& \int_{0}^{W} R(B+t) d t=\frac{1}{\lambda}\left[e^{-(T / \theta)^{\beta}-\lambda(B-T)}-e^{-(T / \theta)^{\beta}-\lambda(B+W-T)}\right] \\
& h(B)=\lambda \\
& R(B)=e^{-(T / \theta)^{\beta}-\lambda(B-T)}
\end{aligned}
$$

Substitution yields

$$
\frac{\partial C}{\partial B}=c_{2}+C_{B} h(B)>0
$$

Thus the expected total unit cost is an increasing function of $B$ when $B$ is greater than $T$. Therefore, the optimal burn-in time must be less than equal to $T$.

Since the integrals in the cost functions are not available, the optimal values for the burn-in time, warranty period and price must be obtained numerically.

\subsubsection{Numerical Example and Sensitivity Analysis}

With the parameters given in Table 4.1, similar sensitivity analysis was performed, and the results are shown in Tables 4.8, 4.9, and 4.10. The warranty period increases with $\theta, a_{1}$, and $a_{2}$. The optimal price remains fixed for all the warranty policies when $\theta$ changes, and increases with the increase in $a_{1}$ and $a_{2}$. The expected profit increases with $\theta$ and $a_{1}$, and decreases with $a_{2}$. The optimal burn-in period was found to be zero for the FRWnonrepairable case with the given parameter values. It decreases for the FRW- repairable products, and increases for the pro-rata warranty as $\theta$ increases. It remains fixed for the FRW-repairable case and increases for the PRW-nonrepairable case when $a_{1}$ and $a_{2}$ 
increase. Also note that the optimal burn-in time is always less than the change point as proved.

Table 4.8 Optimal policies for different $\theta$ values when $\beta=0.7, T=0.1$ year, $a_{l}=-2.2$, and $a_{2}=0.2$

\begin{tabular}{|l|c|c|c|c|c|r|r|}
\hline \hline Warranty policies & $\theta$ & $\begin{array}{l}\text { MTTF } \\
\text { (year) }\end{array}$ & $\begin{array}{l}\text { Price } \\
(\$)\end{array}$ & $\begin{array}{l}\text { Warranty } \\
\text { Period } \\
\text { (year) }\end{array}$ & $\begin{array}{l}\text { Burn-in } \\
\text { Time } \\
(\text { year) }\end{array}$ & $\begin{array}{l}\text { Expected } \\
\text { sales }\end{array}$ & $\begin{array}{l}\text { Expected } \\
\text { Profit }(\$)\end{array}$ \\
\hline \hline \multirow{2}{*}{$\begin{array}{l}\text { Free replacement } \\
\text { warranty for a } \\
\text { repairable product }\end{array}$} & 3 & 1.503 & 45.30 & 1.59 & 0.00054 & 249 & 5130.48 \\
\cline { 2 - 8 } & 4 & 1.845 & 45.30 & 1.95 & 0.00048 & 260 & 5346.54 \\
\hline \hline \multirow{2}{*}{$\begin{array}{l}\text { Free replacement } \\
\text { warranty for a } \\
\text { nonrepairable product }\end{array}$} & 5 & 2.164 & 45.30 & 2.27 & 0.00044 & 268 & 5519.69 \\
\cline { 2 - 8 } & 4 & 1.503 & 45.30 & 0.20 & 0 & 165 & 3384.42 \\
\hline \hline \multirow{2}{*}{$\begin{array}{l}\text { Pro-rata warranty for } \\
\text { a nonrepairable } \\
\text { product }\end{array}$} & 3 & 1.503 & 42.36 & 0.28 & 0.0047 & 204 & 3475.08 \\
\cline { 2 - 8 } & 4 & 1.845 & 42.19 & 0.35 & 0.0049 & 215 & 3715.82 \\
\cline { 2 - 8 } & 5 & 2.164 & 42.06 & 0.41 & 0.0052 & 223 & 3856.95 \\
\hline \hline
\end{tabular}

Table 4.9 Optimal policies for different price elasticity values when $\beta=0.7, \theta=4$, $T=0.1$ year and $a_{2}=0.2$

\begin{tabular}{|c|c|c|c|c|c|c|c|}
\hline Warranty policies & $\bar{a} a_{1}$ & $\begin{array}{l}\text { MTTF } \\
\text { (year) }\end{array}$ & $\begin{array}{l}\text { Price } \\
(\$)\end{array}$ & $\begin{array}{l}\text { Warranty } \\
\text { Period } \\
\text { (year) }\end{array}$ & $\begin{array}{l}\text { Burn-in } \\
\text { Time } \\
\text { (year) }\end{array}$ & $\begin{array}{l}\text { Expected } \\
\text { sales }\end{array}$ & $\begin{array}{l}\text { Expected } \\
\text { Profit (\$) }\end{array}$ \\
\hline \multirow{3}{*}{$\begin{array}{l}\text { Free replacement } \\
\text { warranty for a } \\
\text { repairable product }\end{array}$} & -2.0 & 1.845 & 51.47 & 2.43 & 0.00048 & 451 & 11602.40 \\
\hline & -2.2 & 1.845 & 45.29 & 1.95 & 0.00048 & 260 & 5346.54 \\
\hline & -2.5 & 1.845 & 39.60 & 1.49 & 0.00048 & 110 & 1740.13 \\
\hline \multirow{3}{*}{$\begin{array}{l}\text { Free replacement } \\
\text { warranty for a } \\
\text { nonrepairable product }\end{array}$} & -2.0 & 1.845 & 51.28 & 0.28 & 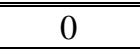 & 295 & 7537.74 \\
\hline & -2.2 & 1.845 & 45.30 & 0.22 & 0 & 168 & 3475.08 \\
\hline & -2.5 & 1.845 & 39.66 & 0.17 & 0 & 71 & 1130.75 \\
\hline \multirow{3}{*}{$\begin{array}{l}\text { Pro-rata warranty for } \\
\text { a nonrepairable } \\
\text { product }\end{array}$} & \begin{tabular}{c|}
-2.0 \\
\end{tabular} & 1.845 & 46.61 & 0.39 & 0.0072 & 381 & 7927.70 \\
\hline & -2.2 & 1.845 & 42.19 & 0.35 & 0.0049 & 215 & 3715.82 \\
\hline & -2.5 & 1.845 & 37.86 & 0.31 & 0.0030 & 89 & 1230.13 \\
\hline
\end{tabular}


Table 4.10 Optimal policies for different warranty elasticity values when $\beta=0.7$, $\theta=4, T=0.1$ year, and $a_{l}=-2.2$

\begin{tabular}{|c|c|c|c|c|c|c|c|}
\hline Warranty policies & $a_{2}$ & $\begin{array}{l}\text { MTTF } \\
\text { (year) }\end{array}$ & $\begin{array}{l}\text { Price } \\
(\$)\end{array}$ & $\begin{array}{l}\text { Warranty } \\
\text { Period } \\
\text { (year) }\end{array}$ & $\begin{array}{l}\text { Burn-in } \\
\text { Time } \\
\text { (year) }\end{array}$ & $\begin{array}{l}\text { Expected } \\
\text { sales }\end{array}$ & $\begin{array}{l}\text { Expected } \\
\text { Profit (\$) }\end{array}$ \\
\hline \multirow{3}{*}{$\begin{array}{l}\text { Free replacement } \\
\text { warranty for a } \\
\text { repairable product }\end{array}$} & 0.15 & 1.845 & 43.14 & 1.38 & 0.00048 & 266 & 5213.53 \\
\hline & 0.20 & 1.845 & 45.29 & 1.95 & 0.00048 & 260 & 5346.54 \\
\hline & 0.25 & 1.845 & 47.68 & 2.56 & 0.00048 & 257 & 5566.55 \\
\hline \multirow{3}{*}{$\begin{array}{l}\text { Free replacement } \\
\text { warranty for a } \\
\text { nonrepairable product }\end{array}$} & 0.15 & 1.845 & 43.24 & 0.16 & 0 & 191 & 3772.61 \\
\hline & 0.20 & 1.845 & 45.30 & 0.22 & 0 & 168 & 3475.08 \\
\hline & 0.25 & 1.845 & 47.47 & 0.29 & 0 & 150 & 3246.13 \\
\hline \multirow{3}{*}{$\begin{array}{l}\text { Pro-rata warranty for } \\
\text { a nonrepairable } \\
\text { product }\end{array}$} & 0.15 & 1.845 & 41.46 & 0.26 & 0.0045 & 226 & 3944.66 \\
\hline & 0.20 & 1.845 & 42.19 & 0.35 & 0.0049 & 215 & 3715.82 \\
\hline & 0.25 & 1.845 & 43.28 & 0.45 & 0.0053 & 206 & 3547.39 \\
\hline
\end{tabular}




\section{CHAPTER 5}

\section{APPLICATION OF THE MODELS}

In order to determine the optimal pricing, warranty and burn-in policy, warranty management needs to know the market and the failure characteristics of the product. If the behavior of the market to changes in the price and warranty period can be modeled, and the total unit cost can be estimated, one can build an optimization model to select the best price and warranty policy for a product.

As stated previously, the expected sales volume can be modeled as a function of certain marketing variables such as price, advertising expenditure, warranty period, etc. In this research, the price and warranty period have been chosen as two controllable marketing variables in order to model the sales. It was assumed that the sales response function is in a multiplicative form and its parameters are known. In fact, the selection of an appropriate sales model and estimation of its parameter should be based on historical data for an exiting product, and based on experts' opinion or test data for a new product. The assumption of multiplicative sales response function simplifies the solution of the models greatly, however, more complicated and accurate sales model may be built with the existence of historical data.

Estimation of expected total unit cost is a very complicated problem since the number of failures, and cost of each failure during both burn-in and warranty period are stochastic variables. In order to simplify the solution of the models, it was assumed that all related costs are known and fixed for each product failure although in reality some of them may be treated as random variables with some distribution functions. For example, the repair 
cost, in general, is a random variable because it depends on the nature of failure. However, this assumption is valid if the variability in the cost is relatively small for all warranty claims. For instance, if the repair cost consists mainly of the labor cost, which tends to be fixed, then it can be treated as a fixed quantity [Glickman, and Berger 1976].

The objective of this chapter is to model item failures from available data, and obtain the optimal burn-in time, warranty period and selling price for item sold with a warranty. To illustrate the application of the models developed in Chapter 4, two sets of failure data were obtained from two different sources. The first set of data belongs to a unit of an electronic ground support equipment and was obtained from the existing literature. The second contains number of repairs of a part of an engine used by Ford Motor Company and was obtained directly from the company.

The general procedure for modeling item failures is to fit, if possible, a theoretical distribution function to the data available, estimate the parameter(s), and check for the appropriateness of the assumed distribution function. This is referred to as the parametric approach. However in some cases, item failures do not fit any of the existing theoretical distribution functions. In such cases, empirical functions that are derived directly from the data can be used to model item failures. The only drawback in this approach is that empirical functions do not provide information beyond the range of the data. Therefore fitting a theoretical distribution should be preferred over empirically developed models [Ebeling, 1997].

In this chapter, availability of an adequate theoretical distribution function will be investigated for these two sets of data. In the absence of adequate theoretical model, the empirical functions will be used to solve the models. 


\subsection{Failure Data}

Accurate and sufficient data are necessary in warranty analysis in order to find the failure distribution function of the product, and to estimate the expected warranty cost.

The failure data can be presented in one of two ways- grouped and ungrouped depending on limitations and convenience in data recording. In grouped data (or failure count data), the number of failures that were experienced during a time interval are recorded. This method should be adopted if the sample size is relatively large. For ungrouped data (or time to failure data), individual times to failure are recorded. This is the most detailed and desirable type of failure data, which allows for more precision in parameter estimation.

Failure data frequently have the so-called censoring problem. Censoring occurs when the exact lifetime of an item is not observed. This is a common problem in warranty data since the manufacturer is usually not aware of failures occurring outside of the warranty coverage. Censored data introduce additional difficulties into analysis and require more complicated statistical methods. Fortunately depending on the type of censoring, available statistical tools can be applied with simple modifications. Two types of censoring can be observed when collecting failure data. Right-censoring occurs when the exact lifetime of the product cannot be observed (i.e. the item is still operational at the end of the test), and leftcensoring occurs when the unit is known to have failed before some specific time. When there is no censoring present, the data are referred to as complete data. Table 5.1 shows 105 complete time to failure observations for a unit of electronic ground support equipment. Table 5.2 contains the number of repairs per 1000 vehicles during the 36 months of warranty 
period. Since the failure times beyond the warranty period are unknown, the data in Table 5.2 are right censored.

Table 5.1 Failure history for a unit of electronic ground support equipment [Juran and Gryna 1970].

\begin{tabular}{rrrrrr}
\hline $\begin{array}{c}\text { Time to Failure Infant } \\
\text { Mortality Period }\end{array}$ & \multicolumn{2}{c}{$\begin{array}{c}\text { Time to failure } \\
\text { Constant Failure Rate Period }\end{array}$} & \multicolumn{2}{c}{$\begin{array}{c}\text { Time to failure } \\
\text { Wear Out } \\
\text { Period }\end{array}$} \\
\hline 1 & 7.2 & 28.1 & 60.2 & 100.8 & 125.8 \\
1.2 & 7.9 & 28.2 & 63.7 & 102.6 & 126.6 \\
1.3 & 8.3 & 29.0 & 64.6 & 103.2 & 127.7 \\
2.0 & 8.7 & 29.9 & 65.3 & 104.0 & 128.4 \\
2.4 & 9.2 & 30.6 & 66.2 & 104.3 & 129.2 \\
2.9 & 9.8 & 32.4 & 70.1 & 105.0 & \\
3.0 & 10.2 & 33.0 & 71.0 & 105.8 & \\
3.1 & 10.4 & 35.3 & 75.1 & 106.5 & \\
3.3 & 11.9 & 36.1 & 75.6 & 110.7 & \\
3.5 & 13.8 & 40.1 & 78.4 & 112.6 & \\
3.8 & 14.4 & 42.8 & 79.2 & 113.5 & \\
4.3 & 15.6 & 43.7 & 84.1 & 114.8 & \\
4.6 & 16.2 & 44.5 & 86.0 & 115.1 & \\
4.7 & 17.0 & 50.4 & 87.9 & 117.4 & \\
4.8 & 17.5 & 51.2 & 88.4 & 118.3 & \\
5.2 & 19.2 & 52.0 & 89.9 & 119.7 & \\
5.4 & & 53.3 & 90.8 & 120.6 & \\
5.9 & & 54.2 & 91.1 & 121.0 & \\
6.4 & & 55.6 & 91.5 & 122.9 & \\
6.8 & & 56.4 & 92.1 & 123.3 & \\
6.9 & & 58.3 & 97.9 & 124.5 & \\
\hline \hline
\end{tabular}


Table 5.2 The number of repairs per 1000 vehicles

\begin{tabular}{|c|c|c|c|}
\hline $\begin{array}{l}\text { Upper limit } \\
\text { (month) }\end{array}$ & $\begin{array}{c}\text { No. of failures } \\
\text { (per } 1000 \text { vehicle) }\end{array}$ & $\begin{array}{l}\text { Upper limit } \\
\text { (month) }\end{array}$ & $\begin{array}{c}\text { No. of failures } \\
\text { (per } 1000 \text { vehicle) }\end{array}$ \\
\hline Pre-delivery & 0.07 & 19 & 0.12 \\
\hline 1 & 0.61 & 20 & 0.10 \\
\hline 2 & 1.70 & 21 & 0.14 \\
\hline 3 & 1.97 & 22 & 0.18 \\
\hline 4 & 1.79 & 23 & 0.09 \\
\hline 5 & 1.33 & 24 & 0.10 \\
\hline 6 & 1.50 & 25 & 0.12 \\
\hline 7 & 0.86 & 26 & 0.06 \\
\hline 8 & 0.89 & 27 & 0.07 \\
\hline 9 & 0.85 & 28 & 0.09 \\
\hline 10 & 0.74 & 29 & 0.06 \\
\hline 11 & 0.85 & 30 & 0.08 \\
\hline 12 & 0.53 & 31 & 0.02 \\
\hline 13 & 0.48 & 32 & 0.06 \\
\hline 14 & 0.38 & 33 & 0.07 \\
\hline 15 & 0.39 & 34 & 0.05 \\
\hline 16 & 0.22 & 35 & 0.01 \\
\hline 17 & 0.25 & 36 & 0.03 \\
\hline 18 & 0.22 & & \\
\hline
\end{tabular}

In the following section, the empirical functions for the grouped data will be discussed. These functions will be used later in the identification of the candidate distribution function and estimation of its parameter(s). 


\subsection{Empirical Distribution Functions}

Let $t_{1}, t_{2}, t_{3}, \ldots t_{n}$ be the time to first failure for $n$ items. Suppose that failure times are identically and independently distributed (i.i.d.) random variables with distribution function $F$. Let $n_{i}$ be the number of units having survived in the $i^{\text {th }}$ interval. Then, the logical estimation of $F$ is [Ebeling, 1997]

$$
\hat{F}\left(t_{i}\right)=1-\frac{n_{i}}{n} \quad i=1,2, \ldots, k
$$

where $n$ is the total number of units and $k$ is the number of intervals. $\hat{F}\left(t_{i}\right)$ is referred to as the empirical distribution function. Empirical functions are the basis for several nonparametric statistical methods. They are often used in goodness of fitness tests and graphical methods such as probability plotting in order to check the adequacy of the fitted model. They also provide rough estimates of the model parameter(s) that can be used later as starting points to obtain more accurate estimates of the parameters. The empirical reliability function is given by

$$
\hat{R}\left(t_{i}\right)=\frac{n_{i}}{n} \quad i=1,2, \ldots, k
$$

The empirical density function from the relationship between $f(t)$ and $R(t)$

(i.e. $f(t)=-d R(t) / d t)$ is given by

$$
\hat{f}(t)=-\frac{\hat{R}\left(t_{i+1}\right)-\hat{R}\left(t_{i}\right)}{t_{i+1}-t_{i}}=\frac{n_{i}-n_{i+1}}{\left(t_{i+1}-t_{i}\right) \cdot n} \quad \text { for } t_{i}<t<t_{i+1}
$$

and the hazard rate function is given by

$$
\hat{h}(t)=\frac{\hat{f}(t)}{\hat{R}(t)}=\frac{n_{i}-n_{i+1}}{\left(t_{i+1}-t_{i}\right) \cdot n_{i}} \quad \text { for } t_{i}<t<t_{i+1}
$$


In the following section, these empirical functions will be used to identify the candidate theoretical distribution functions for the two sets of failure data given in Section 5.1.

\subsection{Solution Procedure for the First Set of Data}

Table 5.1 shows 105 failure times for a unit of an electronic ground support equipment. The data have no censoring. In other words failure data were obtained for all the items. These items have a mean life of 55.603 hours and a standard deviation of 44.136 hours. Estimated $R(t), h(t)$ and $f(t)$ are tabulated in Table 5.3. This table is referred as life table and can be thought of as an enhanced frequency distribution table. The failure times are divided into a certain number of intervals, and for each interval the number of items entered and the number of items failed are computed. Then $R(t), h(t)$ and $f(t)$ are calculated using the formulas given in Section 5.2.

Figure 5.1, 5.2 and 5.3 plot the empirical failure density, hazard rate and reliability functions, respectively. These plots indicate that the item has a bathtub failure rate function. As stated earlier, none of the simple parametric distribution families has this type of failure rate pattern. Statistical tests such as the goodness-of-fit test, and data analytical methods such as probability-probability (PP) plots can be used to determine if any of the theoretical distributions is appropriate. In this research, PP plot will be performed for model adequacy checking. The following theoretical distribution functions will be investigated: exponential, normal, lognormal, Weibull, gamma, and extreme value distributions. Figure 5.4 shows probability-probability plots of these theoretical distribution functions. Linearity of the plots is indicative of a good fit between the data and the assumed model. None of the graphs 
shows linearity, therefore the data cannot be represented by any of these distribution functions.

Table 5.3 Life table for a unit of electronic ground support equipment.

\begin{tabular}{|c|c|c|c|c|c|c|c|c|c|}
\hline 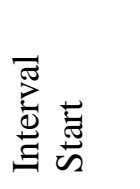 & $\vec{\Sigma} \cdot \vec{\Xi}$ & 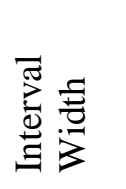 & 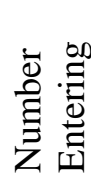 & 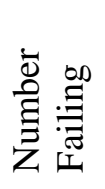 & 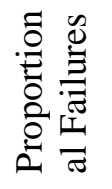 & 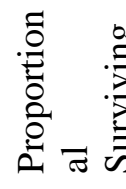 & 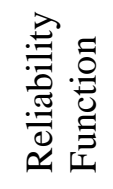 & 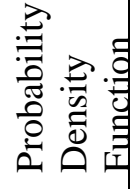 & 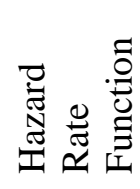 \\
\hline 0.00 & 5.873 & 11.745 & 105 & 29 & 0.276 & 0.724 & 1.000 & 0.024 & 0.0273 \\
\hline 11.745 & 17.618 & 11.745 & 76 & 8 & 0.105 & 0.895 & 0.724 & 0.006 & 0.009 \\
\hline 23.491 & 29.364 & 11.745 & 68 & 7 & 0.103 & 0.897 & 0.648 & 0.006 & 0.009 \\
\hline 35.236 & 41.109 & 11.745 & 61 & 6 & 0.098 & 0.902 & 0.581 & 0.005 & 0.009 \\
\hline 46.982 & 52.854 & 11.745 & 55 & 8 & 0.145 & 0.854 & 0.524 & 0.006 & 0.013 \\
\hline 58.727 & 64.600 & 11.745 & 47 & 6 & 0.128 & 0.872 & 0.448 & 0.005 & 0.012 \\
\hline 70.473 & 76.345 & 11.745 & 41 & 5 & 0.122 & 0.878 & 0.390 & 0.004 & 0.011 \\
\hline 82.218 & 88.091 & 11.745 & 36 & 9 & 0.250 & 0.750 & 0.343 & 0.007 & 0.024 \\
\hline 93.964 & 99.836 & 11.745 & 27 & 7 & 0.259 & 0.741 & 0.257 & 0.006 & 0.025 \\
\hline 105.709 & 111.582 & 11.745 & 20 & 8 & 0.400 & 0.600 & 0.190 & 0.006 & 0.043 \\
\hline 117.454 & 123.327 & 11.745 & 12 & 11 & 0.917 & 0.083 & 0.114 & 0.009 & 0.144 \\
\hline 129.200 & -- & -- & 1 & 1 & 0.500 & 0.500 & 0.010 & -- & -- \\
\hline
\end{tabular}

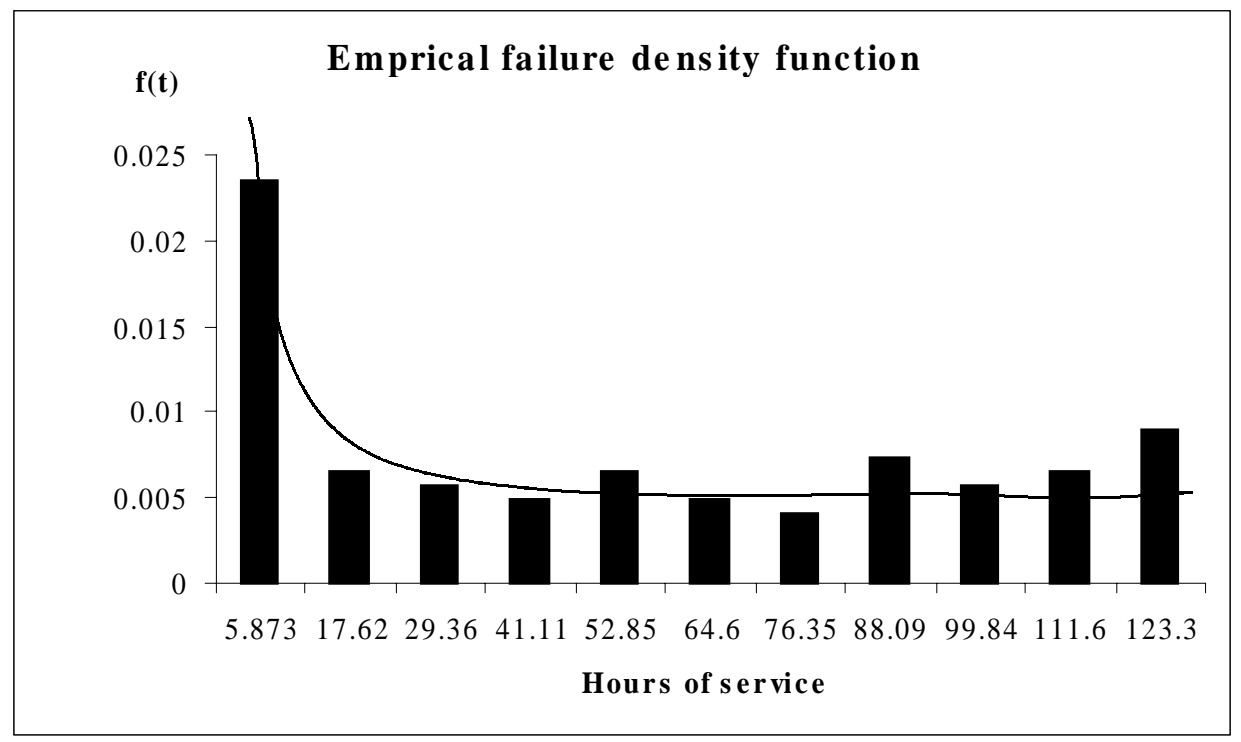

Figure 5.1 Empirical density function 


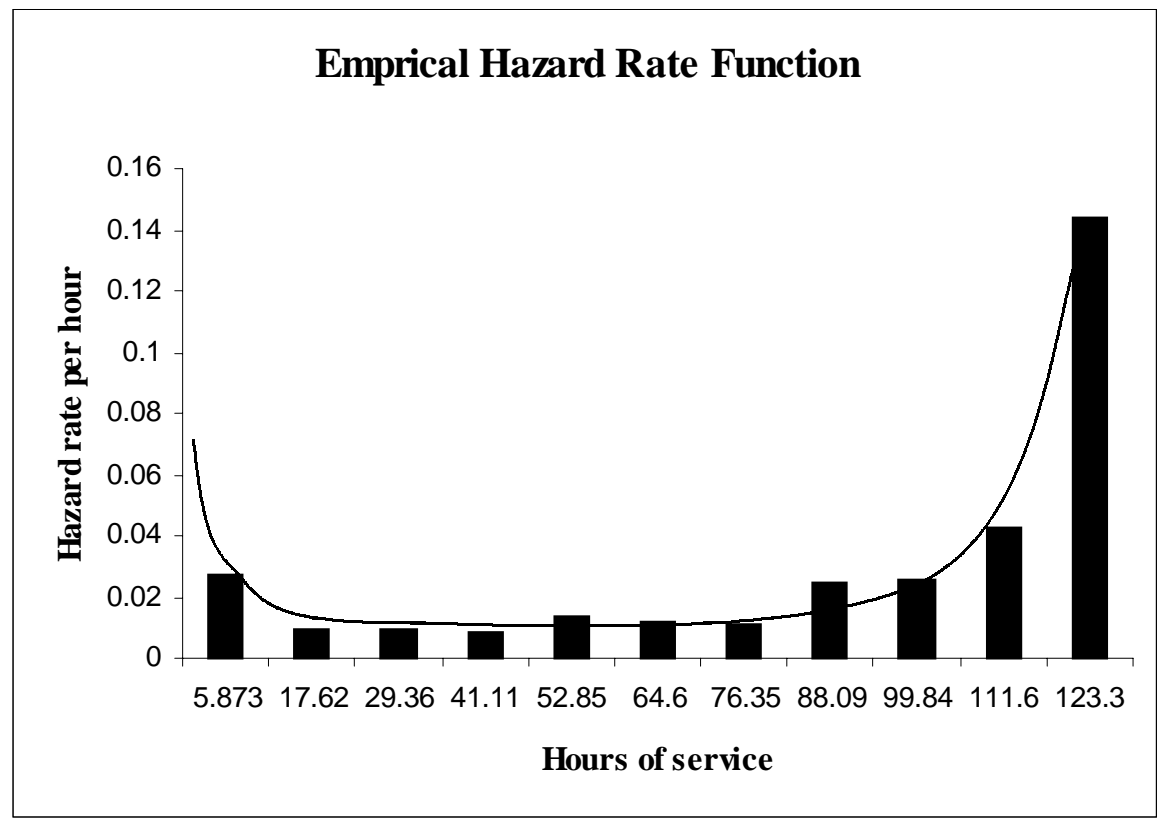

Figure 5.2 Hazard rate vs. service hours.

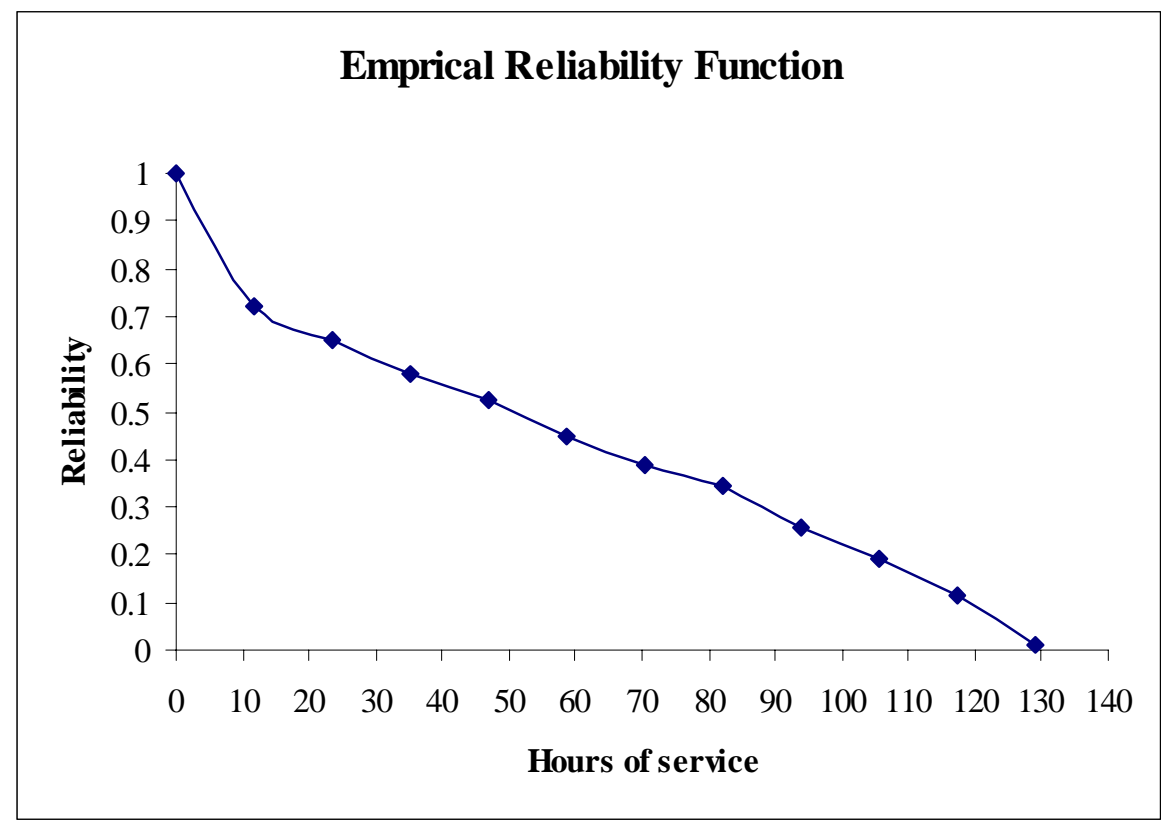

Figure 5.3 Empirical reliability vs. service hours 


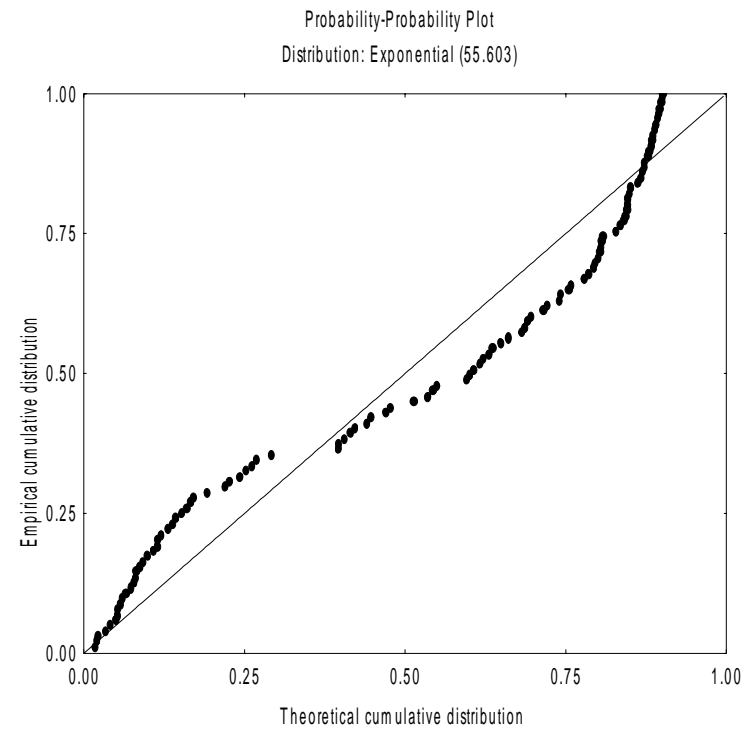

(a)

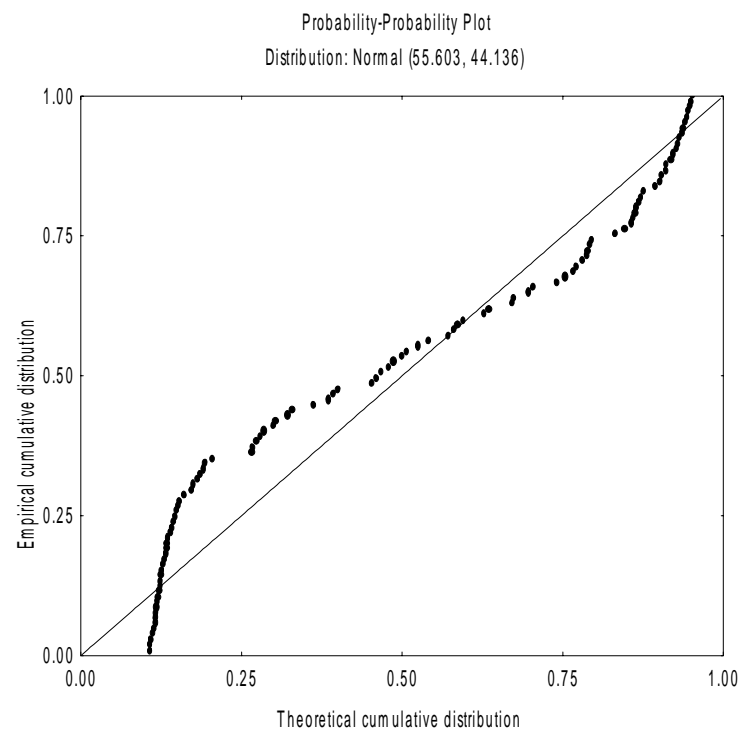

(c)

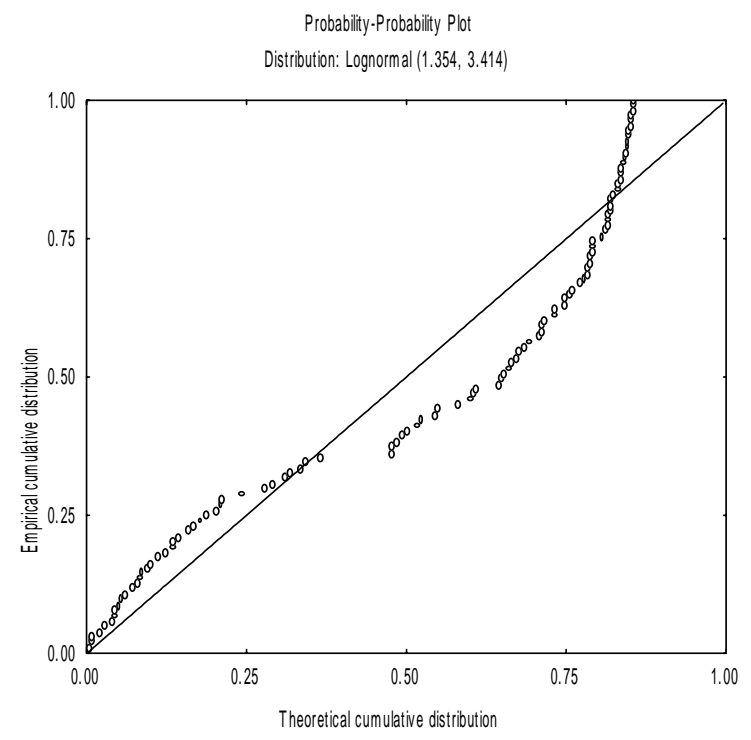

(b)

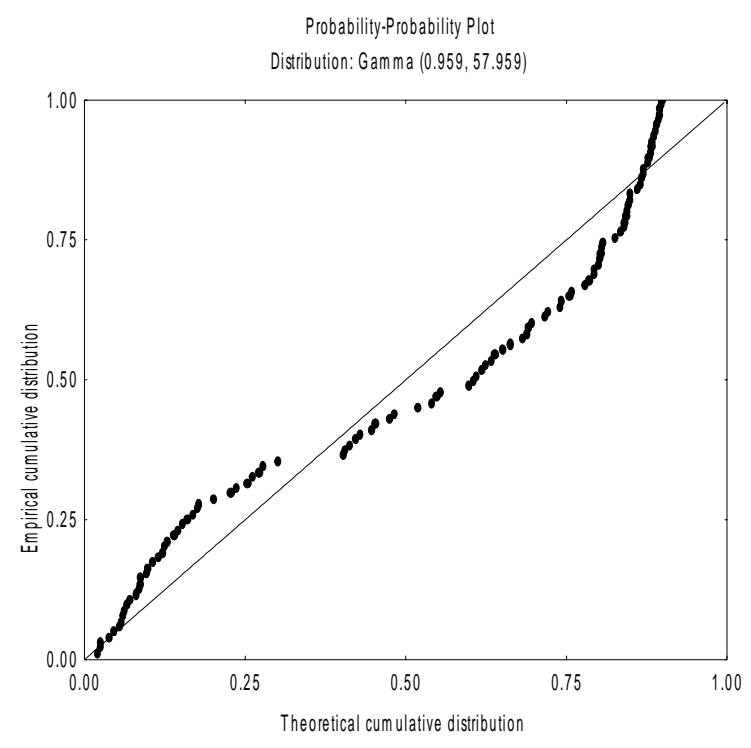

(d)

Figure 5.4 Probability-Probability plot for six theoretical distribution functions 


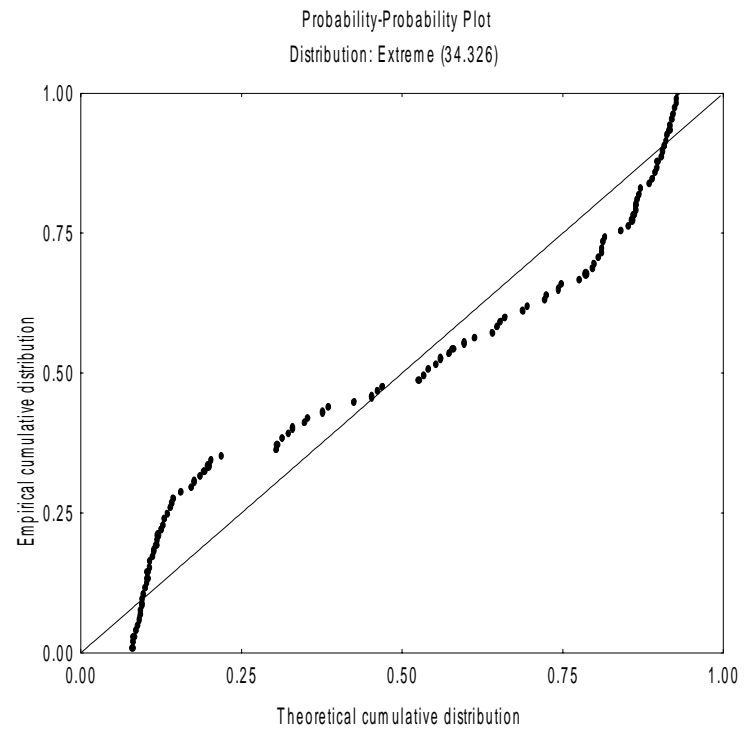

(e)

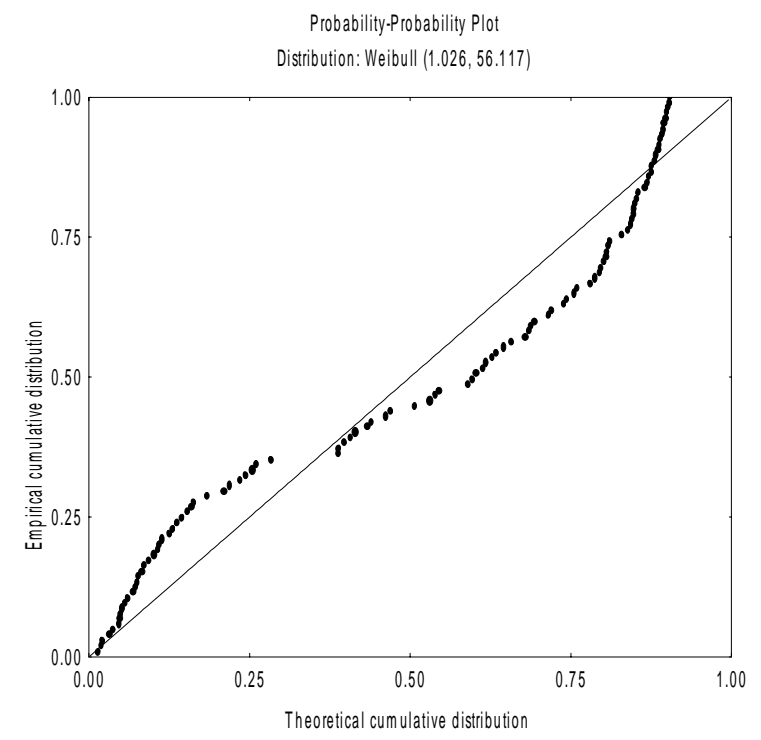

(f)

Figure 5.4 (cont.) Probability-Probability plot for six theoretical distribution functions.

As mentioned earlier, mixed distribution functions can be used to obtain a bathtub failure rate function as shown in Figure 5.2. In Section 4.3, Weibull-Exponential distribution was used to characterize failures of an item that has high failure rate at the early stages of its lifetime and a constant failure rate during the rest of its lifetime. In this case, if the wearout phase is ignored, assuming that the warranty period will expire before the item enters the wearout stage, then the W-E distribution may be an appropriate model for this item. The adequacy of the W-E distribution will be checked under this assumption. From Figure 5.2, it seems that the operational phase starts approximately at the age of 18 hours of service time and ends at the age of 88 hours. Therefore the average constant failure rate during the operational phase from Table 5.3 is

$$
(0.009+0.009+0.009+0.013+0.012+0.011+0.024) / 7=0.0124
$$

The hazard rate function of the W-E distribution from Section 4.3 was defined as 


$$
h(t)= \begin{cases}\beta \theta^{-\beta} t^{\beta-1} & 0 \leq t \leq T \\ \beta \theta^{-\beta} T^{\beta-1} & t \geq T\end{cases}
$$

where $T$ is the change point and is equal to 18 hours. From Table 5.3 the hazard rate at the age of 5.8 and 18 hours approximately are

$$
\begin{aligned}
& h(5.8)=0.0273 \\
& h(18)=0.0124
\end{aligned}
$$

respectively. Substituting these values into the above equation yields

$$
\frac{h(5.8)}{h(18)}=\frac{0.0273}{0.0124}=\left(\frac{5.8}{18}\right)^{\beta-1}
$$

Hence, $\beta$ is found to be 0.30 . The value of $\theta$ is calculated from following equation

$$
0.0273=0.30 \theta^{-0.30}(5.8)^{-0.70}
$$

and is found to be 48.81 hours. Figure 5.5 shows the estimated hazard rate function and the observed values. The graphical model adequacy checking shown in Figure 5.6 indicates that the assumption of W-E distribution cannot be ruled out.

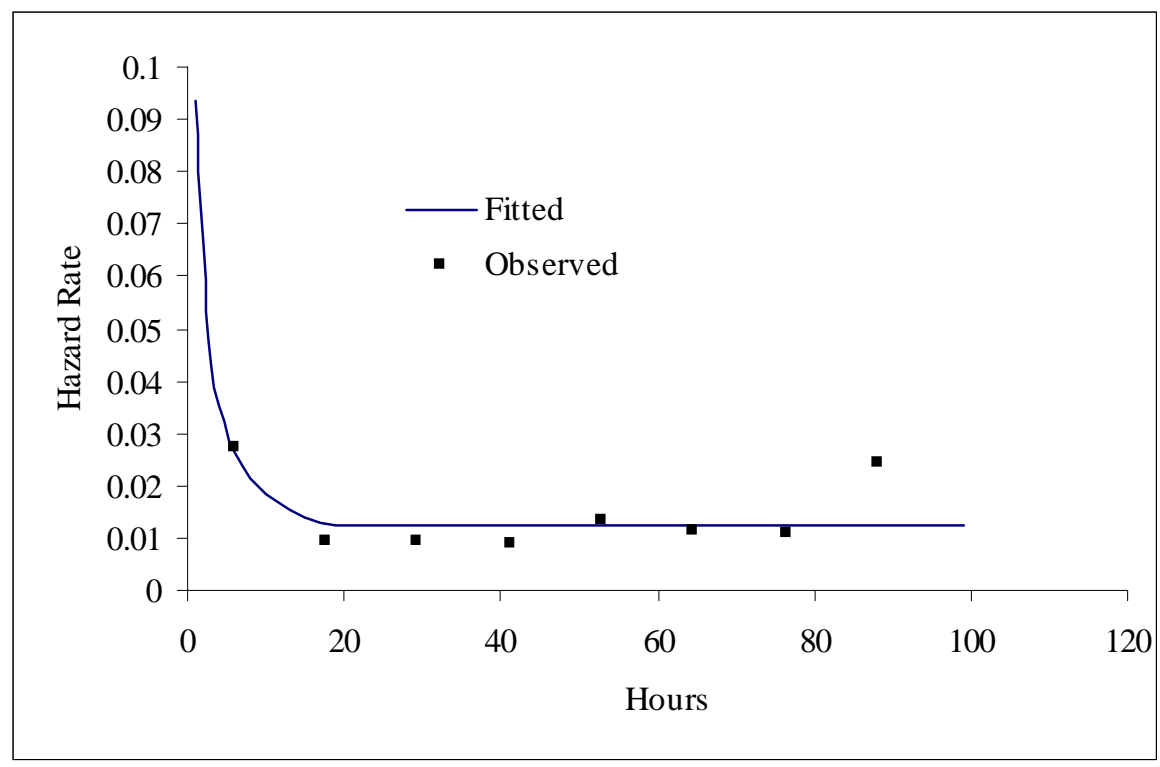

Figure 5.5 Fitted hazard rate function 


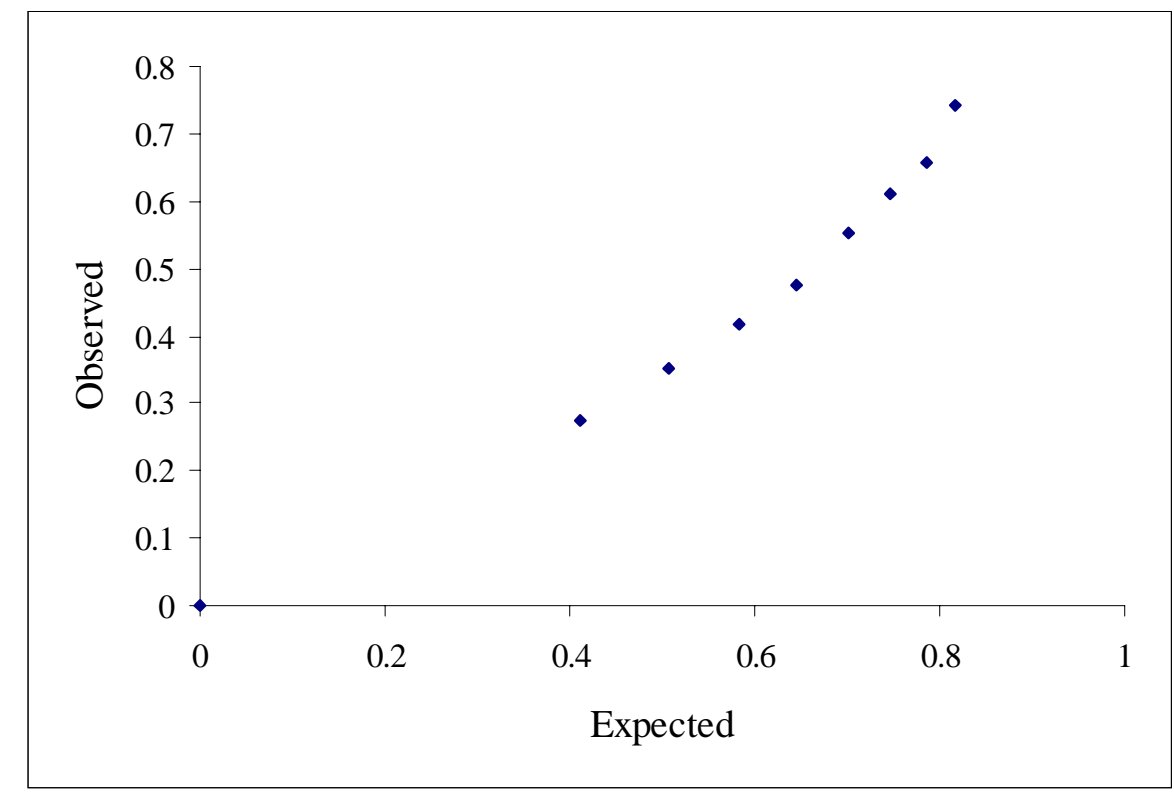

Figure 5.6 PP plot for Weibull-Exponential distribution

Under the Weilbull-Exponential distribution assumption, the optimal burn-in time, warranty period and selling price were calculated for different costs and elasticity values and were tabulated in Table 5.4. It was assumed that the equipment is repairable and the type of repair is minimal.

From Table 5.4, as the price and warranty elasticity values increase, the price and warranty period increase respectively, and the burn-in period remains fixed. As the burn-in cost, $c_{2}$ increases, the burn-in time decreases and the price and warranty period increase, as expected. The increase in the repair cost results in shorter burn-in and warranty periods and higher selling price. On the other hand, the increase in the extra warranty cost, $c_{4}$ results in longer burn-in time and shorter warranty period due to increasing warranty cost. 
Table 5.4 Optimal policies for different parameter values

\begin{tabular}{|c|c|c|c|c|c|c|}
\hline $\begin{array}{l}\text { Free Replacement Warranty } \\
\text { Repairable Case }\end{array}$ & & Price & $\begin{array}{l}\text { Warranty } \\
\text { Period } \\
\end{array}$ & $\begin{array}{l}\text { Burn-in } \\
\text { Time }\end{array}$ & $\begin{array}{l}\begin{array}{l}\text { Expected } \\
\text { sales }\end{array} \\
\end{array}$ & $\begin{array}{l}\text { Expected } \\
\text { Profit } \\
\end{array}$ \\
\hline \multirow{3}{*}{$\begin{array}{l}\text { Price Elasticity (a1) } \\
(\mathrm{a} 2=0.2, \mathrm{~cm}=50, \mathrm{c} 1=1, \mathrm{c} 2=0.5, \\
\mathrm{c} 3=10, \mathrm{c} 4=5)\end{array}$} & -2.0 & 144 & 78 & 0.58 & 115 & 8263 \\
\hline & -2.2 & 127 & 62 & 0.58 & 54 & 3097 \\
\hline & -2.5 & 111 & 48 & 0.58 & 17 & 739 \\
\hline \multirow{3}{*}{$\begin{array}{l}\text { Warranty Elasticity }(\mathrm{a} 2) \\
(\mathrm{a} 1=-2.2, \mathrm{~cm}=50, \mathrm{c} 1=1, \mathrm{c} 2=0.5, \\
\mathrm{c} 3=10, \mathrm{c} 4=5)\end{array}$} & 0.15 & 121 & 45 & 0.58 & 46 & 2539 \\
\hline & 0.20 & 127 & 62 & 0.58 & 53 & 3097 \\
\hline & 0.25 & 134 & 82 & 0.58 & 63 & 3835 \\
\hline \multirow{3}{*}{$\begin{array}{l}\text { Burn Cost }(\mathrm{c} 2) \\
(\mathrm{a} 1=-2.2, \mathrm{a} 2=0.2, \mathrm{~cm}=50, \mathrm{c} 1=1, \\
\mathrm{c} 3=10, \mathrm{c} 4=5)\end{array}$} & 0.4 & 127 & 62 & 0.72 & 54 & 3100 \\
\hline & 1 & 127 & 63 & 0.26 & 54 & 3086 \\
\hline & 2 & 128 & 63 & 0.11 & 53 & 3077 \\
\hline \multirow{3}{*}{$\begin{array}{l}\text { Repair cost }(\mathrm{c} 3) \\
(\mathrm{a} 1=-2.2, \mathrm{a} 2=0.2, \mathrm{~cm}=50, \mathrm{c} 1=1, \\
\mathrm{c} 2=0.5, \mathrm{c} 4=5)\end{array}$} & 8 & 125 & 71 & 0.61 & 57 & 3246 \\
\hline & 14 & 132 & 51 & 0.52 & 47 & 2850 \\
\hline & 20 & 139 & 41 & 0.45 & 41 & 2563 \\
\hline \multirow{3}{*}{$\begin{array}{l}\text { Extra cost during warranty } \\
\text { period }(\mathrm{c} 4) \\
(\mathrm{a} 1=-2.2, \mathrm{a} 2=0.2, \mathrm{~cm}=50, \mathrm{c} 1=1, \\
\mathrm{c} 2=0, \mathrm{c} 3=10)\end{array}$} & 3 & 126 & 71 & 0.29 & 56 & 3218 \\
\hline & 6 & 128 & 59 & 0.73 & 52 & 3044 \\
\hline & 8 & 129 & 53 & 1.0 & 50 & 2950 \\
\hline
\end{tabular}

\subsection{Solution Procedures for the Second Set of Data}

Similar analysis was performed on the failure data obtained for the part of the Ford engine. Table 5.2 contains the number of failures of a part of the engine during the 36 months of warranty period. Table 5.4 shows the calculated empirical functions.

Figure 5.7, 5.8, and 5.9 show the empirical failure distribution, failure rate and reliability functions respectively. The failure rate increases sharply during the early ages of the product and decreases continually after that. This is indication of early product failure characteristic. The lognormal distribution displays this type of failure charecteristic, therefore, its adequacy will be tested. 
Table 5.5 Life table of a part of engine

\begin{tabular}{|c|c|c|c|c|c|}
\hline \begin{tabular}{|l|}
$\begin{array}{l}\text { Upper limit } \\
\text { (month) }\end{array}$ \\
\end{tabular} & $\begin{array}{l}\text { No. of failures } \\
\text { (per } 1000 \text { vehicle) }\end{array}$ & $\begin{array}{l}\text { Number at } \\
\text { Risk }\end{array}$ & $\begin{array}{l}\text { Reliability } \\
\text { Function }\end{array}$ & \begin{tabular}{|l|} 
Density \\
Function
\end{tabular} & $\begin{array}{l}\text { Hazard rate } \\
\text { Function }\end{array}$ \\
\hline Pre-delivery & 0.07 & 999.93 & 0.9999 & 0.00007 & 0.00007 \\
\hline 1 & 0.61 & 999.32 & 0.9993 & 0.00061 & 0.00061 \\
\hline 2 & 1.70 & 997.62 & 0.9976 & 0.00170 & 0.00170 \\
\hline 3 & 1.97 & 995.65 & 0.9957 & 0.00197 & 0.00198 \\
\hline 4 & 1.79 & 993.86 & 0.9939 & 0.00179 & 0.00180 \\
\hline 5 & 1.33 & 992.53 & 0.9925 & 0.00133 & 0.00134 \\
\hline 6 & 1.50 & 991.03 & 0.9910 & 0.00150 & 0.00151 \\
\hline 7 & 0.86 & 990.17 & 0.9902 & 0.00086 & 0.00087 \\
\hline 8 & 0.89 & 989.28 & 0.9893 & 0.00089 & 0.00090 \\
\hline 9 & 0.85 & 988.43 & 0.9884 & 0.00085 & 0.00086 \\
\hline 10 & 0.74 & 987.69 & 0.9877 & 0.00074 & 0.00075 \\
\hline 11 & 0.85 & 986.84 & 0.9868 & 0.00085 & 0.00086 \\
\hline 12 & 0.53 & 986.31 & 0.9863 & 0.00053 & 0.00054 \\
\hline 13 & 0.48 & 985.83 & 0.9858 & 0.00048 & 0.00049 \\
\hline 14 & 0.38 & 985.45 & 0.9854 & 0.00038 & 0.00037 \\
\hline 15 & 0.39 & 985.06 & 0.9851 & 0.00039 & 0.00040 \\
\hline 16 & 0.22 & 984.84 & 0.9848 & 0.00022 & 0.00022 \\
\hline 17 & 0.25 & 984.59 & 0.9846 & 0.00025 & 0.00025 \\
\hline 18 & 0.22 & 984.37 & 0.9844 & 0.00022 & 0.00022 \\
\hline 19 & 0.12 & 984.25 & 0.9842 & 0.00012 & 0.00012 \\
\hline 20 & 0.10 & 984.15 & 0.9841 & 0.00010 & 0.00010 \\
\hline 21 & 0.14 & 984.01 & 0.9840 & 0.00014 & 0.00014 \\
\hline 22 & 0.18 & 983.83 & 0.9838 & 0.00018 & 0.00018 \\
\hline 23 & 0.09 & 983.74 & 0.9837 & 0.00009 & 0.00009 \\
\hline 24 & 0.10 & 983.64 & 0.9836 & 0.00010 & 0.00010 \\
\hline 25 & 0.12 & 983.52 & 0.9835 & 0.00012 & 0.00012 \\
\hline 26 & 0.06 & 983.46 & 0.9835 & 0.00006 & 0.00006 \\
\hline 27 & 0.07 & 983.39 & 0.9834 & 0.00007 & 0.00007 \\
\hline 28 & 0.09 & 983.30 & 0.9833 & 0.00009 & 0.00009 \\
\hline 29 & 0.06 & 983.24 & 0.9832 & 0.00006 & 0.00006 \\
\hline 30 & 0.08 & 983.16 & 0.9837 & 0.00008 & 0.00008 \\
\hline 31 & 0.02 & 983.14 & 0.9831 & 0.00002 & 0.00002 \\
\hline 32 & 0.06 & 983.08 & 0.9831 & 0.00006 & 0.00006 \\
\hline 33 & 0.07 & 983.01 & 0.9830 & 0.00007 & 0.00007 \\
\hline 34 & 0.05 & 982.96 & 0.9829 & 0.00005 & 0.00005 \\
\hline 35 & 0.01 & 982.95 & 0.9829 & 0.00001 & 0.00001 \\
\hline 36 & 0.03 & 982.92 & 0.9829 & & \\
\hline
\end{tabular}




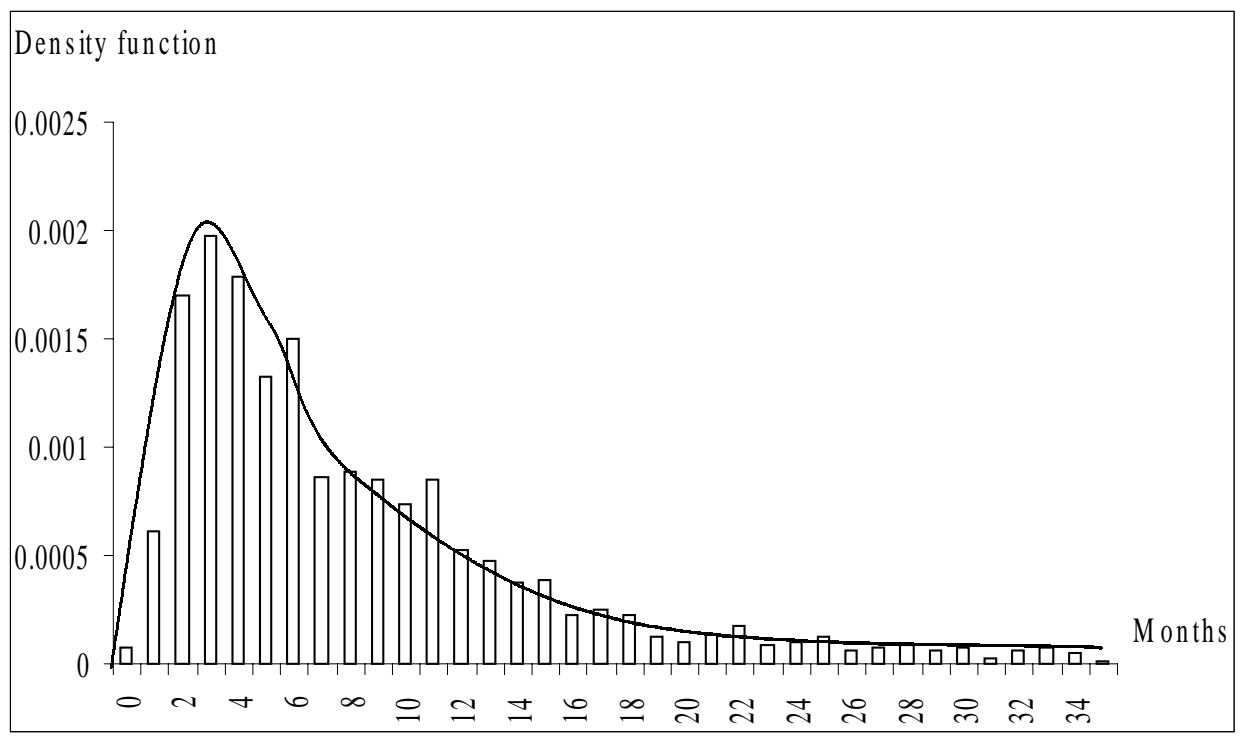

Figure 5.7 Empirical density function

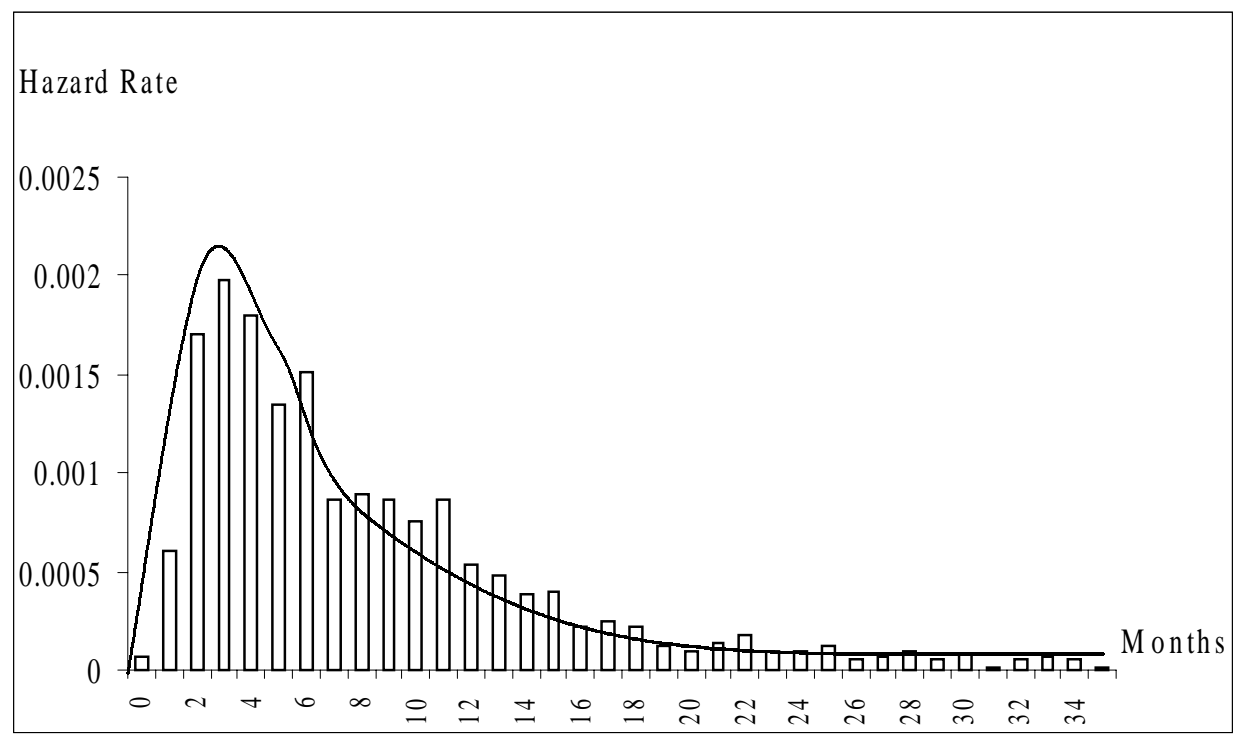

Figure 5.8. Empirical hazard rate function 


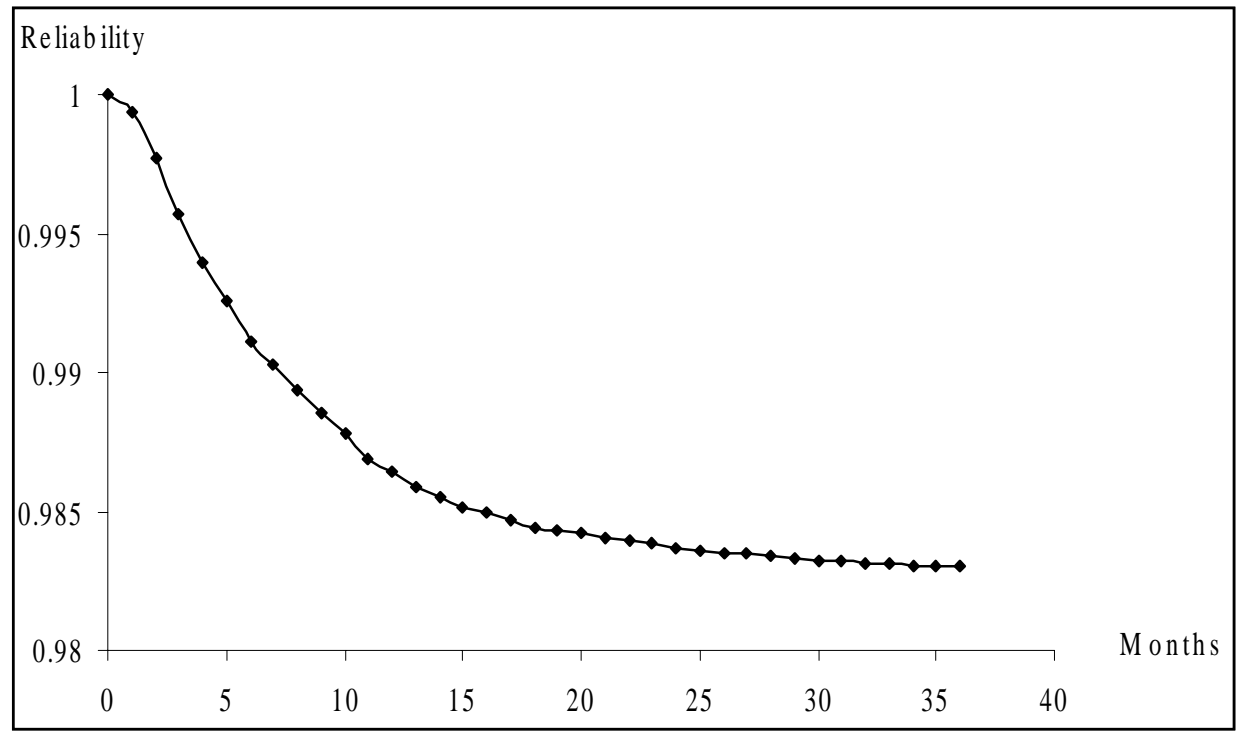

Figure 5.9 Empirical reliability function

Assume that the data come from a lognormal distribution function. The lognormal density is given by [Crowder et. al, 1994].

$$
f(t)=\frac{1}{\sqrt{2 \pi \sigma^{2} t^{2}}} e^{\frac{-(\log t-\mu)^{2}}{2 \sigma^{2}}}
$$

for $t>0$, where $\mu$ and $\sigma$ are the mean and standard deviation of $\log \left(t_{i}\right)$. First, the probability plotting will be performed in order to obtain the parameter estimates of the lognormal distribution. The probability plotting procedure for the lognormal distribution is identical to that used for the normal distribution except that $\log \left(t_{i}\right)$ values are used along the abscissa. Figure 5.10 plots $x=\log \left(t_{i}\right)$ vs. $z=\Phi^{-1}\left\{\hat{F}\left(t_{i}\right)\right\}$ where $\Phi$ is the standard Normal distribution function. The plot seems to be nonlinear suggesting that the lognormal model may be inadequate. The adequacy of the model can be further tested using some statistical methods such as the goodness of fit test or using graphical methods. 


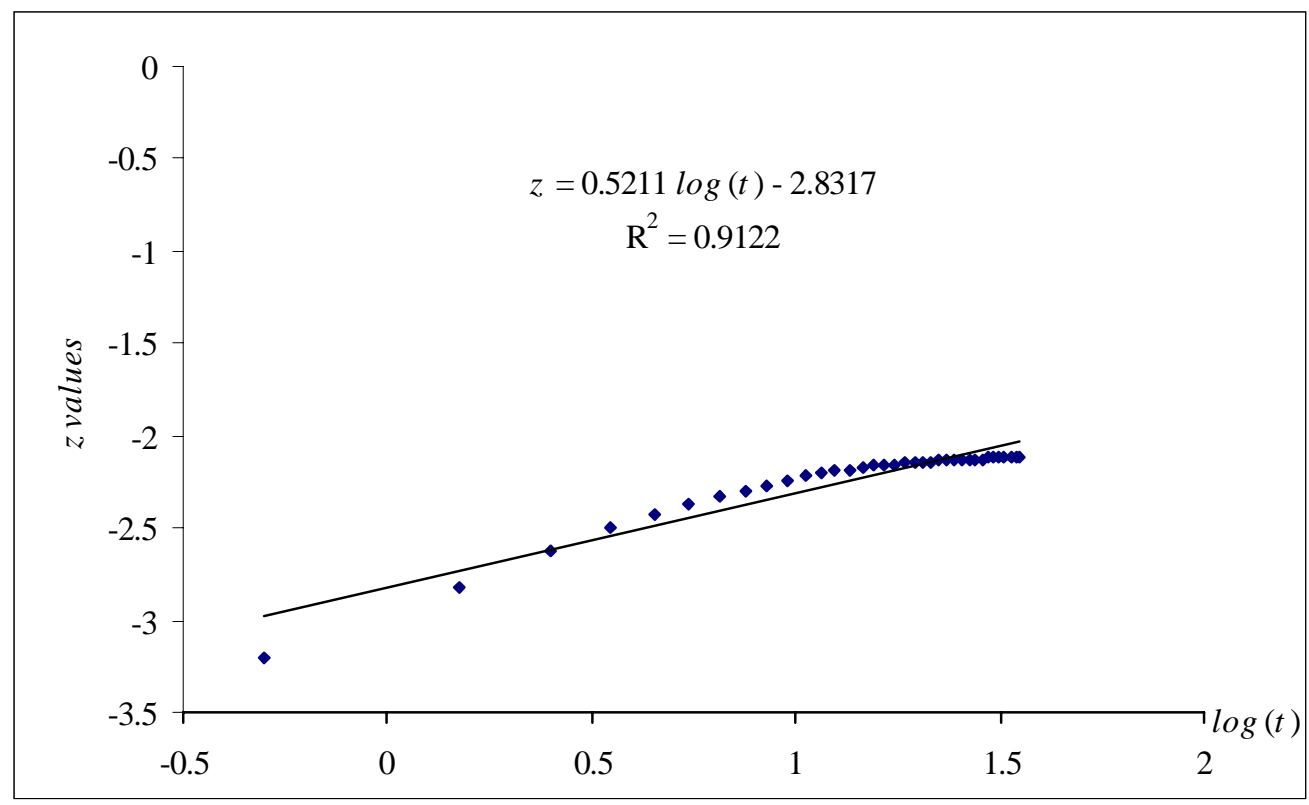

Figure 5.10 Lognormal plot for the part of an engine

If $a$ and $b$ are the slope and intercept of the linear least square estimates respectively, then the rough estimates of $\mu$ and $\sigma$ are [Crowder et. al. 1994]

$$
\begin{aligned}
& \hat{\mu}=\frac{-b}{a} \\
& \hat{\sigma}=\frac{1}{a}
\end{aligned}
$$

From the plot, the least square estimates of the slope and intercept are 0.521 and 2.83 respectively. Therefore

$$
\begin{aligned}
& \hat{\mu}=5.432 \\
& \hat{\sigma}=1.92
\end{aligned}
$$

Figure 5.11 shows the lognormal PP plot for the part of the engine. The nonlinearity indicates that the lognormal distribution is not an adequate model for this set of data as concluded earlier. If desired, more flexible and complex models may be fitted to the data. This approach won't be adopted here due to insufficiency of the data and to the complexity 
that would be encountered in the solution. In the following section, solution procedures based on the empirical functions will be presented. The solution procedures are similar to the ones given in Chapter 4. Here, the theoretical functions will be replaced with the corresponding empirical functions with simple modifications.

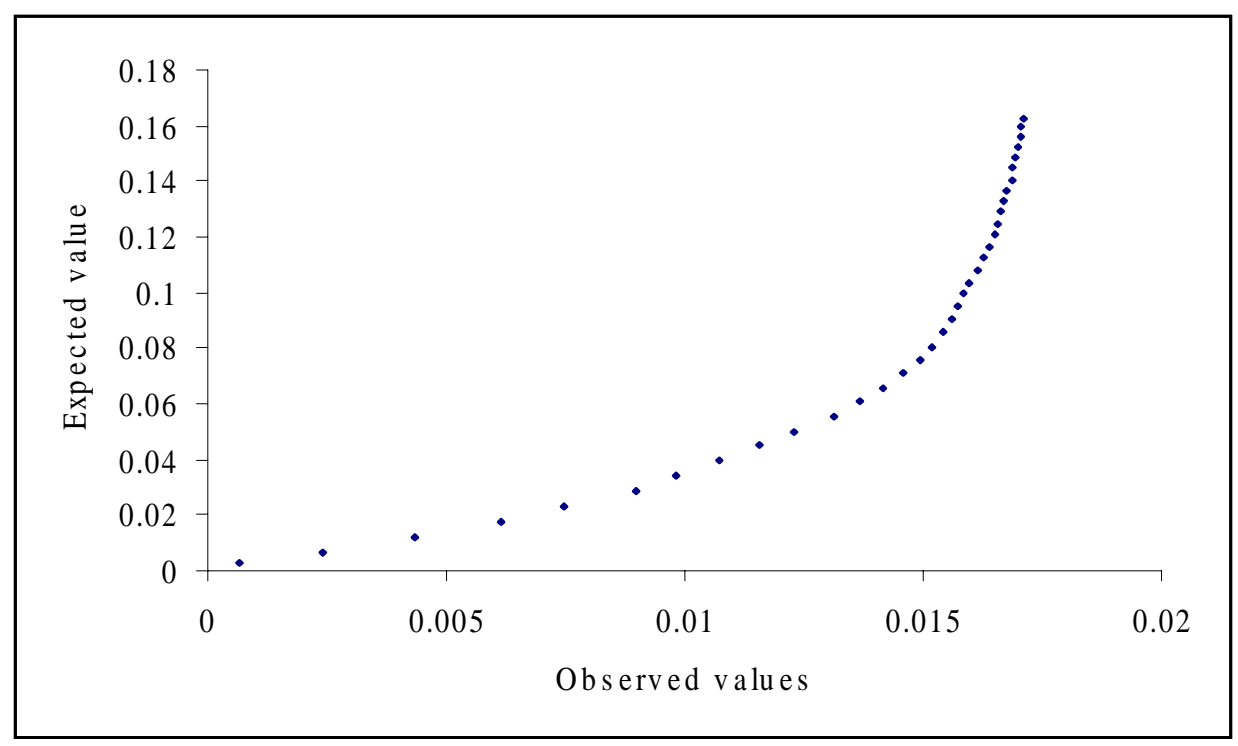

Figure 5.11 Lognormal probability-probability for the part of engine.

\subsubsection{Free Replacement Warranty for Repairable Products}

Failed items during burn-in and warranty periods are repaired by the seller, and the type of repair is minimal. The total unit cost for this policy is calculated as follows:

Manufacturing cost + fixed burn-in cost + (burn-in test cost per unit time $) *($ burn-in time $)+($ ave. no. of failures during burn-in time $) *($ repair cost $)+($ ave. no. of failures during warranty period $)^{*}($ repair cost + extra cost $)$

In order to calculate the total unit cost, the number of failures during both burn-in and warranty periods must be estimated. As stated earlier, the expected number of failures, $E[N(t)]$ in the interval $[a, b]$ for a known hazard rate function, $h(t)$ is given by 


$$
E[N(t)]=\int_{a}^{b} h(t) d t
$$

Let $\hat{h}_{i}$ be the empirical failure rate function in the $i^{\text {th }}$ interval. Then the approximate hazard rate at time $t$ can be obtained by using linear interpolation as

$$
\hat{h}(t)=\frac{\left(t_{i+1}-t\right) \hat{h}_{i}+\left(t-t_{i}\right) \hat{h}_{i+1}}{t_{i+1}-t_{i}} \quad \text { for } \quad t_{i} \leq t \leq t_{i+1} \text { and } i=1,2, \ldots k-1
$$

Here, $\hat{h}(t)$ is a piecewise linear empirical failure rate function. Figure 5.12 shows a typical realization of empirical hazard rate function.

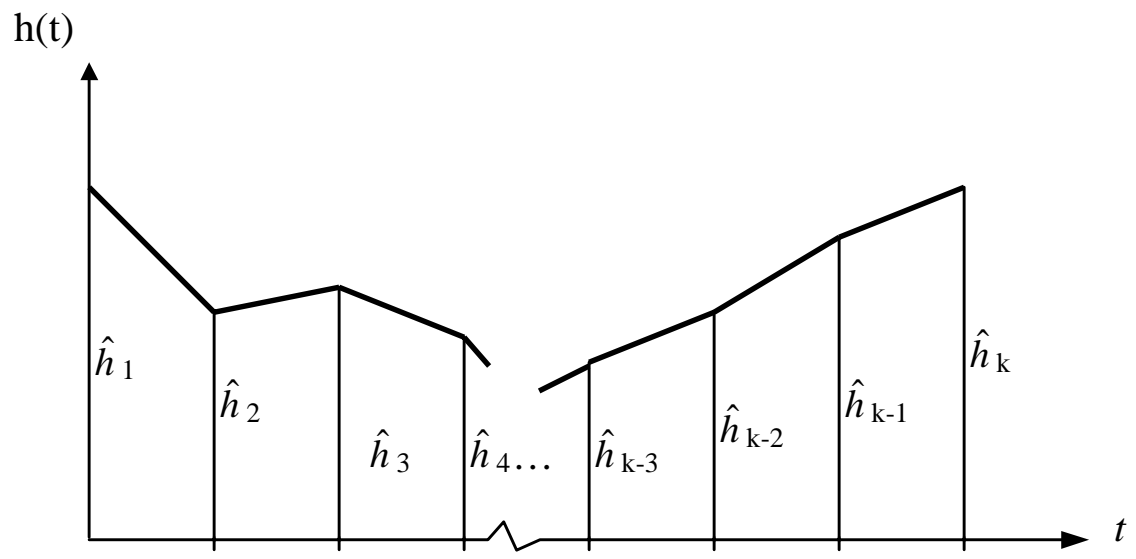

Figure 5.12 Empirical hazard rate function.

In the above integral, $h(t)$ will be replaced by $\hat{h}(t)$. The solution of the integral can be obtained using some numerical methods, and the result can be used later in estimating the total expected unit cost.

\subsubsection{Free Replacement Warranty for Nonrepairable Products:}

Failed items are replaced by the new ones during the burn-in and warranty period. The total unit cost is then simply 
(Manufacturing cost + fixed burn-in cost + expected burn-in test cost)*(no. of replacements $)+$ (no. of replacement during the warranty period)*(cost of each replacement + extra cost)

Since each replacement is identical, the number of replacements during the warranty periods is modeled as a renewal process. The expected number of renewals (replacements), $M(W)$ in the interval $[0, W]$ is given by the following renewal equation [Zhao and Rao, 1997]

$$
M(W)=\int_{0}^{W}(1+M(W-t)) f(t) d t
$$

where $f(t)$ is the failure density function. Let $\hat{f}_{i}$ be the empirical density function at the $i^{t h}$ interval, then point density estimate at time $t$ can be given by

$$
\hat{f}(t)=\frac{\left(t_{i+1}-t\right) \hat{f}_{i}+\left(t-t_{i}\right) \hat{f}_{i+1}}{t_{i+1}-t_{i}} \quad \text { for } \quad t_{i} \leq t \leq t_{i+1} \text { and } i=1,2, \ldots k-1
$$

In the above integral $f(t)$ will be replaced by $\hat{f}(t)$. The solution of the integral equation can be obtained iteratively. A method adopted by Zhao and Rao, [1997] will be used to solve the above integral equation. First, the interval $(0, W]$ will be divided into $N$ equal small intervals with the size of $\delta=W / N$.

$$
0=x_{0}<x_{1}<x_{2}<x_{3}<\ldots<x_{\mathrm{N}}=W
$$

At time zero, there is no renewal, thus;

$$
\hat{M}\left(x_{0}\right)=0,
$$

By using this as a starting point, $\hat{M}\left(x_{i}\right)$ is calculated recursively as follows:

$$
\hat{M}\left(x_{i}\right)=\delta \sum_{j}^{i}\left(1+\hat{M}\left(x_{i-j}\right)\right) \hat{f}\left(x_{j}\right) \quad \text { for } \quad i=1,2, \ldots, N
$$


where $\hat{f}\left(x_{j}\right)$ is obtained as described above.

\subsubsection{Pro-rata Warranty Policy for Nonrepairable Products}

When the item fails under the warranty, a refund is given to the customer. The total unit cost is then simply calculated as follows:

(Manufacturing cost + fixed burn-in cost + burn-in test cost $)^{*}($ no. of replacement $)+$ expected refund during the warranty period

The expected burn-in cost, $C_{B}$ and refund $C_{W}$ from equations (3.4) and (3.8) are given by

$$
\begin{aligned}
& C_{B}=\left[c_{m}+c_{1}+c_{2} \int_{0}^{B} R(t) d t\right] \frac{1}{R(B)} \\
& C_{W}=P\left[1-\frac{1}{W R(B)} \int_{0}^{W} R(t+B) d t\right]
\end{aligned}
$$

Let $\hat{R}\left(t_{i}\right)$ be the empirical reliability function at time $t_{i}$. Similarly, the point estimate of the reliability at time $t$ is given by

$$
\hat{R}(t)=\frac{\left(t_{i+1}-t\right) \hat{R}_{i}+\left(t-t_{i}\right) \hat{R}_{i+1}}{t_{i+1}-t_{i}}
$$

By replacing the empirical reliability function into cost functions, and using numerical methods the expected total unit cost can be easily estimated.

\subsubsection{Numerical Solution of the Problem}

In this section, the solution procedure based on the empirical functions will be illustrated for the data obtained from Ford Motor Company. The equipment is a part of an engine manufactured by Ford and is supplied by a vendor. Since customers purchase cars as 
whole rather than individual parts, the assumption that the price and warranty period affect sales for this particular product is somewhat unrealistic. However, if it is assumed that there are several vendors that supply similar products to several auto companies then the application of the models to this product may be justified.

The repair records show that the part has an average repair cost $\left(c_{3}\right)$ of $\$ 175$. There is no information available for other parameters. Consider that $c_{m}=\$ 300$ (the manufacturing $\operatorname{cost}$ ), $c_{1}=\$ 10$ (the fixed burn-in cost), $c_{2}=\$ 20$ per month (the burn-in test cost), $c_{4}=\$ 10$ (the extra cost during the warranty period), $a_{1}=-2.2$ (the price elasticity value) and $a_{2}=0.20$ (warranty elasticity value).

The optimal solution was obtained by using the computer program given in Appendix 7. The results for the optimal solution are given in Table 5.6. With the parameter values assumed, it was found that no burn-in test is necessary for this part, and the warranty period should be 36 months with a selling price of $\$ 556.00$.

Table 5.6 Result obtained with the optimal solution

\begin{tabular}{|c|c|c|c|}
\hline Burn-in time & 0 & & \\
\hline Warranty period & 36 moths & & \\
\hline Selling Price & & & $\$ 556.00$ \\
\hline Expected number of sales & 186 & & \\
\hline Expected number of failures & 0.01723 & & \\
\hline Manufacturing cost & & $\$ 300.00$ & \\
\hline Expected warranty cost & & $\$ 3.19$ & \\
\hline Expected total unit cost & & $\$ 303.19$ & \\
\hline Expected revenue & & & $\$ 103416$ \\
\hline Expected total cost & & $\$ 56393.34$ & \\
\hline Expected total profit & & & $\$ 47022.66$ \\
\hline
\end{tabular}


A surface plot is given in Figure 5.13 for the expected profit as a function of the warranty period and the price when the burn-in time is zero. The plot shows that the expected profit is influenced more by the selling price than by the warranty period, which is expected. The profit function tends to be flat near the optimal solution. This means that, near the optimal solution, the expected profit is not sensitive to changes in selling price or warranty period, which suggests that the manufacturer may choose from different pricewarranty policies with no substantial decrease in the expected profit.

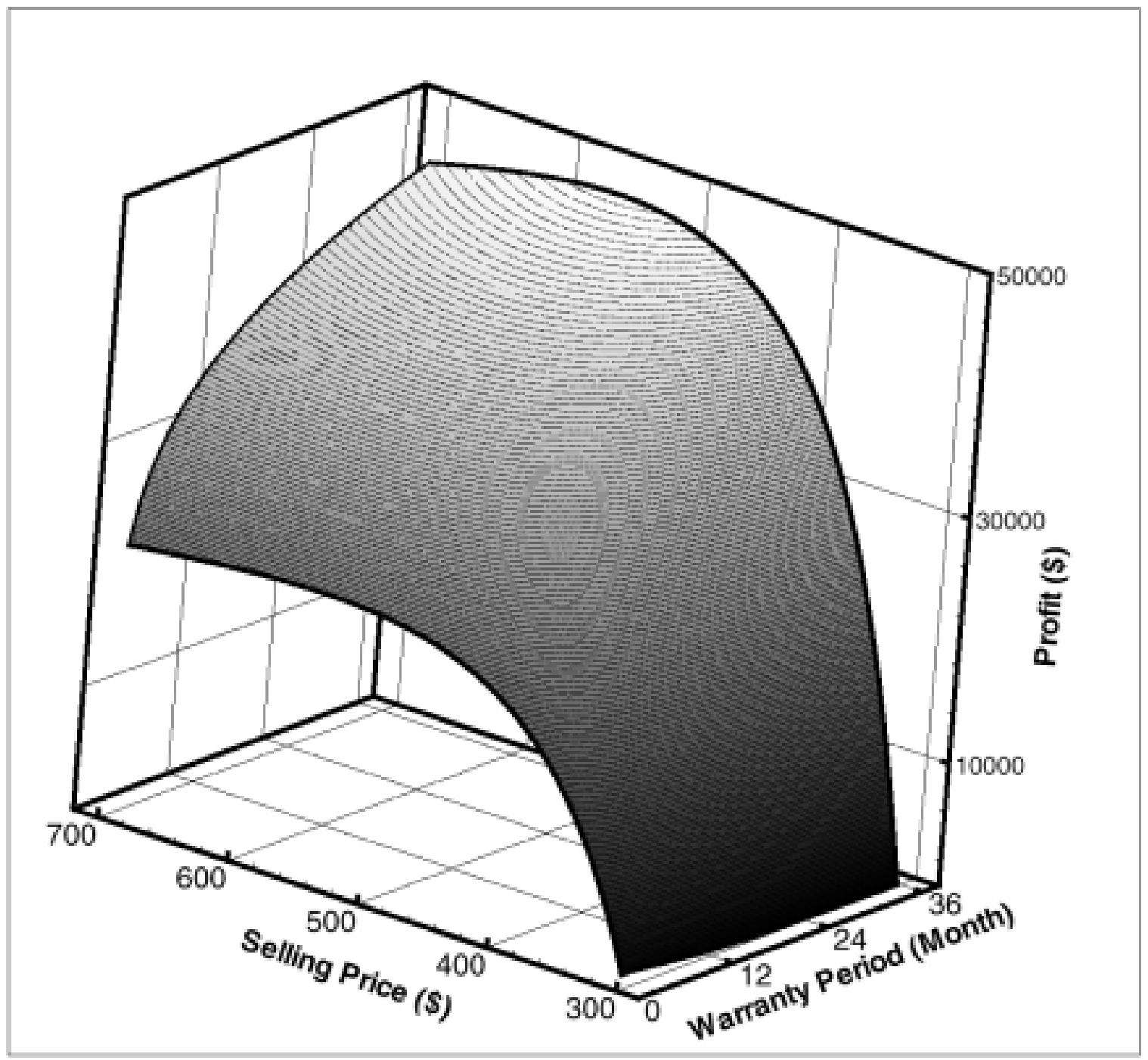

Figure 5.13 Profit as a function of warranty period and price when burn-in time is zero 


\section{CHAPTER 6}

\section{CONLUSIONS AND EXTENSIONS}

This research studies the problem of joint determination of the optimal selling price, warranty period and burn-in time for a product sold with a warranty. It is explicitly assumed that the selling price of a product, and warranty period have a significant effect on sales. A simple multiplicative form has been chosen to model the sales as a function of price and warranty period. Both repairable and nonrepairable products have been investigated for two types of warranty policies. For the repairable case, failures during the burn-in and warranty periods are repaired by the seller with no charge to customers and the type of repair is minimal. For the nonrepairable case, two warranty policies were considered. In the first model, the seller replaces any failed product with an identical one with no charge to the customer; in the second, a rebate, which is calculated based on the age of the item at the time of failure, is given to customers. The main objective of the seller is to maximize profit.

Although the literature on warranty analysis is extensive, the joint determination of price, warranty period, and burn-in time could not be found. The purpose of this research was to develop decision models that incorporate the marketing aspect of warranty and product reliability in order to help sellers to design an effective warranty program.

The models developed can be used with any lifetime distribution function, however analytical solutions are possible for only simple lifetime distribution functions. Numerical methods were used to obtain optimal solutions. Three parametric lifetime distribution functions were chosen to illustrate the application of the models. When the lifetime distribution and its parameter(s) are unknown, a nonparametric solution procedure similar to 
the parametric one was suggested. Two sets of real failure data were used to illustrate both parametric and nonparametric solution procedures.

The number of failures during the warranty period must be calculated in order to estimate the warranty cost. For nonrepairable products, the number of failures during the warranty period exhibits a renewal process. A simple renewal function approximation based on empirical functions was used to find the expected number of replacements.

Several future researches can be recommended as an extension of this study. In this research, it was assumed that the sales depend mainly on the price and warranty period. An extension may be made with the inclusion of other marketing mix variables such as advertising and distribution.

The models developed in this research assumed that all cost parameters are known and fixed. However, in most real world problems, these cost parameters are random variables. One needs to incorporate this randomness into the model formulations.

It was also assumed that all warranty claims are valid and exercised. One may consider the case where some customers may not make the warranty claims when the product fails under the warranty. In this case, the warranty claims can be treated as a random variable with a distribution function.

There are several warranty policies in practice. Only free replacement warranty and pro-rata warranty was considered here. A possible extension would be to consider a combination warranty where two or more FRW and/or PRW policies are used. Also this research has been limited to one-dimensional warranty policies. Two-dimensional warranties as in the automobile warranties are widely used in practice, thus the investigation of the twodimensional warranties could be worthwhile. 
For repairable products this research only considered minimal repair. Future research might consider different types of repair action such as imperfect repair.

Warranty claims occur in the future. Thus the real warranty cost will be discounted due to the time value of money. One might incorporate the time value of money into the model formulations. 


\section{REFERENCES}

Anderson, E.E. (1977), "Product price and warranty terms: an optimization model", Operations Research Quarterly, 28, 731-741.

Amato, H.N., Anderson, E.E, and Harvey, D.W. (1976),”A general model of future period warranty costs", The accounting Review LI, 4, 854-862.

Balachandran, K.R., Maschmeyer, R. A. and Livingstone, J. L. (1981), "Product warranty period: A Markovian approach to estimation and analysis of repair and replacement costs”, The accounting Review LVI, 1, 115-123.

Balcer, Y, and Sahin, I. (1986), "Replacement costs under warranty: Cost moments and time variability", Operations Research, 34, 4, 554-559.

Blair, M. E. and Innis, D. E. (1996) "The effects of product knowledge on the evaluation of warranteed brands" Psychology and Marketing, 13, 5, 445-456.

Blischke, W.R., and Murthy, D.N.P. (1996), Product Warranty Handbook. New York: Marcel Dekker.

Blischke, W.R., and Murthy, D.N.P. (1992), "Product warranty management -I: A taxonomy for warranty policies”, European Journal of Operations Research, 62, 127-148.

Blischke, W.R. and Scheuer, E.M. (1975), "Calculation of the cost of warranty policies as a function of estimated life distribution", Naval Research Logistics, 22, 4, 681-696.

Blischke, W.R. and Scheuer, E.M. (1981), “Applications of renewal theory in analysis of the free replacement warranty" Naval Research Logistics, 28, 193-205.

Brennan, R. J. (1994), Warranties: Planning, Analysis, and Implementation. New York: McGraw Hill.

Birolini, A. (1994), Quality and Reliability of Technical Systems. Berlin: Springer-Verlag. 
Chou, K., and Thang, K. (1992), "Burn-in time and estimation of change point with weibullexponential mixture distribution" Decisions Sciences, 23, 973-990.

Chun, Y.H., and Tang, K. (1995), "Determining the optimal warranty price based on producer and customers' risk preferences", European Journal of Operational Research, 85, 97-110.

Crowder, M. J., Kimber, A. C., Smith, R. L. and Sweeting, T.J. (1994) Statistical Analysis of Reliability Data. London: Chapman \& Hall.

Ebeling, C.E. (1997), Reliability and Maintainability Engineering. New York: McGraw-Hill.

Eliashberg, J., Singpurwalla, N.D., and Wilson, S.P. (1997), "Calculating the reserve for a time and usage indexed warranty", Management Science, 43, 7, 966-975.

Frees, E.W. (1986), "Warranty analysis and renewal function estimation", Naval Research Logistics Quarterly, 33, 361-372.

Frees, E.W., and Nam, S.H. (1988), “Approximating expected warranty costs”, Management Science, 34, 1441-1449.

Glickman, T.S., and Berger, P.D. (1976), "Optimal price and protection period decision for a product under warranty", Management Science, 22, 12, 1381-1390.

Hanssens, D.M., Parsons, L.J., and Schultz, R.L. (1990), Market Respond Models: Econometric and Time Series Analysis. Boston: Kluwer Academic.

Jensen, F. and Petersen, N. E. (1982) Burn-in: An Engineering Approach to the Design and Analysis of Burn-in Procedure, Chichester: John Wiley \& Sons.

Juran, J. and Gryna, F. (1970) Quality planning and Analysis. New York: McGraw-Hill Kao, E.P., and Smith, M.S. (1993), "Discounted and per unit revenues and cost of product warranty: the case of phase type lifetime”, Management Science, 39, 10, 1246-1255. 
Kececioglu, D. (1993) Reliability and Life Testing Handbook. New Jersey: Prentice Hall.

Lie, C. H. and Chun, Y. H. (1987), "Optimum Single-Sample Inspection Pans for Products Sold Under Free and Rebate Warranty”, IEEE Transaction on Reliability, R-36, 5, 634637.

Mamer, J.W. (1982), "Cost analysis of pro-rata and free replacement warranties", Naval Research Logistics Quarterly, 29, 2, 345-356.

Mamer, J.W. (1987), "Discounted and per unit costs of product warranty", Management Science, 33, 7, 916-930.

Menezes, M.A.J., and Currim, I.S. (1992), “An approach for determination of warranty length”, International Journal of Research in Marketing, 9, 177-195.

Mesak, H.I. (1996), "Modeling monopolist pricing and protection period decision for new product under warranty", Optimal Control Applications and Methods, 17, 231-252.

Mi, J. (1997), “Warranty policies and burn-in”, Naval Research Logistics 44, 199-209.

Mitra, A., and Patankar, J.G. (1993), "An Integrated multicriteria model for warranty cost estimation and production", IEEE Transaction on Engineering Management, 40, 3, 300311.

Murthy, D.N.P. (1992), “A usage dependent model for warranty costing”, European Journal of Operations Research, 57, 1, 89-99.

Murthy, D.N.P., and Blischke, W.R. (1992), "Product warranty management -II: An integrated framework for study", European Journal of Operations Research, 62, 261281.

Murthy, D.N.P., and Blischke, W.R. (1992), "Product warranty management -III: A review of mathematical models", European Journal of Operations Research, 62, 1-34. 
Murthy, D.N.P., Iskandar, B.P., and Wilson, R.J. (1995), "Two-dimensional failure free warranty policies: Two-dimensional point process models", Operations Research, 43, 2, 356-366.

Nguyen, D.G., and Murthy, D.N.P. (1982), "Optimal burn-in time to minimize cost for products sold under warranty", IIE Transactions, 14, 167-174.

Nguyen, D.G., and Murthy, D.N.P. (1984a), “A general model for estimating warranty costs for repairable products", IIE Transactions, 16, 379-386.

Nguyen, D.G., and Murthy, D.N.P. (1984b), "Cost analysis of warranty policies", Naval Research Logistics, 31, 525-541.

Nguyen, D.G., and Murthy, D.N.P. (1986), “An optimal policy for serving warranty”, Operational Research Society, 37, 11, 1081-1088.

Nguyen, D.G., and Murthy, D.N.P. (1988), “Optimal reliability allocation for products sold under warranty", Engineering Optimization, 13, 35-45.

Patankar, J.G., and Mitra, A. (1989), “A multi objective model for warranty cost estimation using multiple products", Computers Operations research, 16, 4, 341-351.

Ritchken, P.H., and Tapiero, C.S. (1986), "Warranty design under buyer and seller risk aversion”, Naval Research Quarterly, 33, 657-671.

Ross, S.H. (1970), Applied Probability Models with Optimization Applications. San Francisco: Holden-Day.

Tapiero, C.S, and Posner, M.J. (1988), "Warranty reserving”, Naval Research Logistics Quarterly, 35, 473-479.

Thomas, M.U. (1983), “Optimal warranty policies for non-repairable products”, IEEE Transactions on Reliability, R-32, 3, 282-288. 
Thomas, M.U. (1989), “A prediction model for manufacturer warranty reserves", Management Science, 35, 1515-1519.

Wiener, J.L. (1985), “Are warranties accurate signals of product reliability”, Journal of Consumer Research, 12, 245-250.

Zhoa, Q and Rao, S.S. (1997) "Nonparametric renewal function estimation based on estimated densities", Asia-Pacific Journal of Operational Research, 14, 115-126. 
APPENDICES 


\section{Appendix 1: The expected burn-in time for non-repairable products}

The expected time spent in the burn-in test is given as

$$
E[t]=\int_{0}^{B} t f(t) d t+\int_{B}^{\infty} B f(t) d t
$$

Since

$$
f(t)=-\frac{\mathrm{d} R(t)}{\mathrm{d} t}
$$

It becomes

$$
E[t]=-\int_{0}^{B} t \mathrm{~d} R(t)-\int_{B}^{\infty} B \mathrm{~d} R(t)
$$

Using integration by parts

$$
\begin{aligned}
& E[t]=-\left.t R(t)\right|_{0} ^{B}+\int_{0}^{B} R(t) \mathrm{d} t-B\left[\left.R(t)\right|_{B} ^{\infty}\right] \\
& E[t]=-B R(B)+\int_{0}^{B} R(t) \mathrm{d} t-B[R(B)-0] \\
& E[t]=\int_{0}^{B} R(t) \mathrm{d} t
\end{aligned}
$$


Appendix 2: Expected time to first failure during the warranty period after the burn-in period of $B$ (Pro-rata warranty)

$$
\begin{aligned}
& \mu_{B}(W) \text { is defined as } \\
& \mu_{B}(W)=\int_{0}^{W} t f_{B}(t) d t
\end{aligned}
$$

where $f_{B}(t)$ is the conditional probability density function

$$
f_{B}(t)=\frac{f(B+t)}{R(B)}
$$

Substituting into the above integral,

$$
\mu_{B}(W)=\frac{1}{R(B)} \int_{0}^{W} t f(B+t) d t
$$

Using integration by parts yields

$$
\begin{aligned}
& \mu_{B}(W)=\frac{1}{R(B)}\left[\left.t F(B+t)\right|_{0} ^{W}-\int_{0}^{W} F(B+t) d t\right] \\
& =\frac{1}{R(B)}\left[W F(B+W)-\int_{0}^{W} F(B+t) d t\right]
\end{aligned}
$$


Appendix 3: Partial derivative of expected unit burn-in cost with respect to burn-in time (Non-repairable case)

The expected burn-in cost from (3.4)

$$
C_{B}=\left[c_{m}+c_{1}+c_{2} \int_{0}^{B} R(t) d t\right] \frac{1}{R(B)}
$$

Differentiating with respect to $B$ yields

$$
\frac{\partial C_{B}}{\partial B}=c_{2} \frac{\partial \int_{0}^{B} R(t) d t}{\partial B} \frac{1}{R(B)}+\left[c_{m}+c_{1}+c_{2} \int_{0}^{B} R(t) d t\right] \frac{-\partial R(B) / \partial B}{R(B)^{2}}
$$

where by using Leibnetz formula

$$
\begin{aligned}
& \frac{\partial \int_{0}^{B} R(t) d t}{\partial B}=R(B) \\
& \frac{\partial R(B)}{\partial B}=-f(B)
\end{aligned}
$$

Substitution yields

$$
\frac{\partial C_{B}}{\partial B}=c_{2} R(B) \frac{1}{R(B)}+\left[c_{m}+c_{1}+c_{2} \int_{0}^{B} R(t) d t\right] \frac{f(B)}{R(B)^{2}}
$$

The failure rate function is defined as

$$
h(B)=\frac{f(B)}{R(B)}
$$

Hence

$$
\begin{aligned}
\frac{\partial C_{B}}{\partial B} & =c_{2}+\left[c_{m}+c_{1}+c_{2} \int_{0}^{B} R(t) d t\right] \frac{1}{R(B)} h(B) \\
& =c_{2}+C_{B} h(B)
\end{aligned}
$$


Appendix 4: Partial Derivative of Expected total unit cost with respect to burn-in time (non-repairable products)

The expected total cost

$$
\begin{aligned}
& C=C_{B}+C_{W} \\
& \frac{\partial C}{\partial B}=\frac{\partial C_{B}}{\partial B}+\frac{\partial C_{W}}{\partial B}
\end{aligned}
$$

From Appendix 3,

$$
\frac{\partial C_{B}}{\partial B}=c_{2}+C_{B} h(B)
$$

From (3.8)

$$
C_{W}=P\left[1-\frac{1}{W R(B)} \int_{0}^{W} R(t+B) d t\right]
$$

and

$$
\frac{\partial C_{W}}{\partial B}=P\left[-\frac{f(B)}{W R(B)^{2}} \int_{0}^{W} R(t+B) d t-\frac{1}{W R(B)} \frac{\partial}{\partial B} \int_{0}^{W} R(t+B) d t\right]
$$

From Leibnetz formula

$$
\frac{\partial}{\partial B} \int_{0}^{W} R(t+B) d t=\int_{0}^{W} \frac{\partial}{\partial B} R(t+B) d t+0+0
$$

where

$$
\frac{\partial}{\partial B} R(t+B)=-f(t+B)
$$

Hence 


$$
\begin{aligned}
\frac{\partial}{\partial B} \int_{0}^{W} R(t+B) d t & =\int_{0}^{W}-f(t+B) d t \\
& =-[F(B+W)-F(B)]
\end{aligned}
$$

Substitution yields

$$
\begin{aligned}
\frac{\partial C_{W}}{\partial B} & =P\left[-\frac{h(B)}{W R(B)} \int_{0}^{W} R(t+B) d t+\frac{1}{W R(B)}[F(B+W)-F(B)]\right] \\
& =\frac{P}{W R(B)}\left[F(B+W)-F(B)-h(B) \int_{0}^{W} R(t+B) d t\right]
\end{aligned}
$$

Therefore

$$
\frac{\partial C}{\partial B}=c_{2}+C_{B} h(B)+\frac{P}{W R(B)}\left[F(B+W)-F(B)-h(B) \int_{0}^{W} R(t+B) d t\right]
$$


Appendix 5: The optimal warranty period under pro-rata warranty (the exponential case)

$$
W^{*}=\frac{C}{\frac{P}{W^{* 2}\left[\int_{0}^{W^{*}} R(t) d t-W^{*} R\left(W^{*}\right)\right]}}\left(\frac{a_{1}}{a_{1}+\frac{1}{W^{*}} \int_{0}^{W^{*}} R(t) d t}-1\right) a_{2}
$$

where

$$
\begin{aligned}
& C=c_{m}+P\left[1-\frac{1}{\lambda W}\left(1-e^{-\lambda W}\right)\right] \\
& P^{*}=c_{m} \frac{a_{1} \lambda W^{*}}{\left(a_{1}+1\right)\left(1-e^{-\lambda W^{*}}\right)} \\
& \int_{0}^{W^{*}} R(t) d t=\frac{1}{\lambda}\left(1-e^{-\lambda W^{*}}\right) \\
& R(W)=e^{-\lambda W^{*}}
\end{aligned}
$$

Substituting $P$ into $C$

$$
C=c_{m} \frac{a_{1} \lambda W^{*}+1-e^{-\lambda W^{*}}}{\left(a_{1}+1\right)\left(1-e^{-\lambda W^{*}}\right)}
$$

Substituting all yields

$$
\begin{gathered}
W^{*}=\frac{c_{m} \frac{a_{1} \lambda W^{*}+1-e^{-\lambda W^{*}}}{\left(a_{1}+1\right)\left(1-e^{-\lambda W^{*}}\right)}}{c_{m} \frac{a_{1} \lambda W^{*}}{\left(a_{1}+1\right)\left(1-e^{-\lambda W^{*}}\right) W^{* 2}}\left(\frac{1}{\lambda}\left(1-e^{-\lambda W^{*}}\right)-W^{*} e^{-\lambda W^{*}}\right)}\left(\frac{a_{1} \lambda W^{*}}{a_{1} \lambda W^{*}+1-e^{-\lambda W^{*}}}-1\right) a_{2} \\
W^{*}=\frac{e^{-\lambda W^{*}}-1}{\frac{a_{1} \lambda}{W^{*}}\left(\frac{1}{\lambda}\left(1-e^{-\lambda W^{*}}\right)-W^{*} e^{-\lambda W^{*}}\right)} a_{2}
\end{gathered}
$$




$$
\begin{aligned}
& a_{1} \lambda\left(\frac{1}{\lambda}\left(1-e^{-\lambda W^{*}}\right)-W^{*} e^{-\lambda W^{*}}\right)=\left(e^{-\lambda W^{*}}-1\right) a_{2} \\
& e^{-\lambda W^{*}}\left(a_{1}+a_{1} \lambda W^{*}+a_{2}\right)=a_{1}+a_{2}
\end{aligned}
$$




\section{Appendix 6: The computer program used when the failure time distribution is known}

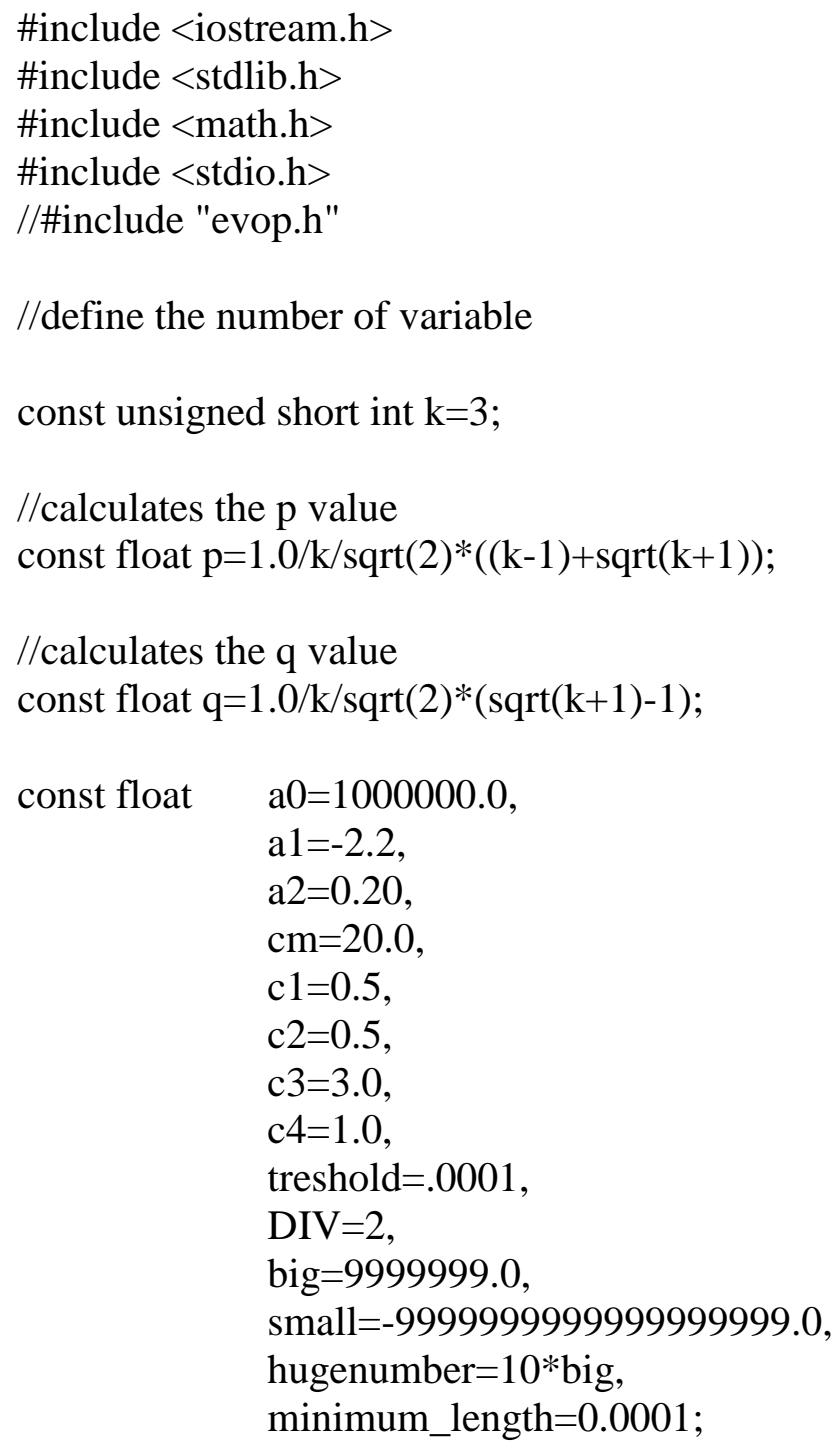

double

$\mathrm{R}$,

$\mathrm{a} 1, \mathrm{a} 2$,

step1,

step2,

min, max,

$x \min [k]=\{0,0,0\}$,

$\mathrm{x} \max [\mathrm{k}]=\{$ big, big, big $\}$,

$\mathrm{b}=1$,

$\mathrm{t}=1$,

$\mathrm{CP}=$ big,

$\mathrm{x} 1=-1$, 


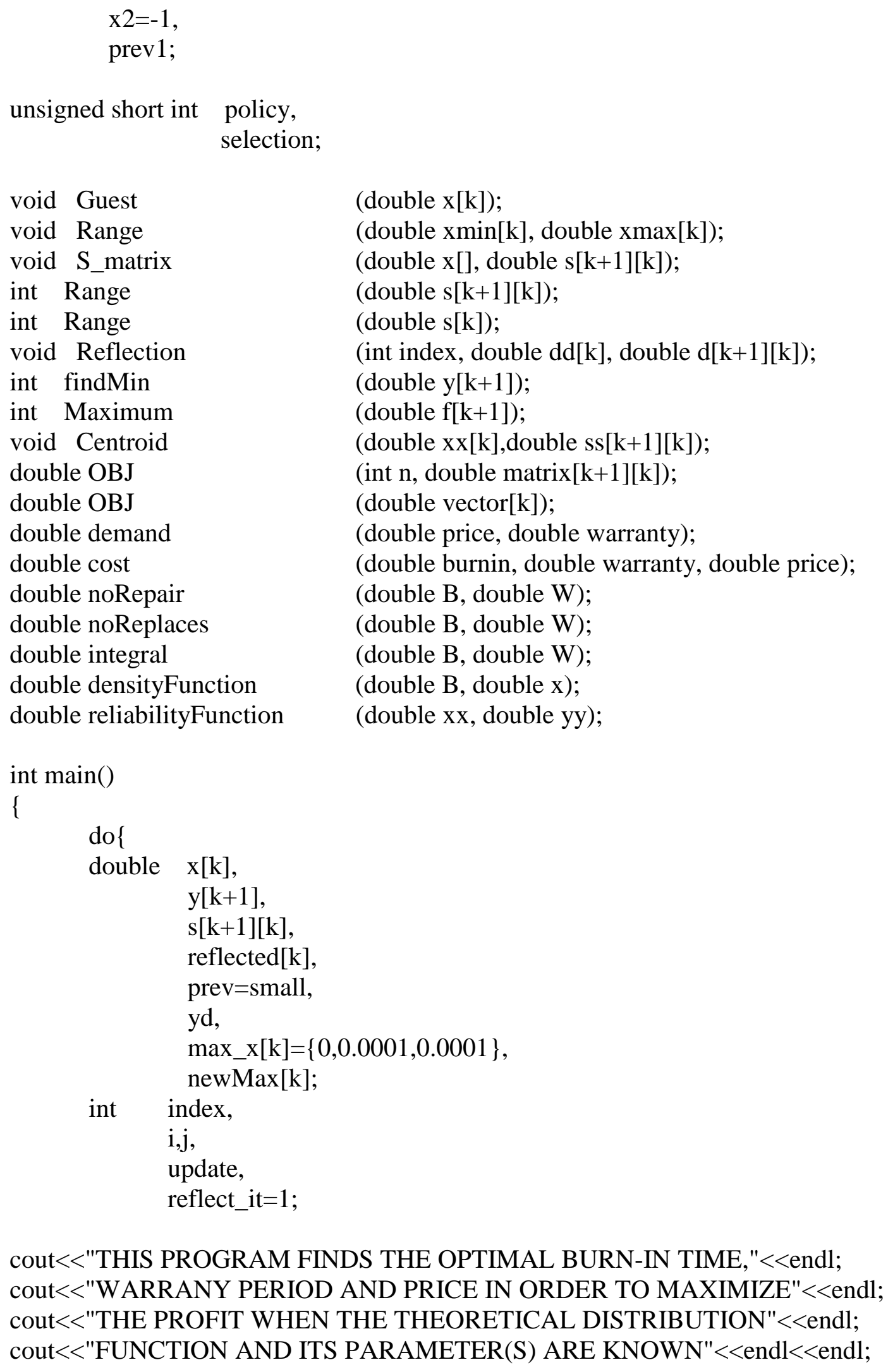

cout<<"THIS PROGRAM FINDS THE OPTIMAL BURN-IN TIME,"<<endl; cout $<<$ "WARRANY PERIOD AND PRICE IN ORDER TO MAXIMIZE"<<endl; cout $<<"$ THE PROFIT WHEN THE THEORETICAL DISTRIBUTION"<<endl; cout<<"FUNCTION AND ITS PARAMETER(S) ARE KNOWN"<<endl<<endl; 
cout $<<$ "THE FOLLOWING DISTRIBUTION FUNCTIONS ARE AVAILABLE"<<endl;

cout $<<" \backslash n \backslash n[1]$ EXPONENTIAL DISTRIBUTION\n";

cout $<<"[2]$ TWO-PARAMETER WEIBULL DISTRIBUTION"<<endl;

cout<<"[3] WEIBULL-EXPONENTIAL MIXTURE DISTRIBUTION"<<endl;

do \{

cout $<<"$ \n\nPlease enter your selection...:";

cin $>>$ selection;

switch(selection)

\{

case 1:

$\mathrm{b}=1$;

cout $<<" \backslash$ nPlease enter the mean time to failure (MTTF) :";

$\operatorname{cin}>>t$;

cout $<<" \ln \backslash n "$;

break;

case 2: cout $<<$ "InPlease enter the shape parameter (BETA) :";

cin $>>b$;

cout $<<$ "InPlease enter the scale parameter (TETA) :";

$\operatorname{cin}>>t$;

cout $<<" \ln \backslash n "$

break;

case 3: cout <<"|nPlease enter the shape parameter (BETA) :";

$\operatorname{cin}>>b$;

cout $<<" \backslash$ nPlease enter the scale parameter (TETA) :";

$\operatorname{cin}>>t$;

cout $<<" \backslash$ nPlease enter the change point............:";

$\operatorname{cin}>>\mathrm{CP}$;

cout $<<" \ln \backslash n "$;

break;

default:selection $=-1$;

\}

while (selection=-1);

cout<<"THE TYPE OF WARRANTY POLICY\n\n";

cout $<<"[1]$ : Free Replacement warrantyln";

cout $<<"[2]$ : Pro-rata Warranty $\backslash n \backslash n "$;

cout $<<$ "Please enter your choice :";

cin $>>$ policy;

if $($ policy $==1)\{$

cout $<<" \backslash n \backslash n T H E$ TYPE OF REMEDY ACTION\n\n";

cout $<<"[1]$ Repair upon failure $\backslash n "$;

cout $<<"[2]$ Replace upon failure $\backslash n \backslash n "$;

cout $<<$ "Please enter your choice :";

cin $>>$ policy;

\} 
else

$$
\text { policy }=3 \text {; }
$$

Range(xmin, $x \max )$;

Guest(x);

cout $<<" \backslash n \backslash n P l e a s e$ enter the length of the step : ";

cin>>step1;

step2=step1;

cout $<<" \backslash n \backslash n P l e a s e$ enter price elasticity :";

cin $>>$ a1;

cout $<<" \backslash n \backslash n$ Please enter warranty elasticity :";

$\operatorname{cin}>>\mathrm{a} 2$

long int control,sayac $=0$;

do \{

$$
\mathrm{R}=(\mathrm{p} * \text { step } 1+(\mathrm{k}-1) * \mathrm{q} * \text { step } 1) /(\mathrm{k}+1)
$$

$\mathrm{S} \_$matrix $(\mathrm{x}, \mathrm{s})$;

while (!Range(s)) \{

step1=step1/DIV;

$\mathrm{R}=(\mathrm{p} *$ step $1+(\mathrm{k}-1) * \mathrm{q} *$ step 1$) /(\mathrm{k}+1)$;

S_matrix $(\mathrm{x}, \mathrm{s})$;

\}

for $(\mathrm{i}=0 ; \mathrm{i}<\mathrm{k}+1 ; \mathrm{i}++)$

$\mathrm{y}[\mathrm{i}]=\mathrm{OBJ}(\mathrm{i}, \mathrm{s})$;

do \{

sayac++;

if(sayac $>30)$

break;

index $=$ findMin $(y)$;

// The objective densityFunction approaches to infinity

// if minimum value is greater than specified value

if $(\mathrm{min}>\mathrm{big})\{$

cout $<<"$ "nOBJECTIVE FUNCTION APPROACHING INFINITY";

\} exit(1);

Reflection(index,reflected,s);

if (Range(reflected) \{

$\mathrm{yd}=\mathrm{OBJ}($ reflected $)$;

if $(\mathrm{yd}>\min )\{$

reflect_it $=1$;

for $(\mathrm{j}=0 ; \mathrm{j}<\mathrm{k} ; \mathrm{j}++)$

$s[$ index $][j]=$ reflected $[\mathrm{j}]$;

$\mathrm{y}[$ index $]=\mathrm{yd}$;

\}

else

reflect_it $=0$; 


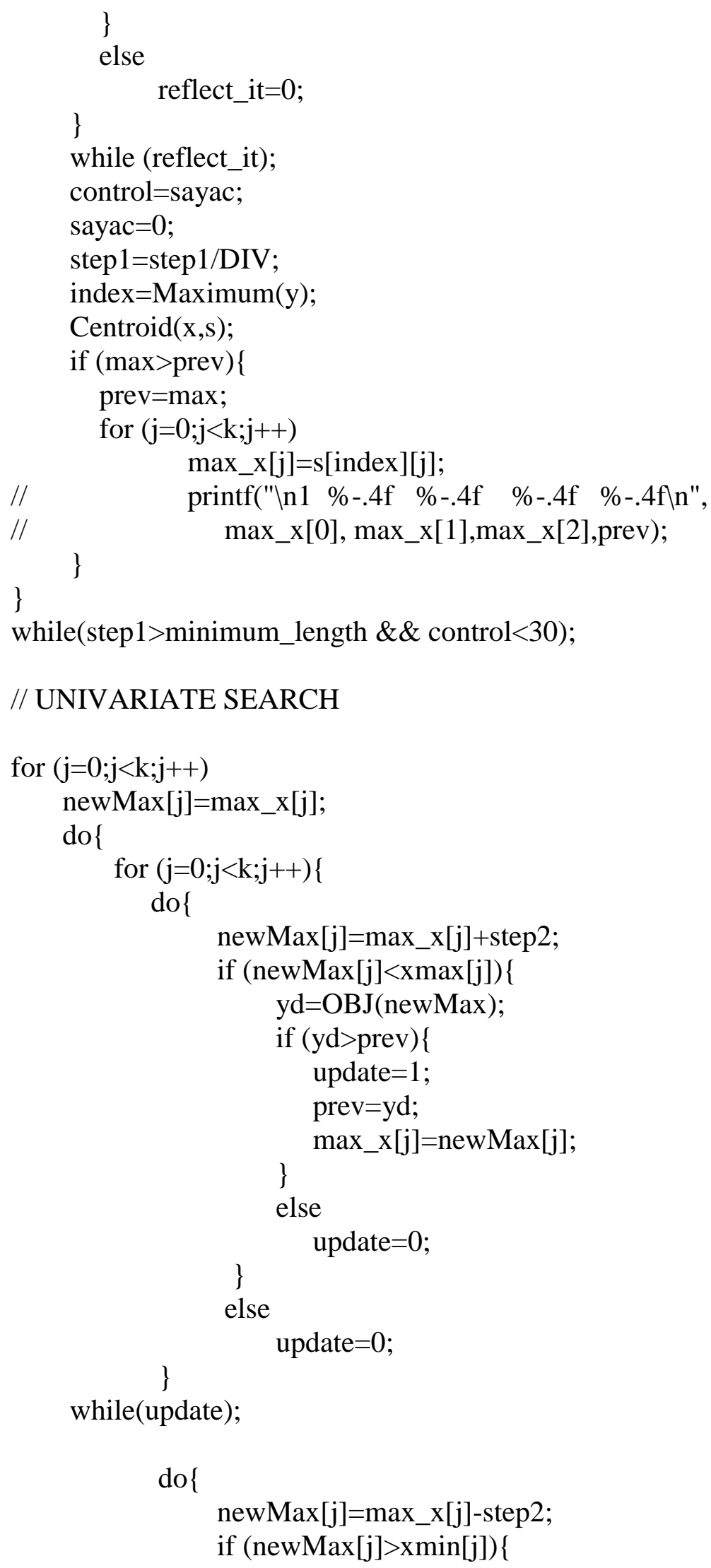




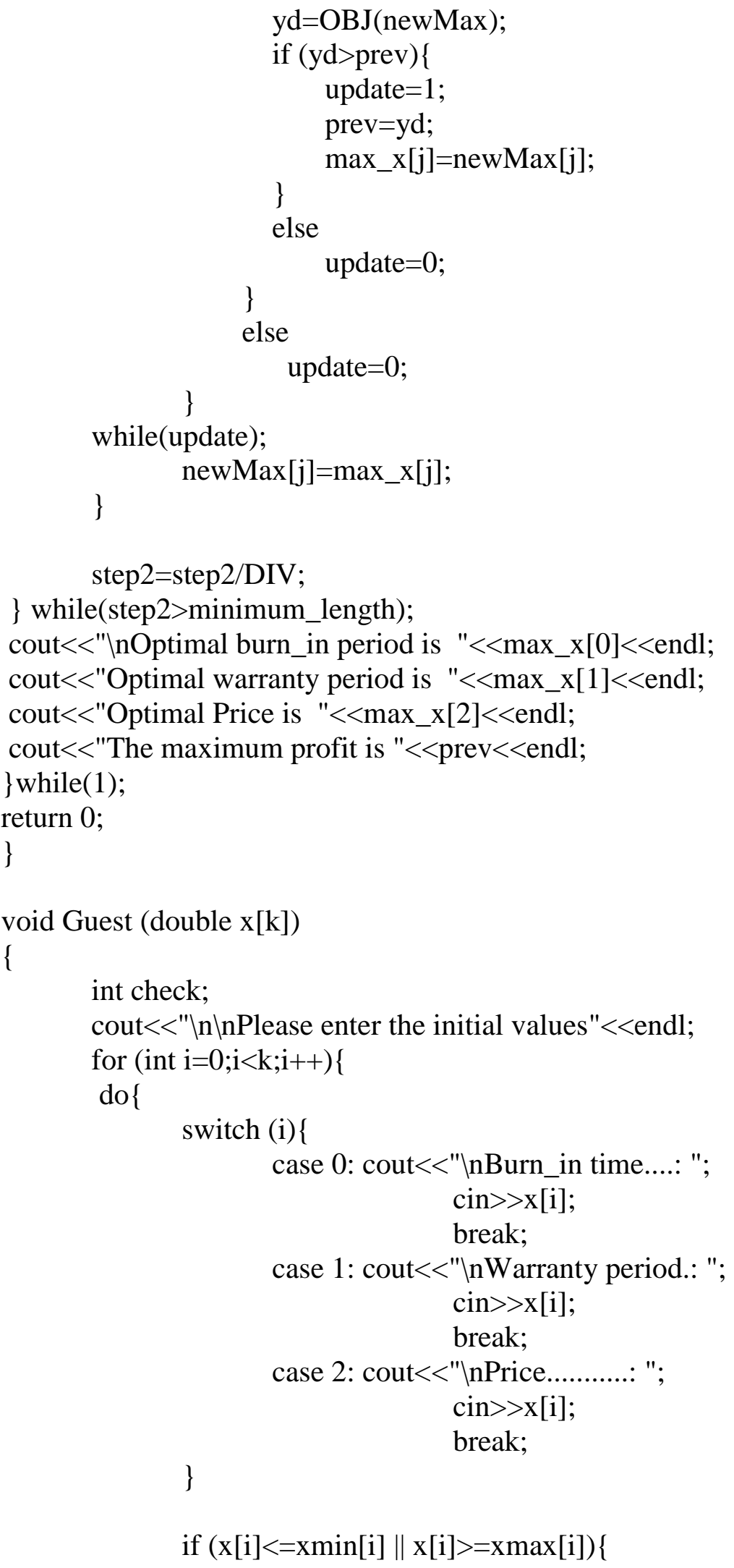




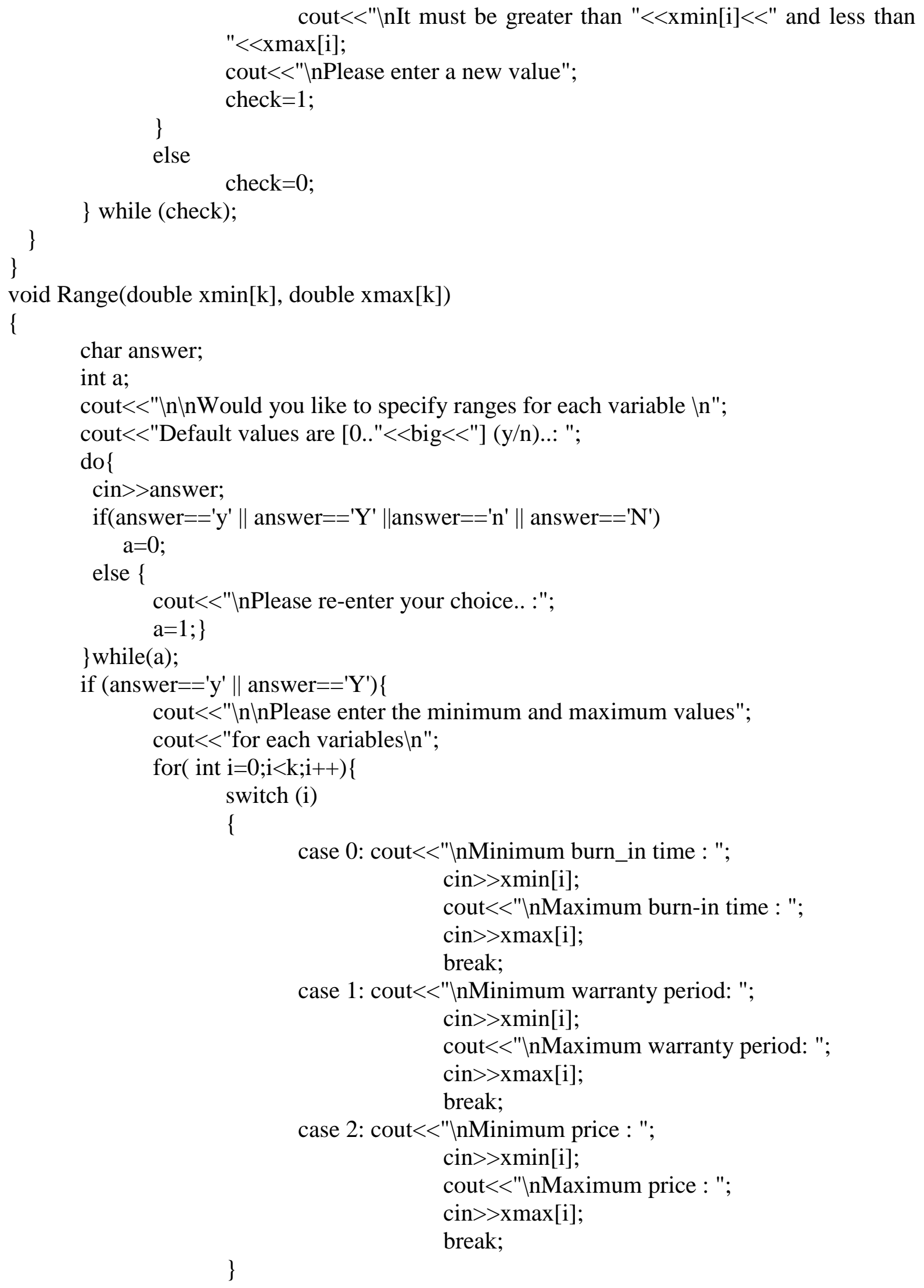




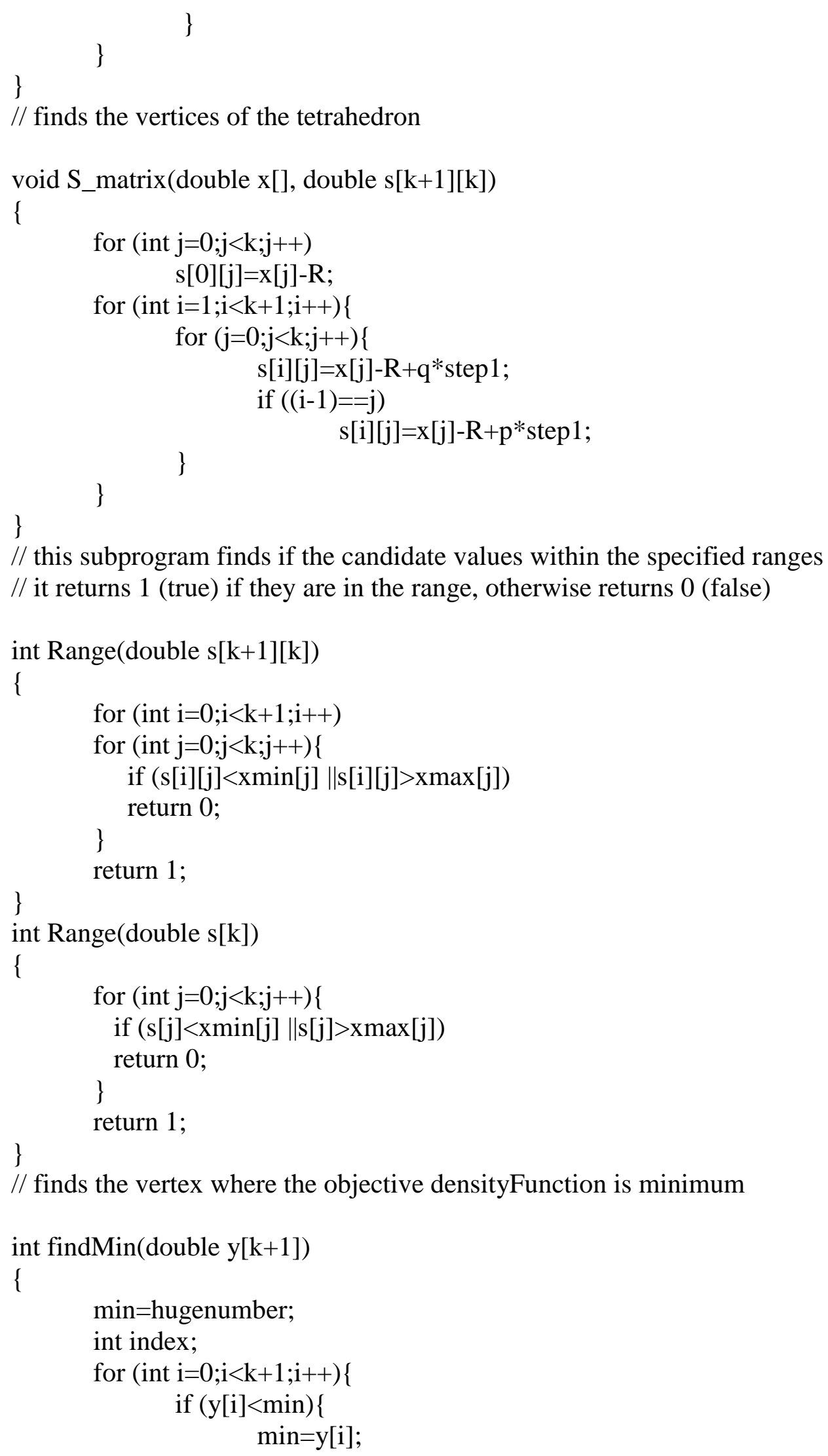




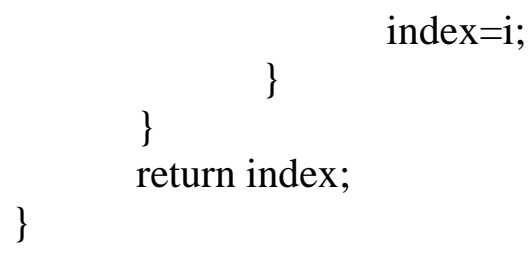

// this subprogram finds the reflection matrix and // if the reflection is within the range, returns one // otherwise returns zero

void Reflection (int index, double dd[k], double $\mathrm{d}[\mathrm{k}+1][\mathrm{k}]$ )

\{

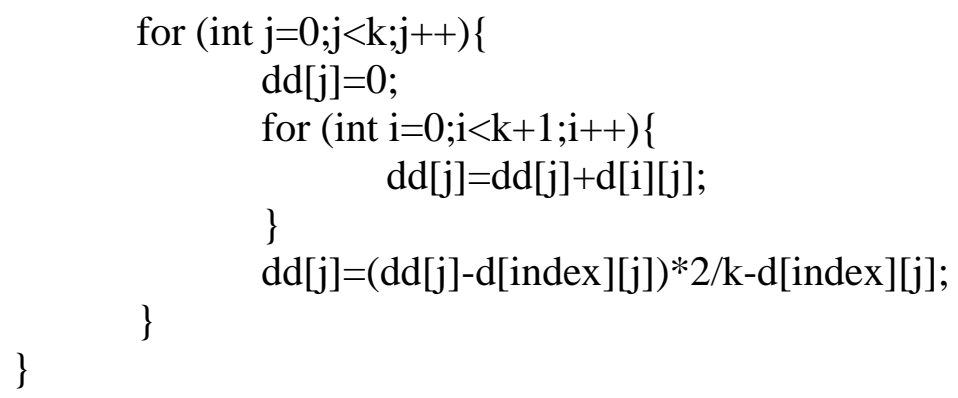

//this program finds the new centroid

void Centroid (double xx[k],double ss[k+1][k])

\{

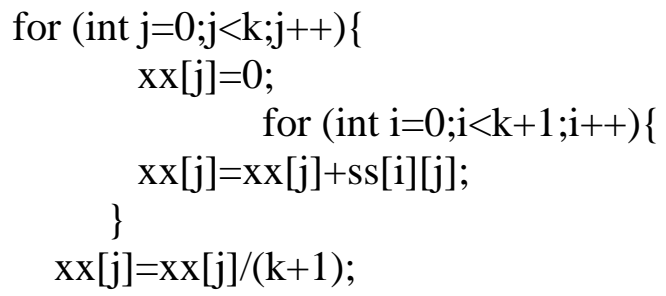




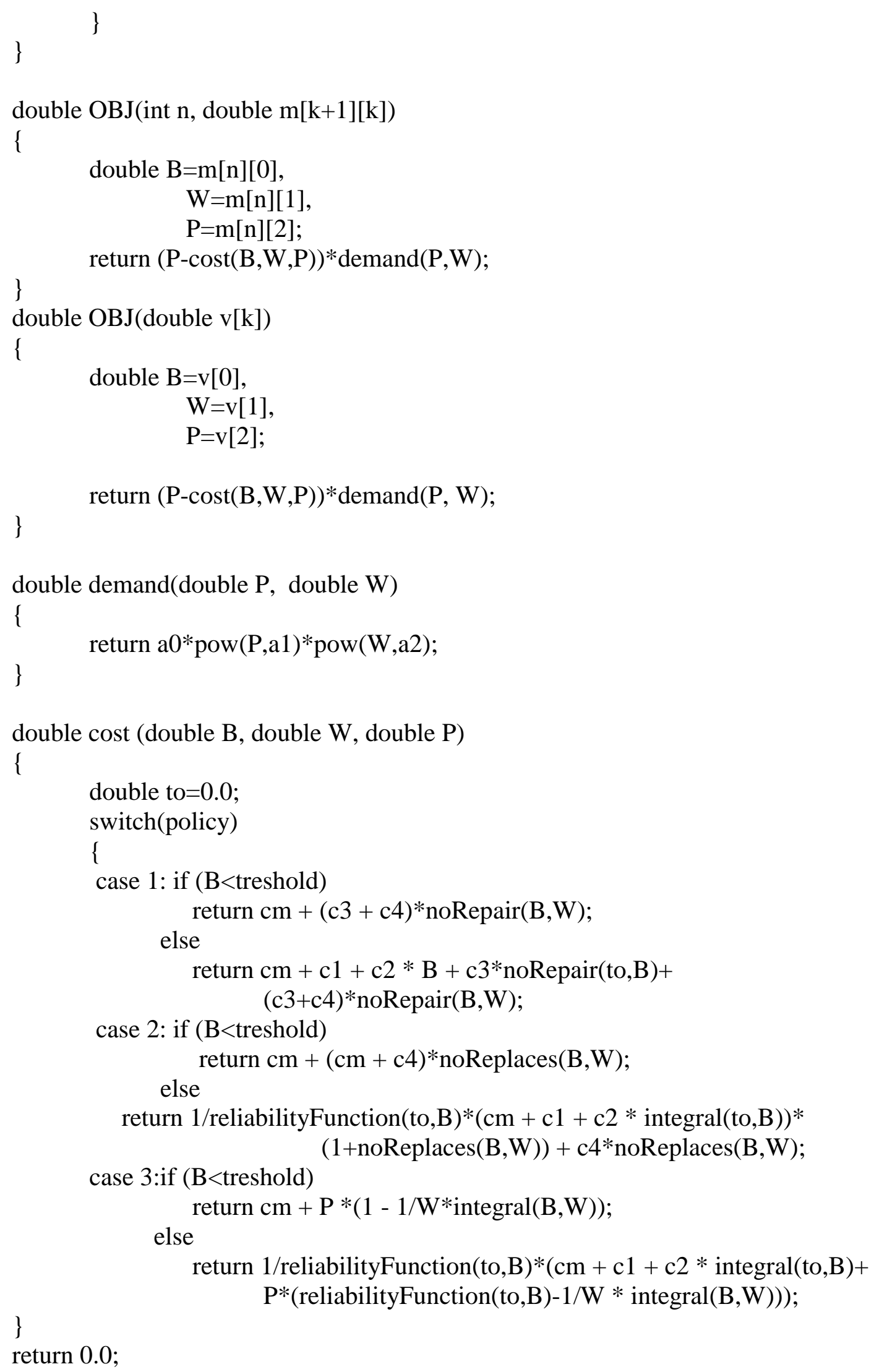




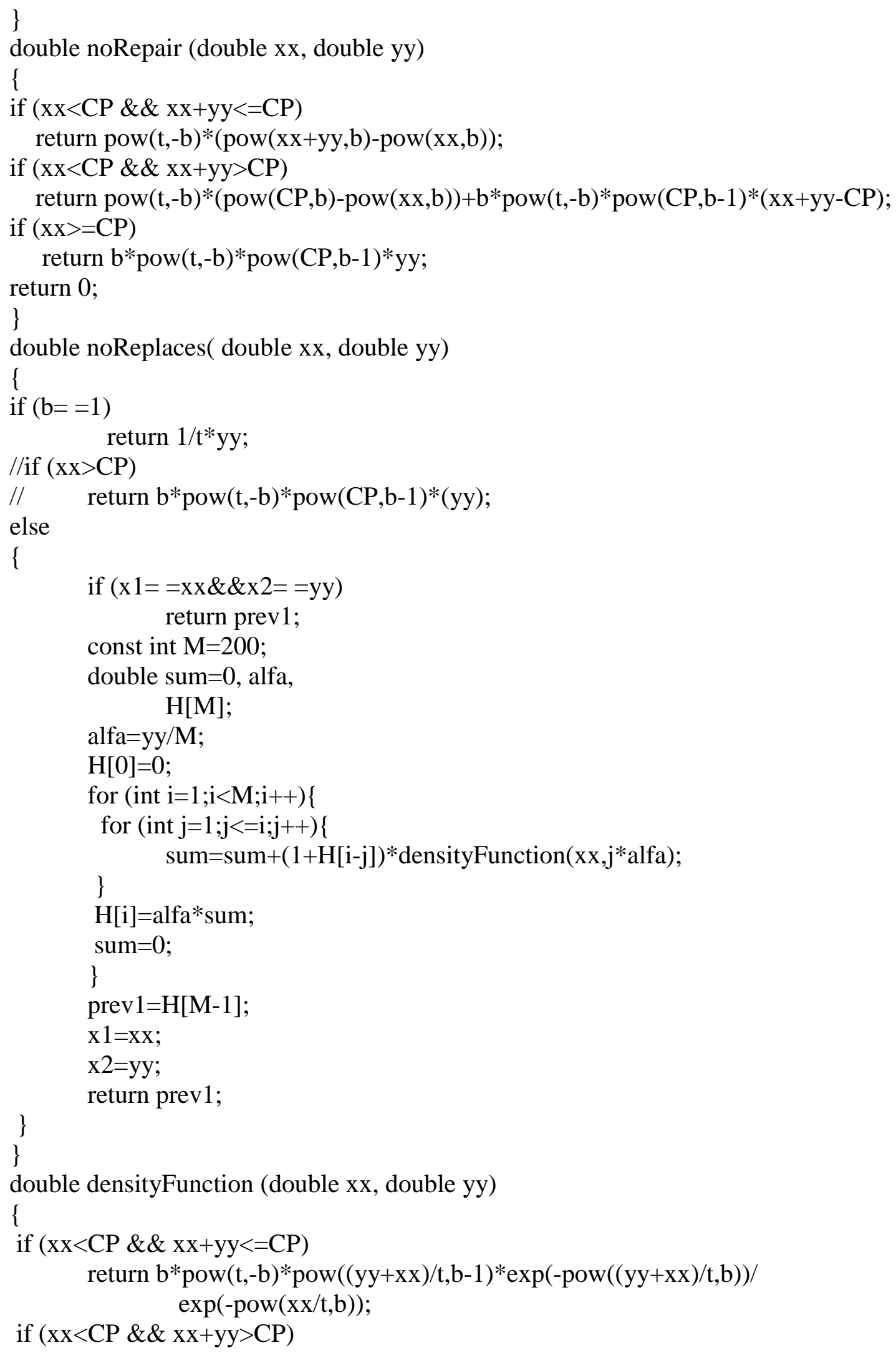


return $b^{*} \operatorname{pow}(\mathrm{t},-\mathrm{b}) * \operatorname{pow}(\mathrm{CP} / \mathrm{t}, \mathrm{b}-1) * \exp (-\operatorname{pow}(\mathrm{CP} / \mathrm{t}, \mathrm{b})-\mathrm{b} * \operatorname{pow}(\mathrm{t},-$ b)*pow $(\mathrm{CP}, \mathrm{b}-1) *(\mathrm{xx}+\mathrm{yy}-\mathrm{CP})) / \exp (-\operatorname{pow}(\mathrm{xx} / \mathrm{t}, \mathrm{b}))$;

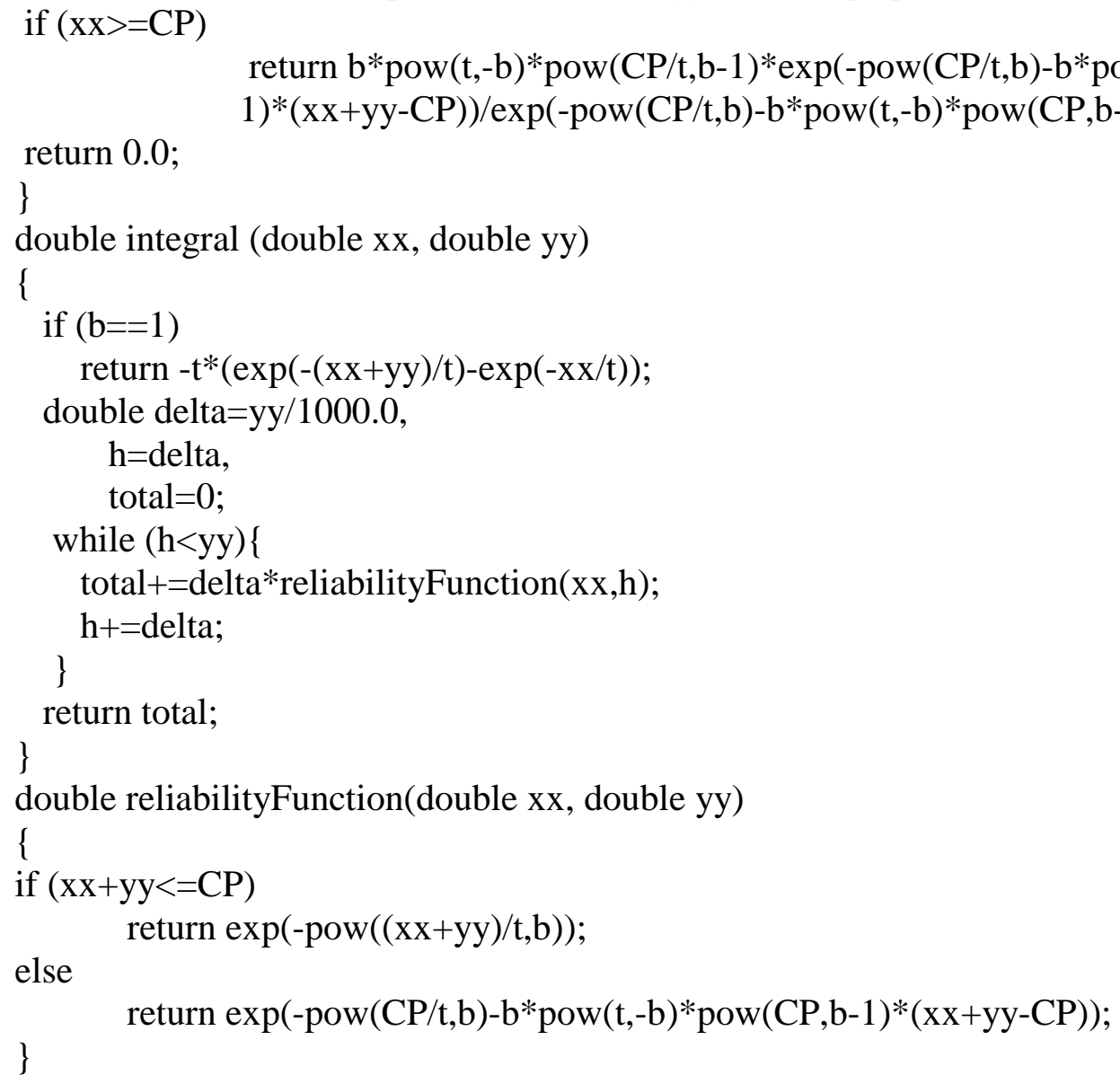




\section{Appendix 7: The computer program used when the failure time distribution is unknown (nonparametric solution methods)}

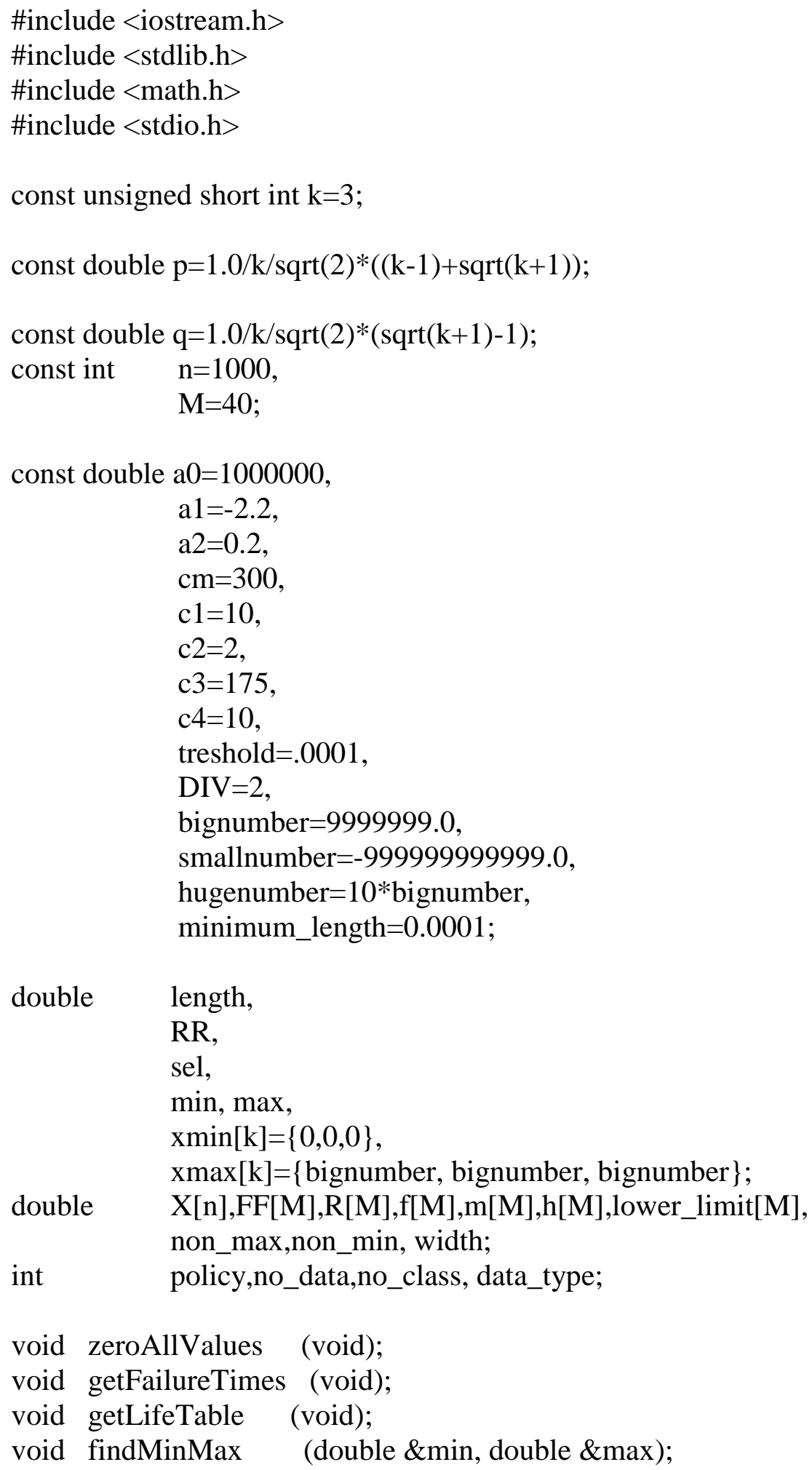


void calculateEmpricalFunctions (void);

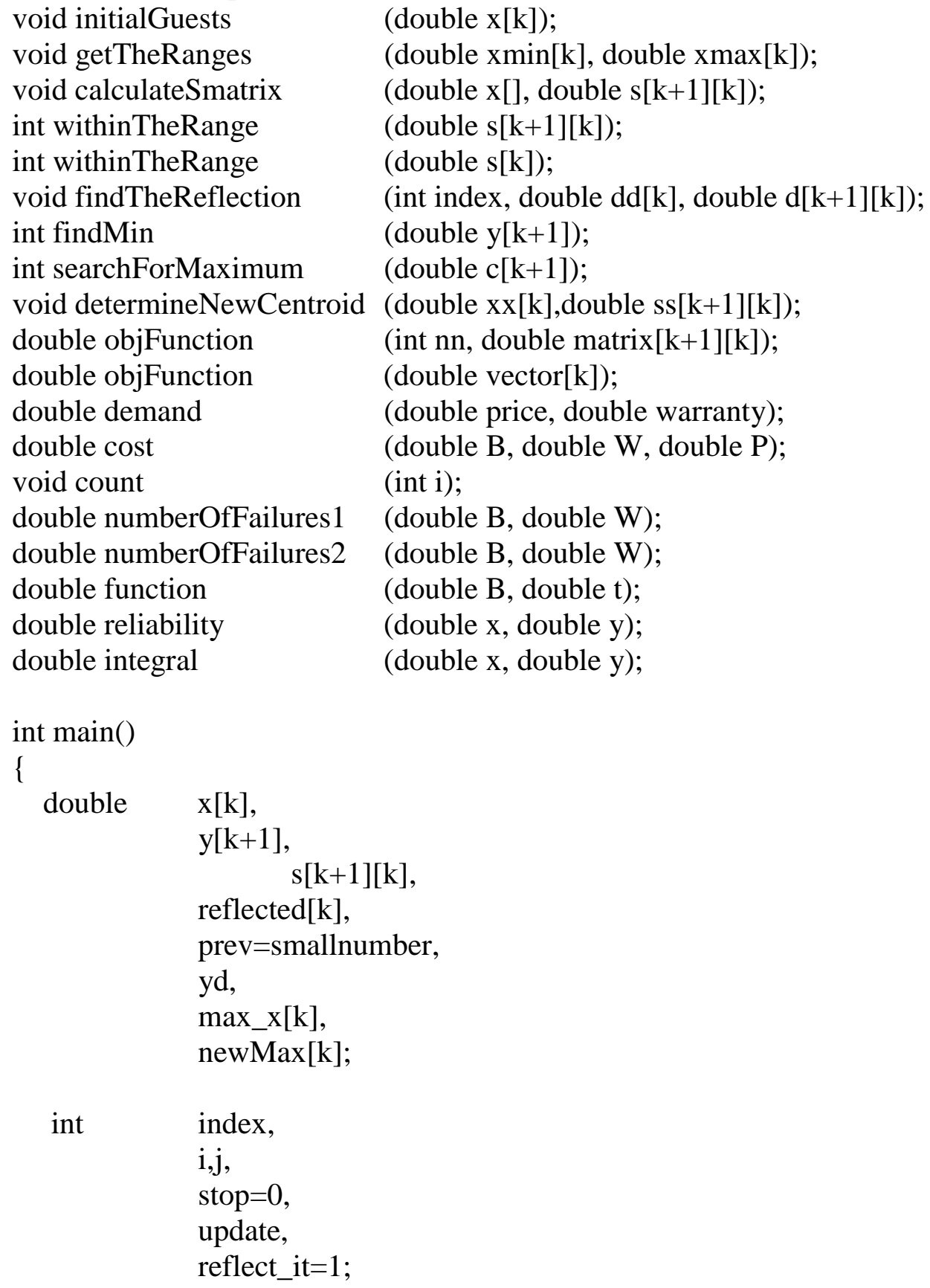

cout $<<$ "THIS PROGRAM FINDS THE OPTIMAL BURN-IN TIME,"<<endl; cout $<<$ "WARRANY PERIOD AND PRICE IN ORDER TO MAXIMIZE"<<endl; cout $<<$ "THE PROFIT WHEN THE THEORETICAL DISTRIBUTION"<<endl; cout $<<$ "FUNCTION IS UNKNOWN. "<<endl <<endl; cout $<<$ THE TYPE OF WARRANTY POLICY $\backslash n \backslash n "$; cout $<<"[1]$ : Free Replacement warrantyln"; cout<<"[2]: Pro-rata Warranty $\backslash n \backslash n "$; cout $<<$ "Please enter your choice :"; cin>>policy; 


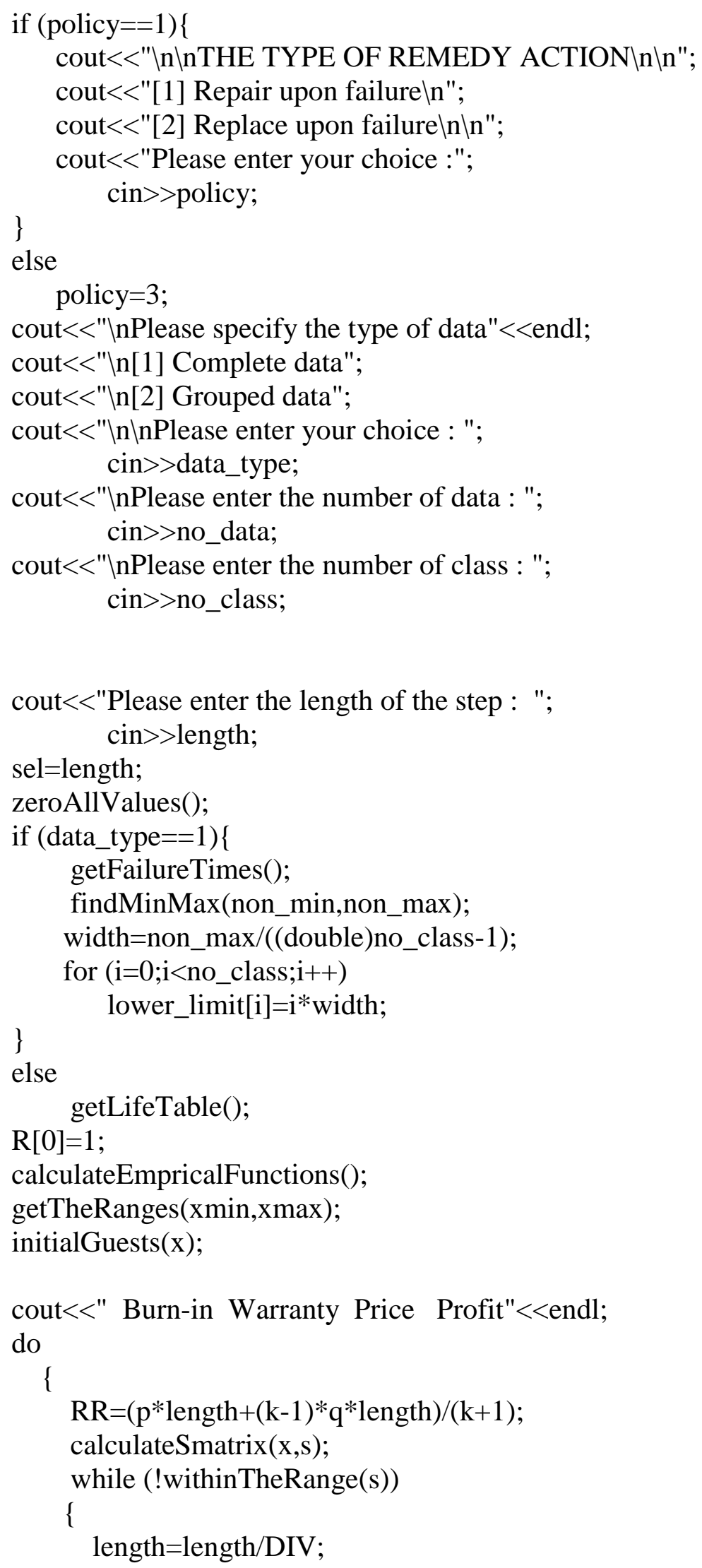




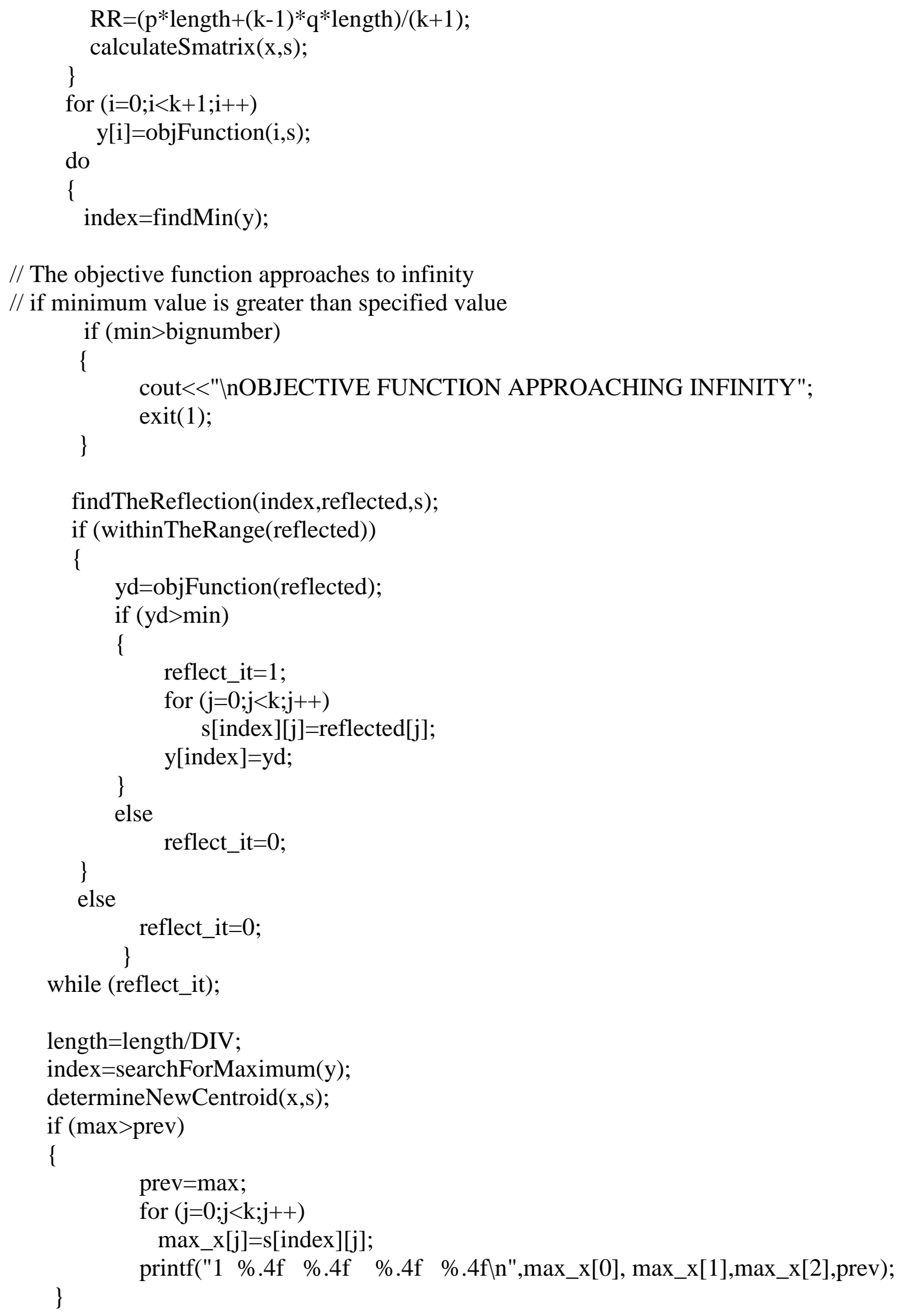




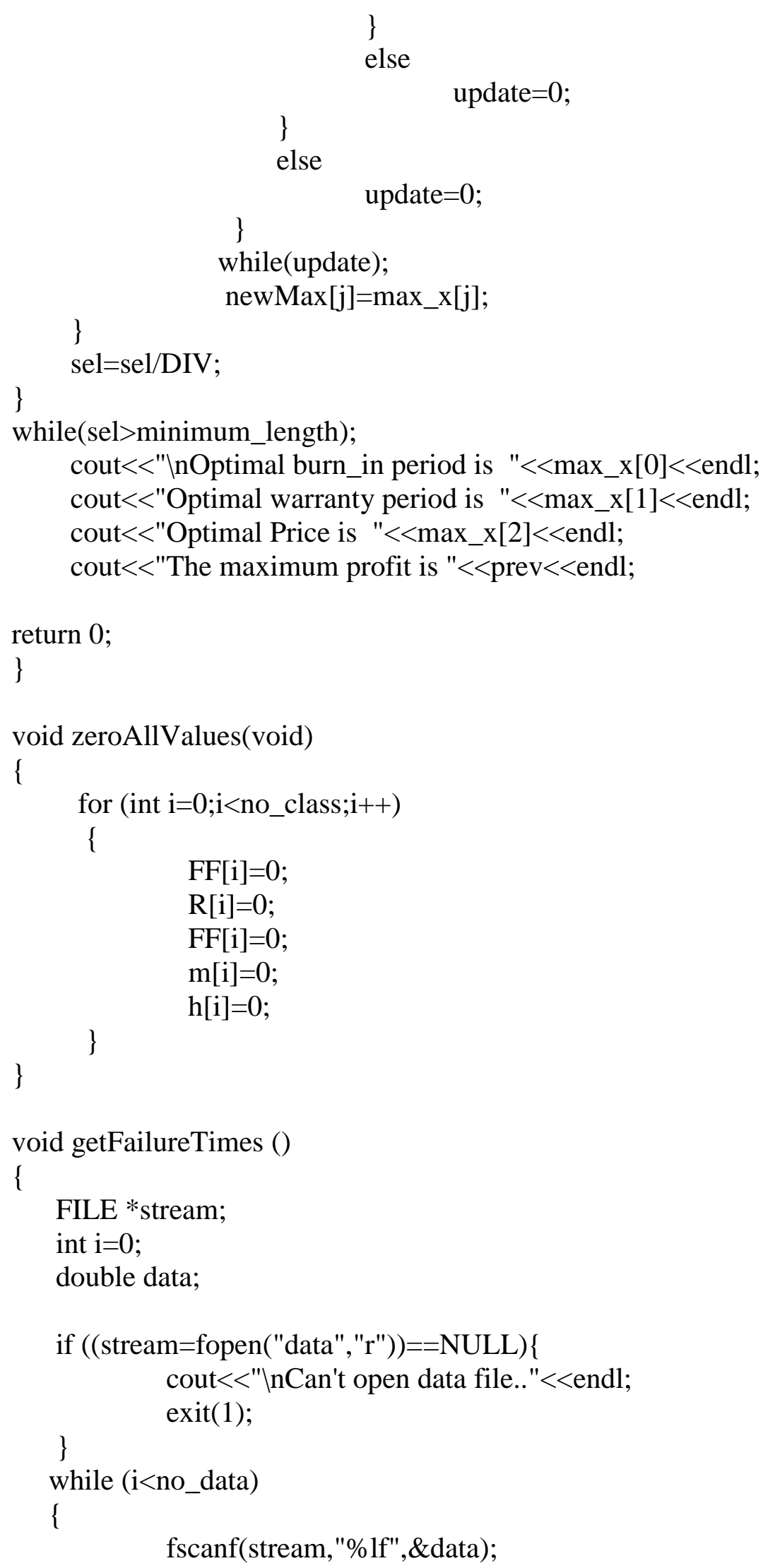




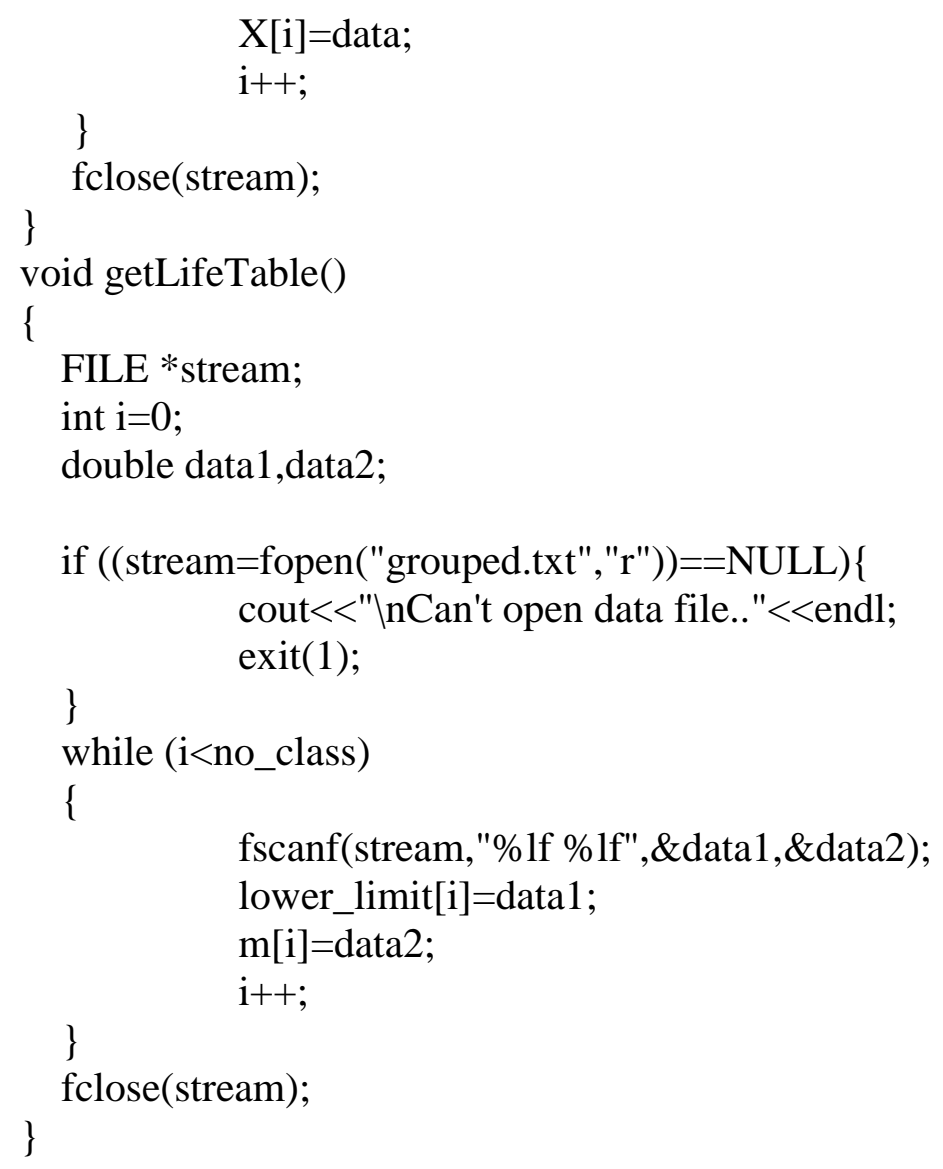




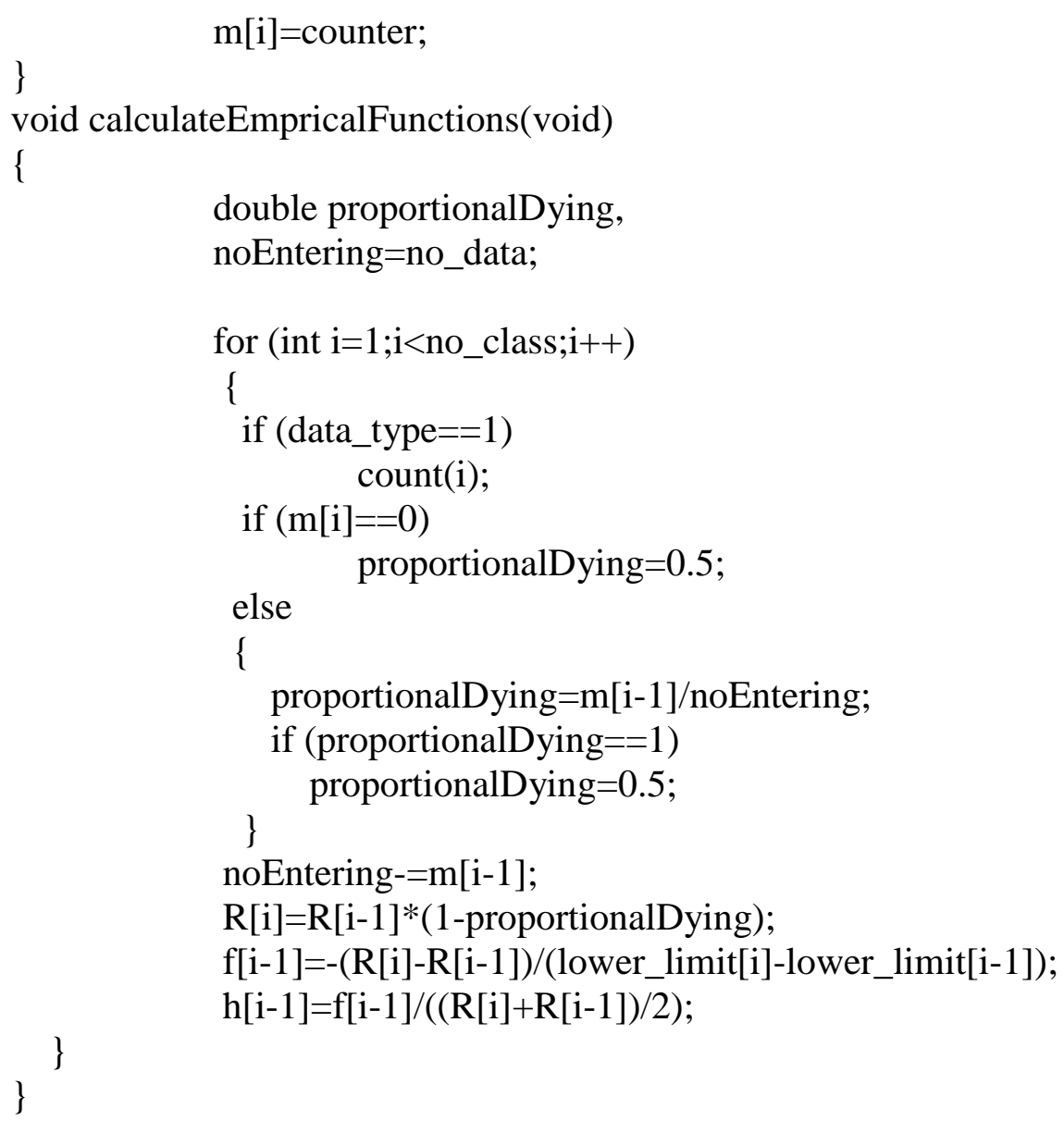




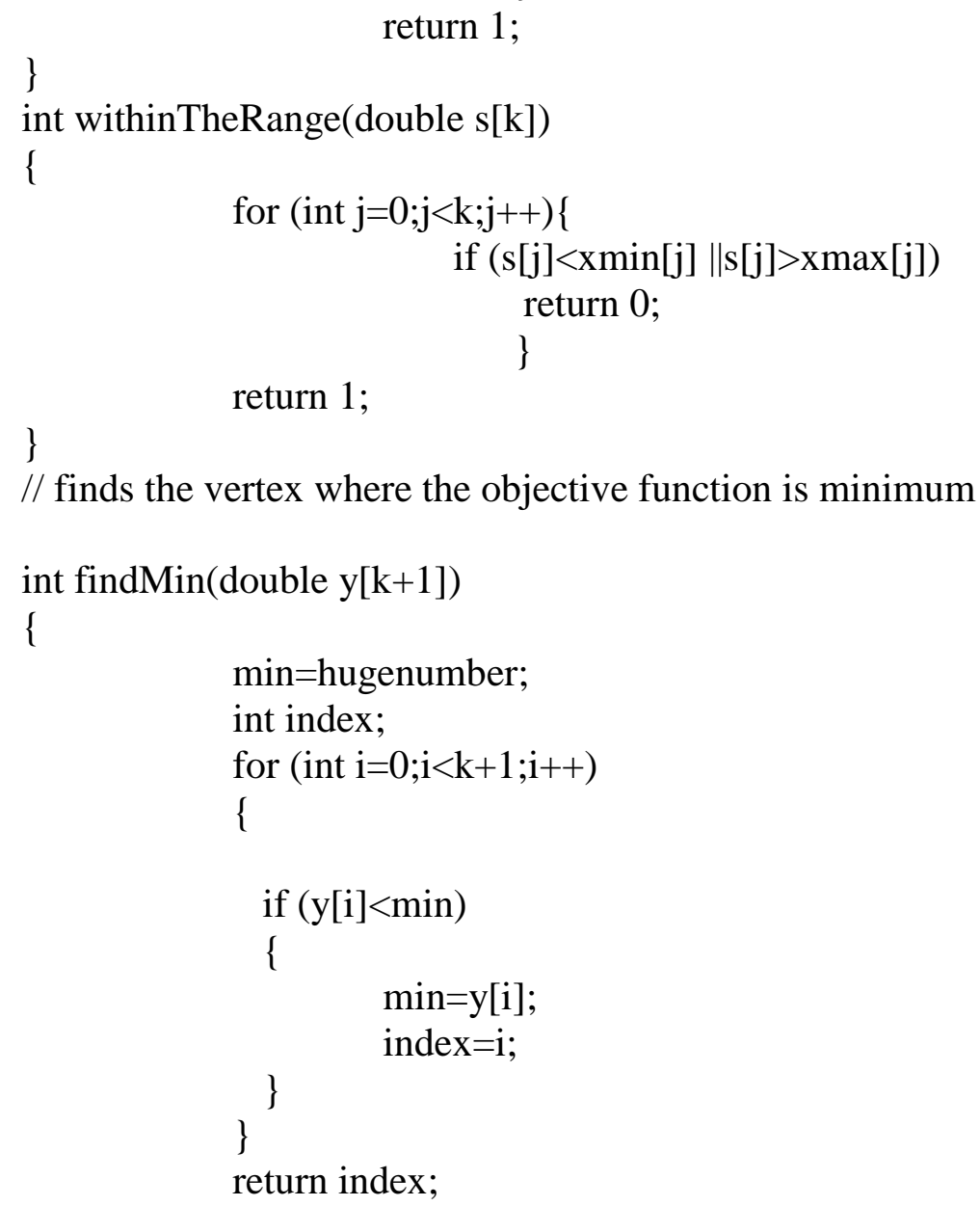


int searchForMaximum(double $\mathrm{c}[\mathrm{k}+1])$

\{

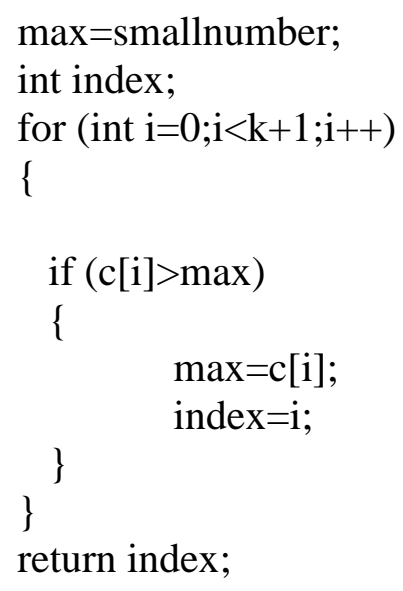




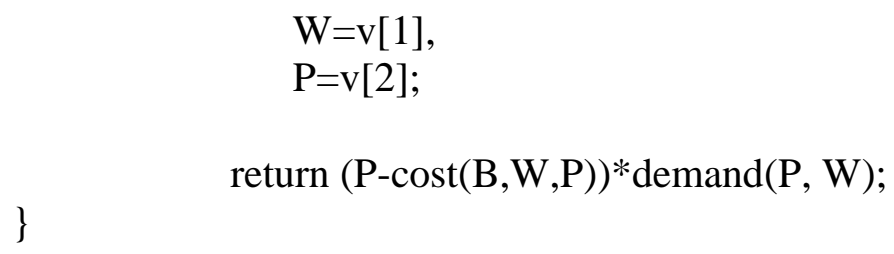




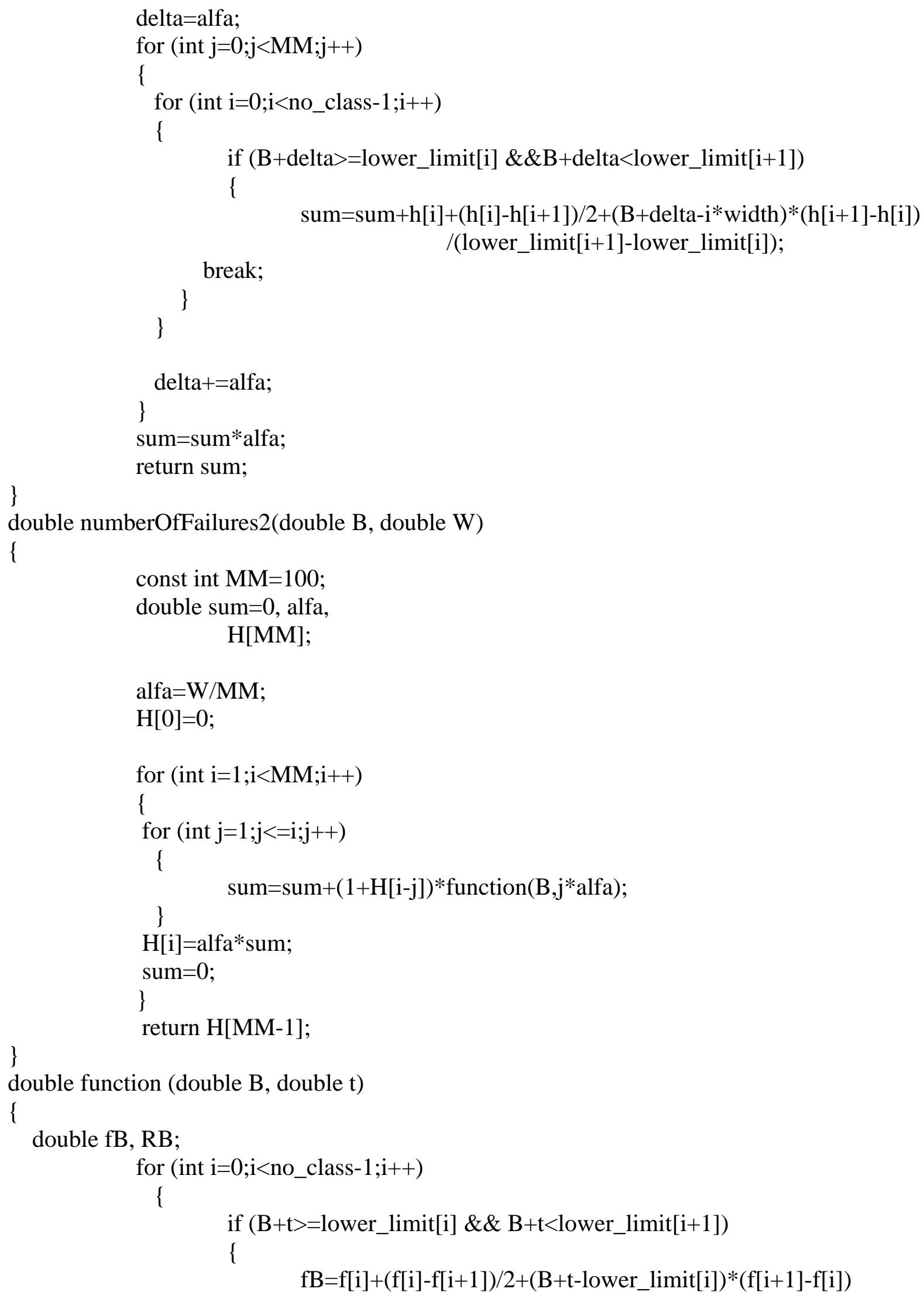




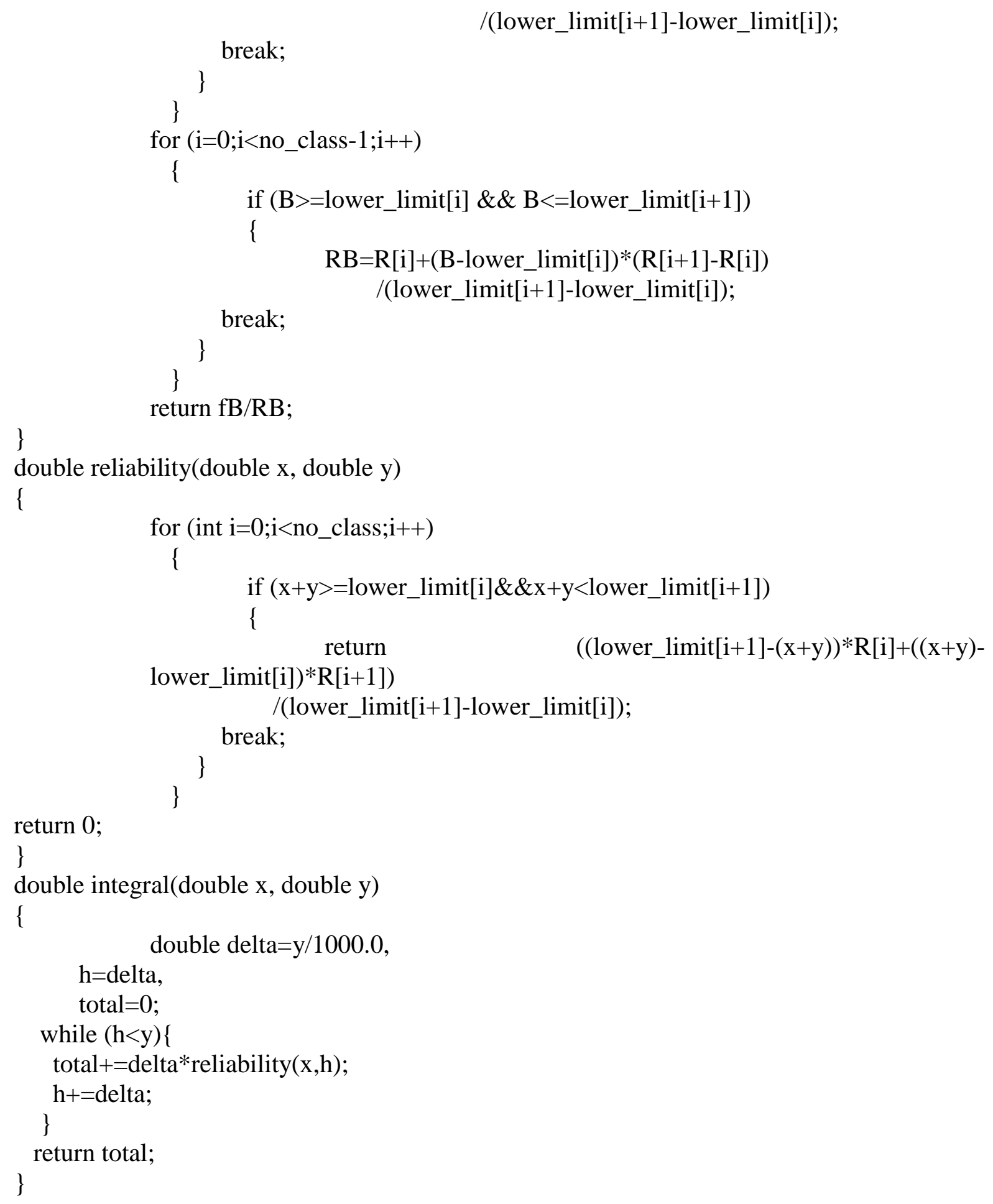

